San Jose State University

SJSU ScholarWorks

Master's Theses

Master's Theses and Graduate Research

Fall 2010

\title{
Surfactant-Assisted Hydrothermal Synthesis of Titania Nanorod Thin Films
}

Ben Milo Petersen

San Jose State University

Follow this and additional works at: https://scholarworks.sjsu.edu/etd_theses

\section{Recommended Citation}

Petersen, Ben Milo, "Surfactant-Assisted Hydrothermal Synthesis of Titania Nanorod Thin Films" (2010). Master's Theses. 3890.

DOI: https://doi.org/10.31979/etd.s4cs-unxu

https://scholarworks.sjsu.edu/etd_theses/3890

This Thesis is brought to you for free and open access by the Master's Theses and Graduate Research at SJSU ScholarWorks. It has been accepted for inclusion in Master's Theses by an authorized administrator of SJSU ScholarWorks. For more information, please contact scholarworks@sjsu.edu. 


\title{
SURFACTANT-ASSISTED HYDROTHERMAL SYNTHESIS OF TITANIA NANOROD THIN FILMS
}

\author{
A Thesis \\ Presented to \\ The Faculty of the Department of Chemical and Materials Engineering \\ San José State University \\ In Partial Fulfillment \\ of the Requirements for the Degree \\ Master of Science
}

by

Benjamin Milo Petersen

December 2010 
(C) 2010

Benjamin Milo Petersen

ALL RIGHTS RESERVED 
The Designated Thesis Committee Approves the Thesis Titled

\title{
SURFACTANT-ASSISTED HYDROTHERMAL SYNTHESIS OF TITANIA NANOROD THIN FILMS
}

\author{
by \\ Benjamin Milo Petersen \\ APPROVED FOR THE DEPARTMENT OF CHEMICAL AND MATERIALS \\ ENGINEERING
}

SAN JOSÉ STATE UNIVERSITY

December 2010

Dr. Stacy Gleixner

Department of Chemical and Materials Engineering

Dr. Melisa Buie

Department of Chemical and Materials Engineering

Dr. John Bass

IBM Almaden Research Center 


\begin{abstract}
SURFACTANT-ASSISTED HYDROTHERMAL SYNTHESIS OF TITANIA NANOROD THIN FILMS

by Benjamin M. Petersen
\end{abstract}

Titania $\left(\mathrm{TiO}_{2}\right)$ nanorods have shown promise for applicability in dye-sensitized solar cells (DSSC) and may present a cost-effective solution for the fabrication of efficient and affordable solar power generation. In contrast to traditional silicon solar cell fabrication, the fabrication of DSSCs does not require expensive high energy, vacuum, and temperature processes. Titania nanorods have the potential to increase the electron transport rate in DSSCs by forming a direct electrical pathway, thus improving the performance. This study set out to investigate ways in which titania nanorod hydrothermal growth could be enhanced and made more reliable through (1) experimentation with procedures to control temperature and pressure to hydrothermally grow titania nanotubes in a more reproducible way, and (2) experimentation with different additives to study their effect on nanorod growth. Optimum nanorod growth occurred when the temperature and pressure were kept constant. Use of multiple molecular weights of polyethylene gyclol (PEG) as an additive was shown to significantly enhance nanorod growth. 


\section{ACKNOWLEDGMENTS}

Thanks go to Dr. Stacy Gleixner, Dr. John Bass, Dr. Ho-Cheol Kim, and Dr.

Melisa Buie for all of their guidance throughout the research and writing process.

Thanks also go to the IBM Almaden Research Center and its staff for the opportunity to

conduct this research, especially to Blake Davis for helping with the SEM. I would also like to thank my wife; I could not have done this without her help and support. 
TABLE OF CONTENTS

CHAPTER ONE INTRODUCTION

$1.1 \quad$ BACKGROUND

$1.2 \quad$ APPLICATIONS

1.3 HOW A PHOTOVOLTAIC CELL WORKS $\ldots \ldots \ldots$

1.4 DYE-SENSITIZED SOLAR CELLS $\ldots \ldots \ldots$

1.5 PHOTOVOLTAIC EFFICIENCY EVALUATION

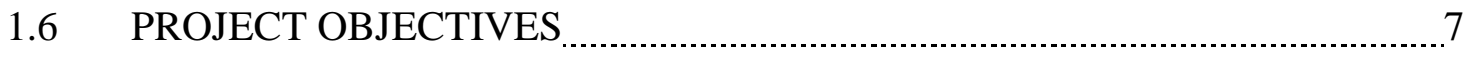

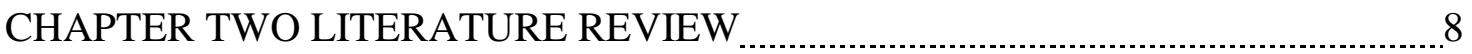

$2.1 \quad$ INTRODUCTION

2.2 TITANIA NANOROD THIN FILM DEPOSITION

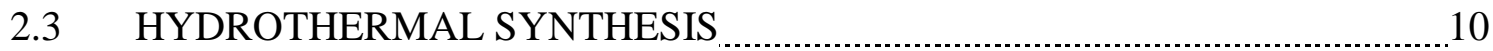

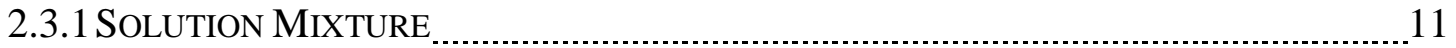

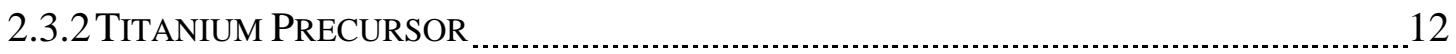

2.3.3 SUBSTRATE

2.3.4BAKING TIME AND TEMPERATURE

2.3.5 ADDITIVES

2.4 CHARACTERIZATION 18

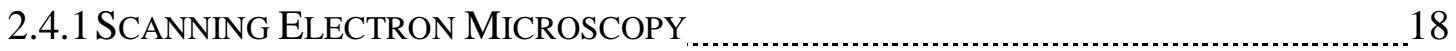

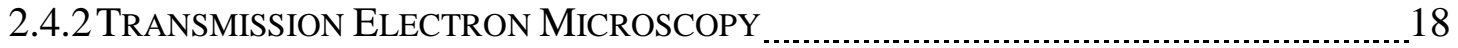

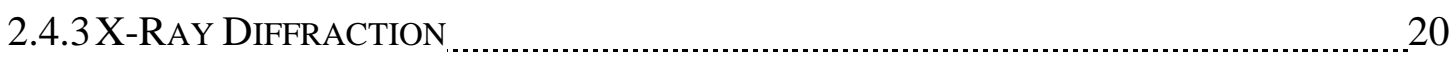


4.1 INTRODUCTION 22

4.2 SUBSTRATE PREPARATION 22

4.2.1 CLEANING

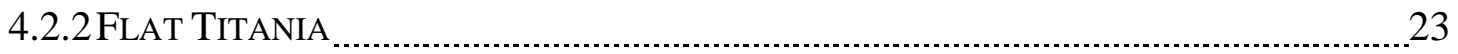

4.2.3 EVAPORATING $\mathrm{SIO}_{2}$

4.3 SOLUTION PREPARATION

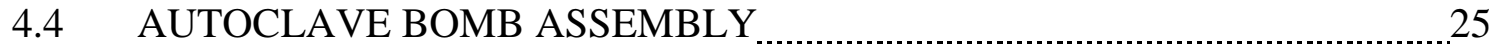

4.5 HEATING

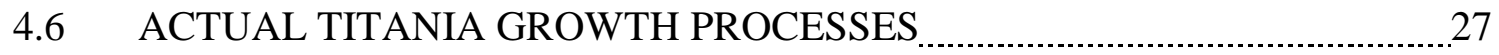

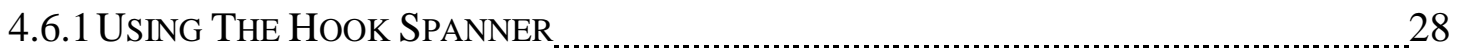

4.6.2 Silicone OIL BATH VERSUS FURNACE

4.6.3 ADDITIVES

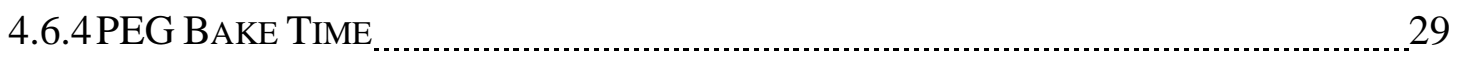

4.6.5 PEG BAKE TEMPERATURE

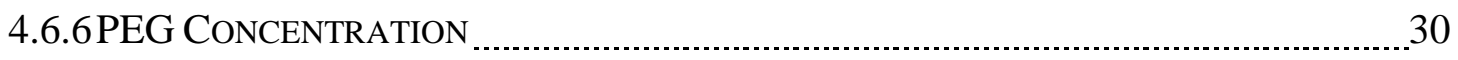

4.6.7 PEG Molecular Weight

4.6.8 DiFFERENT PEG BOTTLES

$4.7 \quad$ FILM CHARACTERIZATION

CHAPTER FIVE RESULTS AND DISCUSSION

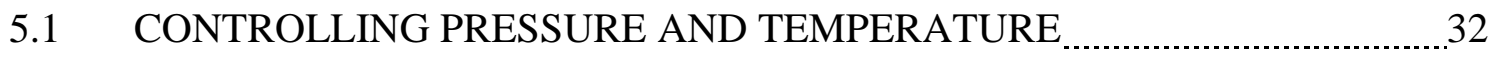


5.1.1 Tightening Autoclave Bombs With the Hook SPANNER

5.1.2 Heating In A Silicone Oil Bath 36

5.2 REPRODUCIBILITY WITHOUT ADDITIVES _ $\ldots$

5.3 ADDITIVES

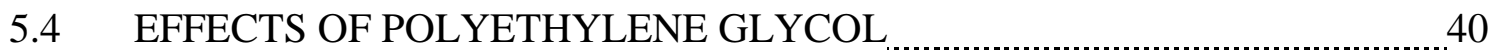

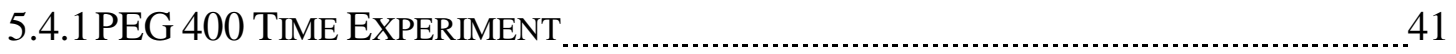

5.4.2 LOWER TEMPERATURE TITANIA NANOROD GROWTH _.......................................... 42

5.4.3 EFFECT OF AdDITIVE CONCENTRATION ON NANOROD GROWTH _........................... 43

5.4.4DifFERENT MOLECULAR WEIGHTS OF POLYETHYLENE GLYCOL _.............................. 46

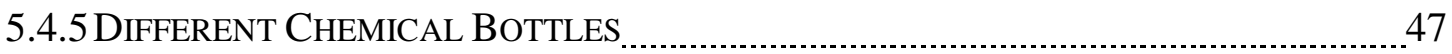

CHAPTER SIX CONCLUSIONS _ _ _ $\quad 48$

CHAPTER SEVEN FUTURE WORK

REFERENCES

APPENDIX A SEM IMAGES OF THE NANORODS GROWN WITHOUT

ADDITIVES

APPENDIX B SEM IMAGES OF THE NANORODS GROWN WITH ADDITIVES

IN BATCHES B-7, B-8, AND B-9 $\ldots$

APPENDIX C SEM IMAGES OF THE NANORODS GROWN WITH PEG 400

FOR 4, 5.5, 7, AND 8 HOURS IN BATCH B-10 _............................. 64 


\section{LIST OF FIGURES}

Figure 1 A p-n junction showing depletion zone and ionized donors and acceptors.

Figure 2 Essential requirements for photovoltaics.

Figure 3 Schematic showing the operation of a dye-sensitized solar cell.

Figure 4 Current-voltage characteristics of a silicon solar cell.

Figure 5 SEM images of silicon dioxide nanorods deposited by oblique angle deposition.

Figure 6 SEM cross-section of vertically aligned silicon dioxide nanorods deposited with GLAD.

Figure 7 FESEM images of $\mathrm{TiO}_{2}$ nanorods grown in $30 \mathrm{~mL}$ DI water and $30 \mathrm{~mL}$ concentrated hydrochloric acid.

Figure 8 FESEM image of $\mathrm{TiO}_{2}$ nanorods on glass grown at $80{ }^{\circ} \mathrm{C}$ for $168 \mathrm{hrs}$

Figure 9 FESEM images of titania nanorods grown on (a) glass, (b) glass coated with a flat $\mathrm{TiO}_{2}$ dried seed layer, and (c) glass coated with a flat $\mathrm{TiO}_{2}$ dried and annealed seed layer.

Figure 10 TEM images of a $\mathrm{TiO}_{2}$ nanorod structure.

Figure 11 TEM image and corresponding electron diffraction pattern of an anatase titania nanorod.

Figure 12 Parts of the steel autoclave bomb used in the hydrothermal synthesis.

Figure 13 Flow chart of the titania nanorod thin film fabrication process.

Figure 14 60K magnification SEM images of titania nanorods, from batch B-1, hydrothermally grown in autoclave bombs not tightened with the hook spanner.

Figure 15 60K magnification SEM images of titania nanorods, from batch B-2, hydrothermally grown in autoclave bombs not tightened with the hook spanner. 
Figure 16 60K magnification SEM images of titania nanorods in batch B-3, hydrothermally grown in autoclave bombs tightened with the hook spanner.

Figure 17 60K magnification SEM images of titania nanorods in batch B-4, hydrothermally grown in autoclave bombs tightened with the hook spanner.

Figure 18 60K magnification SEM images of titania nanorod batch B-5, hydrothermally grown in autoclave bombs heated in silicone oil bath. 36

Figure 19 60K magnification SEM images of titania nanorod batch B-6, hydrothermally grown in autoclave bombs heated in silicone oil bath.

Figure 20 25k magnification cross-sectional view SEM images of titania nanorods grown hydrothermally in autoclave bombs heated in a silicone oil bath. 38

Figure 21 SEM images of PEG 400 assisted hydrothermally grown titania nanorods.

Figure 22 25k magnification SEM images of PEG 400 assisted hydrothermally grown titania nanorods, from batch B-10.

Figure 23 60k magnification SEM images of PEG 400 assisted hydrothermally grown titania nanorods grown at $90{ }^{\circ} \mathrm{C}$.

Figure 24 60k magnification SEM images of titania nanorods grown with different concentrations of PEG 400.

Figure 25 60k magnification SEM images of titania nanorods grown with different concentrations of PEG 400.

Figure 26 60k magnification SEM images of titania nanorods grown with different concentrations of PEO 1,000,000.

Figure 27 60k magnification SEM images of titania nanorods grown with different concentrations of PEG 2000.

Figure 28 60k magnification SEM images of titania nanorods grown with different molecular weights of polyethylene glycols.

Figure 29 60k magnification SEM images of titania nanorods grown with PEG 400 from different bottles. 
Figure 30 Top view, 60k magnification, SEM image of the titania nanorods grown without additives in batch B-7.

Figure 31 Cross-sectional view, 25k magnification, SEM image of the titania nanorods grown without additives in batch B-7.

Figure 32 Top view, 60k magnification, SEM image of the titania nanorods grown without additives in batch B-8.

Figure 33 Cross-sectional view, 25k magnification, SEM image of the titania nanorods grown without additives in batch B-8.

Figure 34 Top view, 60k magnification, SEM image of the titania nanorods grown without additives in batch B-9.

Figure 35 Cross-sectional view, 25k magnification, SEM image of the titania nanorods grown without additives in batch B-9.

Figure 36 Top view, 60k magnification, SEM image of the titania nanorods grown with oleic acid in batch B-7.

Figure 37 Cross-sectional view, 25k magnification, SEM image of the titania nanorods grown with oleic acid in batch B-7.

Figure 38 Top view, 60k magnification, SEM image of the titania nanorods grown with $\mathrm{NaDDS}$ in batch B-7.

Figure 39 Cross-sectional view, 25k magnification, SEM image of the titania nanorods grown with NaDDS in batch B-7.

Figure 40 Top view, 25k magnification, SEM image of the titania nanorods grown with TDPA in batch B-7.

Figure 41 Top view, 60k magnification, SEM image of the titania nanorods grown with PEI in batch B-7.

Figure 42 Cross-sectional view, 25k magnification, SEM image of the titania nanorods grown with PEI in batch B-7.

Figure 43 Top view, 60k magnification, SEM image of the titania nanorods grown with $\mathrm{LiCl}$ in batch $\mathrm{B}-8$. 
Figure 44 Cross-sectional view, 25k magnification, SEM image of the titania nanorods grown with $\mathrm{LiCl}$ in batch $\mathrm{B}-8$.

Figure 45 Top view, 60k magnification, SEM image of the titania nanorods grown with $\mathrm{KCl}$ in batch $\mathrm{B}-8$.

Figure 46 Cross-sectional view, 25k magnification, SEM image of the titania nanorods grown with $\mathrm{KCl}$ in batch $\mathrm{B}-8$.

Figure 47 Top view, 60k magnification, SEM image of the titania nanorods grown with $\mathrm{CaCl}_{2}$ in batch $\mathrm{B}-8$.

Figure 48 Cross-sectional view, 25k magnification, SEM image of the titania nanorods grown with $\mathrm{CaCl}_{2}$ in batch B-8.

Figure 49 Top view, 35 magnification, SEM image of the titania nanorods grown with PEG 400 in batch B-9.

Figure 50 Top view, 1k magnification, SEM image of the titania nanorods grown with PEG 400 in batch B-9.

Figure 51 Top view, 5k magnification, SEM image of the titania nanorods grown with PEG 400 in batch B-9.

Figure 52 Top view, 25k magnification, SEM image of the titania nanorods grown with PEG 400 for 4 hours in batch B-10.

Figure 53 Cross-sectional view, 25k magnification, SEM image of the titania nanorods grown PEG 400 for 4 hours in batch B-10.

Figure 54 Top view, 25k magnification, SEM image of the titania nanorods grown with PEG 400 for 5.5 hours in batch B-10.

Figure 55 Cross-sectional view, 25k magnification, SEM image of the titania nanorods grown PEG 400 for 5.5 hours in batch B-10.

Figure 56 Top view, 25k magnification, SEM image of the titania nanorods grown with PEG 400 for 7 hours in batch B-10.

Figure 57 Cross-sectional view, 25k magnification, SEM image of the titania nanorods grown PEG 400 for 7 hours in batch B-10.

Figure 58 Top view, 25k magnification, SEM image of the titania nanorods grown with PEG 400 for 8 hours in batch B-10. 
Figure 59 Cross-sectional view, 25k magnification, SEM image of the titania nanorods grown PEG 400 for 8 hours in batch B-10. 


\section{LIST OF TABLES}

Table 1 The hydrothermal solutions and titanium precursors used by several research groups.

Table 2 Initial process parameters for hydrothermal synthesis of titania nanorods.

Table 3 Summary of the experiments, batches, and number of bombs per batch.......28

Table 4 Summary of the results of the tightening method experiment batches.

Table 5 Comparison of titania nanorods that were grown hydrothermally, without surfactant assistance.

Table 6 The effects of different surfactants on the hydrothermal growth of titania nanorods.

Table 7 Dimensions of titania nanorods grown for different times by PEG 400 assisted hydrothermal process in batch B-10. 


\section{CHAPTER ONE}

\section{INTRODUCTION}

\subsection{Background}

As the population of the world and worldwide development increase, so does the

demand for energy. Between 1980 and 2000, energy consumption worldwide increased by $40 \%$. Worldwide energy consumption is predicted to increase another $70 \%$ by 2030 [1]. This growing demand for energy combined with the limitations on traditional fuels (coal, oil, and natural gas) and the increase in global warming have necessitated the development of sustainable, environmentally friendly energy sources. Many renewable energy technologies have been developed, including hydroelectric, wind, solar, tidal, and biofuels. Of all of the renewable energy technologies, photovoltaic (PV) solar cells are considered to show the most potential [2]. One main reason for this is the abundance of energy that reaches earth from the sun: $3 \times 10^{24} \mathrm{~J}$ a year, 10,000 times the amount of energy presently consumed per year [3]. Currently, the main disadvantage of PV electricity is its high cost. However, as manufacturing technology improves solar power is becoming more cost-effective. By way of example, in $1954 \mathrm{PV}$-generated power cost roughly $\$ 300$ per watt, while today it costs less than $\$ 5$ per watt [1].

There are several different types of PV cells currently being researched, including single crystal silicon, amorphous silicon, polycrystalline silicon, ribbon silicon, thin film silicon, copper indium diselenide, silicon gallium, cadmium telluride, titanium dioxide nano-crystalline dye-sensitized, and molecular and polymer organics [4-7]. One PV type, using aligned single crystal wide bandgap semiconductor nanorods, has recently drawn 
considerable attention. These nanorods could improve the performance of PV cells by increasing the electron transport rate because they form a direct electrical pathway [8]. Based on the performance of titania nanoparticles as n-type material in dye-sensitized solar cells (DSSC), titanium dioxide $\left(\mathrm{TiO}_{2}\right.$ or titania) has been shown to have great potential as the material for nanorods in PV cells [9].

\subsection{Applications}

PV cells have a wide range of applications. They have been used to power satellites [2] and small electronics. They have also been used on a limited scale to power residential and commercial grids, for example the 14-megawatt Nellis solar power station in Nevada [1]. As the technology improves and correspondingly becomes more costeffective, PV cells can be used more widely to power homes and businesses.

\subsection{How a Photovoltaic Cell Works}

PV cells work because of the photovoltaic effect, which was first described by Bequerel in 1839 [10]. The photovoltaic effect is defined as "the emergence of an electric voltage between two electrodes attached to a solid or liquid system upon shining light onto this system" [4]. Most PV devices use semiconductor p-n junctions made of solid-state silicon to create the photovoltage. When a p-n junction is formed, the concentration difference in the charge carriers results in the diffusion of electrons from the n-type material to the p-type material and therefore results in holes from the p-type material to the n-type material. This removal of the majority carriers results in the 
production of an electric field by the ionized donors of the n-type material and the ionized acceptors of the p-type material. This electric field then drives the net diffusion of holes and electrons to zero. The region of exposed donors and acceptors (shown in Figure 1), called the depletion zone, is effectively depleted of electrons and holes. The potential difference caused by the formation of the junction is called the built-in voltage [11]. The built-in voltage makes the photoelectric effect possible.

\begin{tabular}{|c|c|c|c|}
\hline \multirow{5}{*}{ n-type } & ++ & - & \\
& ++ & - & \\
++ & - & p-type \\
& ++ & - & \\
++ & - & \\
++ & - & \\
& ++ & - & \\
& Depletion & \\
& Zone &
\end{tabular}

Figure 1. A p-n junction showing depletion zone and ionized donors and acceptors.

Using silicon p-n junctions as an example, photons are absorbed by exciting electrons in the p-type silicon from the valence band to the conduction band. These excited electrons flow first from the p-type to the n-type silicon and then to the contacts, while the newly created holes in the valence band flow away from the p-n interface. The movement of the holes and electrons is caused by the built-in voltage of the p-n junction. In general terms, the energy absorbed from a photon excites an electron into a highenergy state, which allows the high-energy state electron to be transported to a contact. The empty lower-energy, or ground, state must then be refilled by another electron from 
the lower-energy contact. It is important that the high-energy electron contact does not supply electrons to the ground state and that the high-energy electrons do not reach the low-energy contact [12]. Figure 2 shows the requirements for PV.

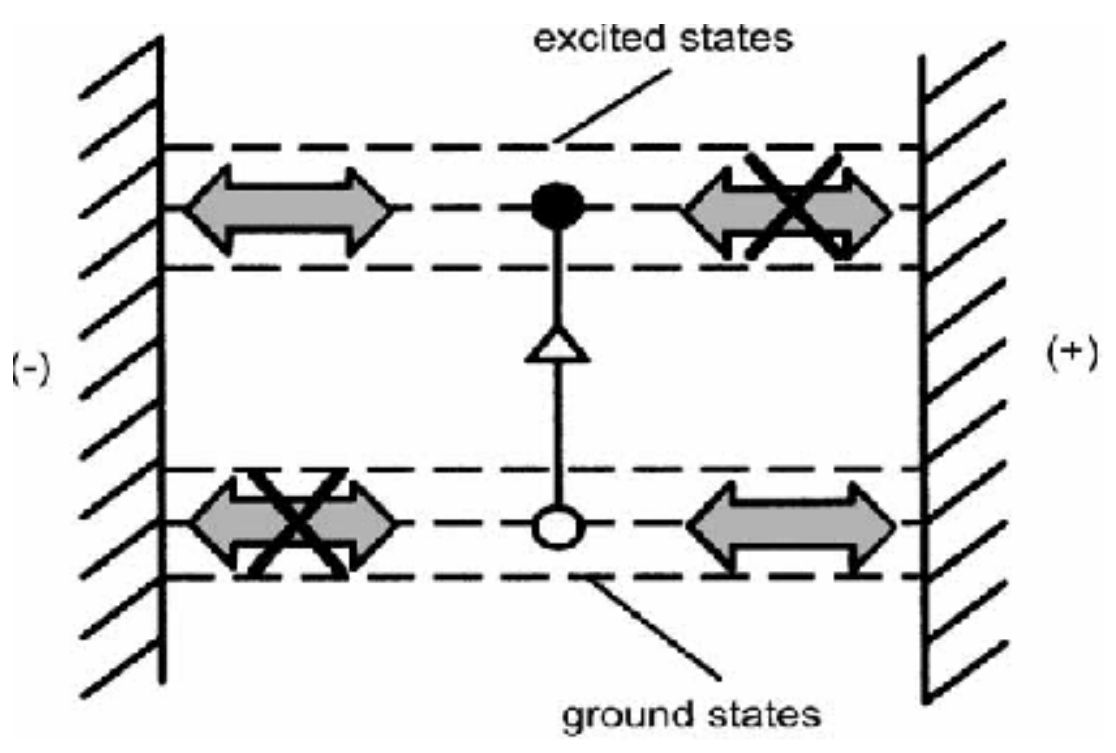

Figure 2. Essential requirements for photovoltaics. Reprinted from Physica E, Vol. 14, M.A. Green, Photovoltaic principles, 15, copyright 2002, with permission from Elsevier.

\section{$1.4 \quad$ Dye-Sensitized Solar Cells}

DSSC and other departures from the solid-state silicon solar cell are receiving attention because of several attractive features [3]. DSSCs are attractive, in part, because of a relatively low fabrication cost. They can be fabricated without the high vacuum, high energy, and high temperature processes used in traditional silicon solar cell fabrication. DSSCs consist of a semiconductor material and an electrolyte sandwiched between electrodes. The semiconductor is coated with a photon-sensitive dye, and the electrolyte contains a redox reaction mediator. Figure 3 shows a schematic of an operating DSSC. 


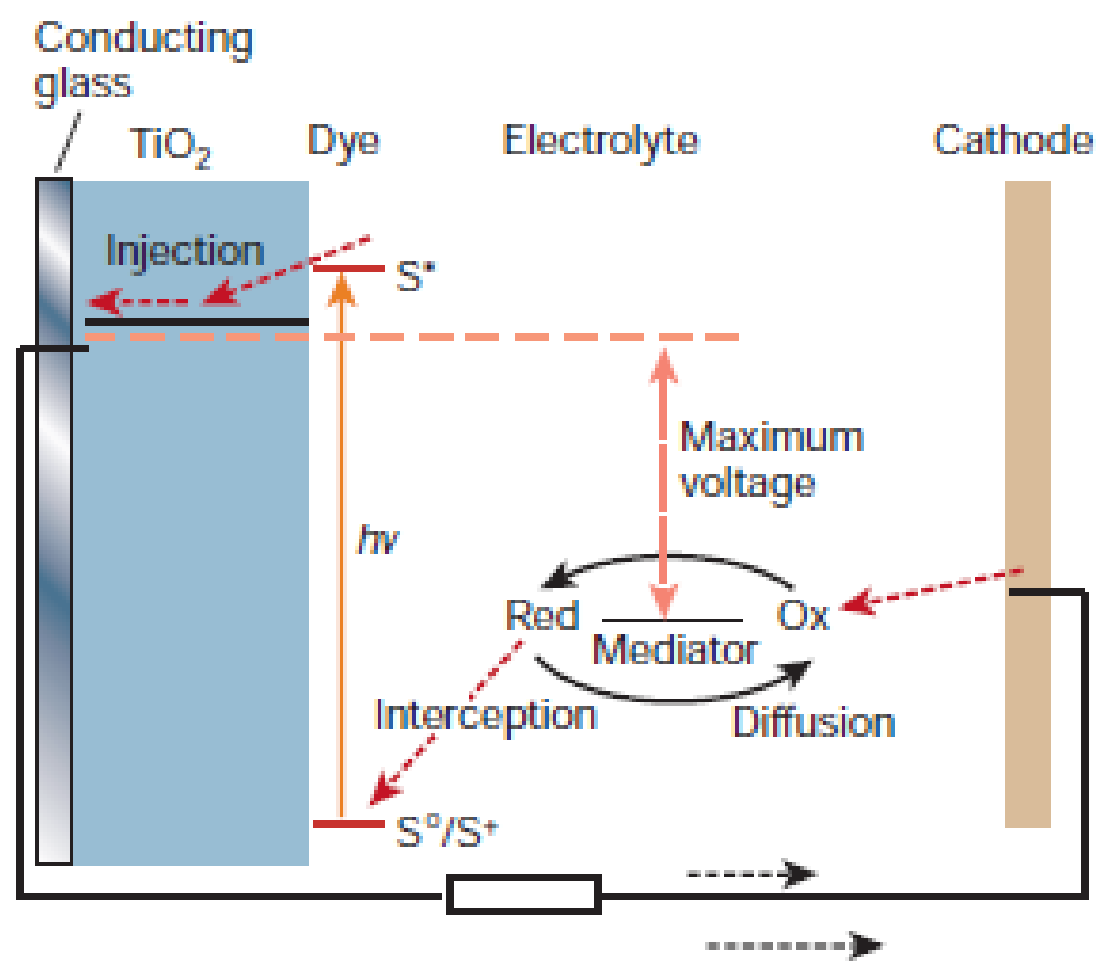

Figure 3. Schematic showing the operation of a dye-sensitized solar cell. Reprinted by permission from Macmillan Publishers Ltd: Nature, M. Grätzel, "Photoelectrochemical cells," Nature, 414, 338-344 (2001).

DSSC also works because of the photovoltaic effect, whereby photons with energy hv excite electrons to the $\mathrm{S}^{*}$ state. This excitation of electrons takes place in a photosensitive dye. As shown in Figure 3, the electrons flow into the semiconductor anode, oxidizing the dye. The dye oxidizes the mediator in the electrolyte and the mediator is reduced at the cathode. The electrons then flow from the semiconductor anode to the cathode through an external circuit. 


\subsection{Photovoltaic Efficiency Evaluation}

One factor contributing to the high cost of PV cells is low conversion efficiency. Conversion efficiency, shown in Equation 1, is a measure of the ratio of useable output compared to input, where $\eta$ is the efficiency, $P_{\text {out }}$ is the usable energy output and $P_{\text {in }}$ is the energy input.

$$
\eta=\frac{P_{\text {out }}}{P_{\text {in }}} \quad \text { Equation } 1
$$

The 1954 Bell Laboratory PV cell, the first PV cell developed, had an efficiency of around $6 \%$ [13]. Current conversion efficiencies range from $15 \%$ to $20 \%$ [2].

Some important electrical characteristics of PV cells can be determined by generating a current-voltage (I-V) curve. I-V curves are generated by exposing a PV cell to constant light, varying the load resistance, and measuring the resulting current. Figure 4 shows an I-V curve for a silicon solar cell and the properties that can be measured.

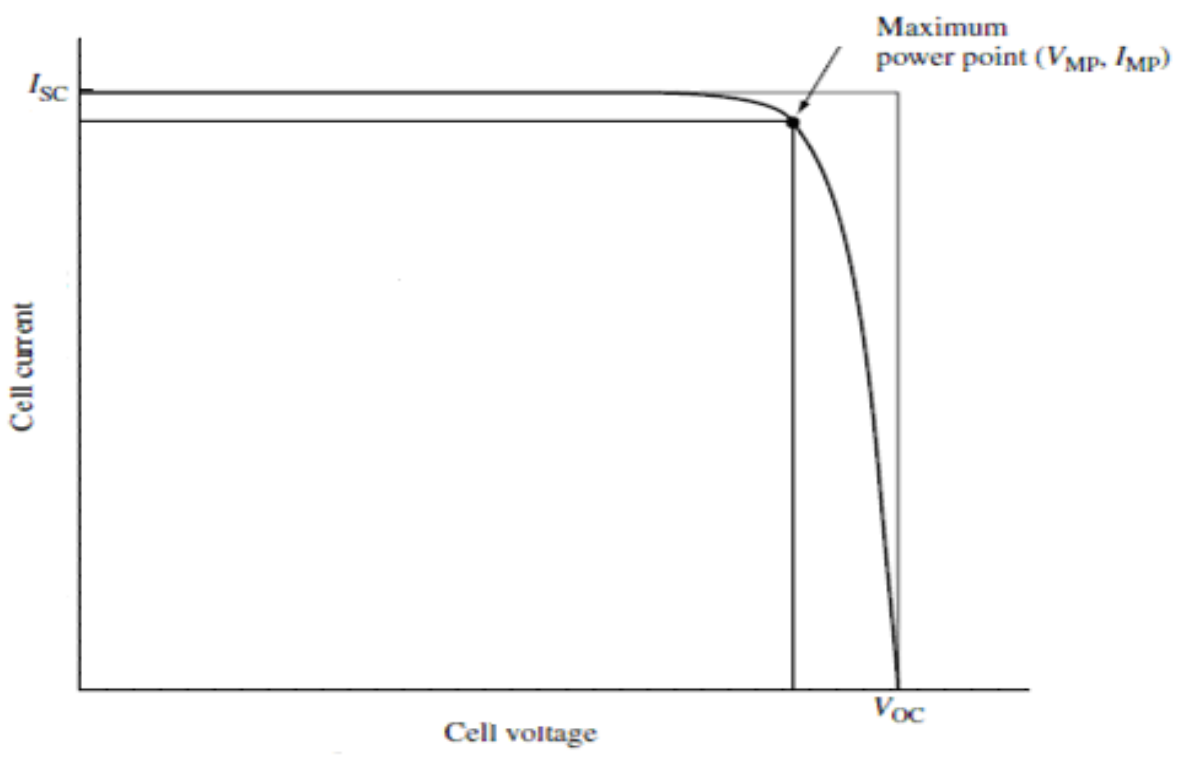

Figure 4. Current-voltage characteristics of a silicon solar cell. 
The measurable properties include short-circuit current $\left(\mathrm{I}_{\mathrm{SC}}\right)$, open-circuit voltage $\left(\mathrm{V}_{\mathrm{OC}}\right)$, maximum power point $\left(\mathrm{P}_{\mathrm{MAX}}\right)$, and fill factor $(\mathrm{FF})$. The short-circuit current is the maximum current produced when the voltage is zero. The open-circuit voltage is the maximum voltage produced when the current is zero. The maximum power point is the point where the power, the product of the current and the voltage, is the highest. The fill factor, shown in Equation 2, is used to characterize the maximum power point, and measures the squareness of the I-V curve by comparing the rectangle defined by $\mathrm{I}_{\mathrm{SC}}$ and $\mathrm{V}_{\mathrm{OC}}$ with the rectangle defined by $\mathrm{I}_{\mathrm{MP}}$ and $\mathrm{V}_{\mathrm{MP}}$ (the voltage and current at $\mathrm{P}_{\mathrm{MAX}}$ ).

$$
F F=\frac{I_{M P} V_{M P}}{I_{S C} V_{O C}} \quad \text { Equation 2 }
$$

\subsection{Project Objectives}

The primary objectives of this project were: (1) to develop a surfactant-assisted hydrothermal solution fabrication method for controlled growth of single-crystal titaniananorod thin films; (2) to characterize titania nanorod thin films hydrothermally grown with several different surfactants; and (3) to test in greater depth the effects of one promising additive. 


\section{CHAPTER TWO}

\section{LITERATURE REVIEW}

\subsection{Introduction}

In this chapter, several titanium dioxide nanorod thin film fabrication techniques are presented and low temperature hydrothermal solution synthesis is discussed in detail. The hydrothermal synthesis section includes a discussion of surfactants that are known to or may affect the growth of titanium dioxide $\left(\mathrm{TiO}_{2}\right.$ or titania) nanorods. Several methods of film characterization are also covered.

\subsection{Titania Nanorod Thin Film Deposition}

There are several established methods for depositing titanium dioxide nanorod thin films. These methods vary with respect to technique, cost, and difficulty. Park et al. studied the technique of titania nanostructure fabrication using cylindrical nanopore arrays [14]. In this study, they developed a nanoporous template with controllable diameter, vertically aligned, cylindrical pores that can be used to fabricate nanostructures of numerous materials including titanium dioxide. The template is made from an organic polymer that is patterned through oxygen plasma etching. Park et al. reported nanoposts of titania with an aspect ratio of four and a height of about 100nm.

Wu et al. studied the technique of rutile and anatase aligned titania nanorod deposition by metalorganic chemical vapor deposition (MOCVD) [15]. This method deposited aligned nanorods without needing a template or catalyst. They proposed that well-aligned growth occurs because of differing growth rates of the facets of the 
tetragonal titania nanocrystal. They also proposed that the anatase crystal facets have a relative growth rate of $R_{(110)}>R_{(011)}>R_{(112)}$. It was reported that rutile and anatase crystal structures were deposited at different temperatures, $630^{\circ} \mathrm{C}$ and $560{ }^{\circ} \mathrm{C}$, respectively.

Xi et al. studied the deposition of oxide nanorods by oblique-angle electron beam deposition $[16,17]$. In these experiments, silicon dioxide and titanium dioxide nanorods were deposited at different angles depending on the angle of incidence of the vapor flux. Oblique angle deposition results in nanorods because of a self-shadowing effect. The initial, random nucleation on the substrate creates a shadow region that the incident flux cannot reach, thereby creating oriented nanorods. Figure 5 shows SEMs image of oriented silicon dioxide nanorods deposited by oblique angle deposition.

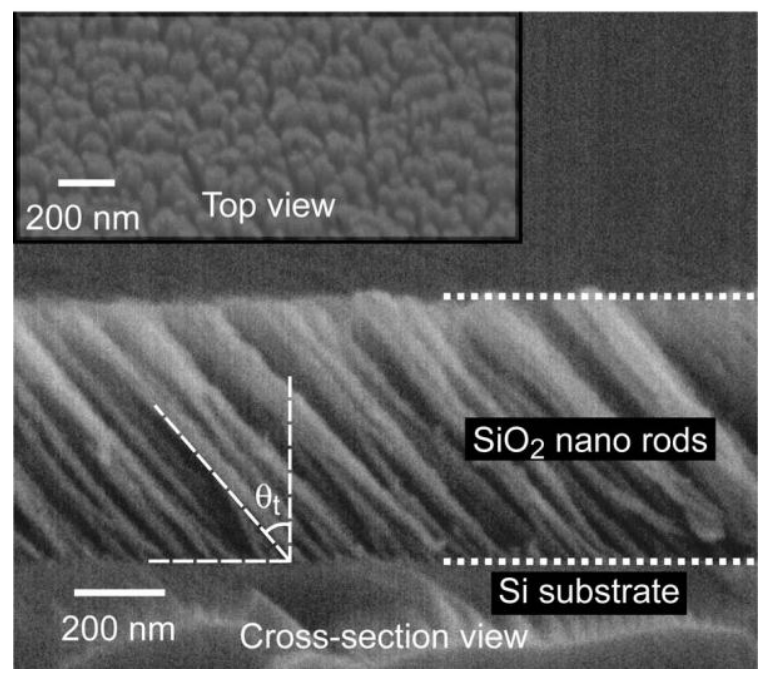

Figure 5. SEM images of silicon dioxide nanorods deposited by oblique angle deposition. Reprinted with permission from J. Xi, J.K. Kim, E.F. Schubert, D. Ye, T. Lu and S. Lin, "Very low-refractive-index optical thin films consisting of an array of $\mathrm{SiO}_{2}$ nanorods," Opt. Lett., 31(5), 601-603 (2006). Copyright 2006 Optical Society of America. 
Zhoa et al. showed that glancing angle deposition (GLAD) can also produce various nanostructures including vertically aligned nanorods [18]. GLAD combines oblique-angle deposition and controlled substrate motion. In Zhoa et al.'s experiment, GLAD was used to deposit vertically aligned nanorods by continually rotating the substrate. Figure 6 shows vertically aligned nanorods that were deposited by GLAD.

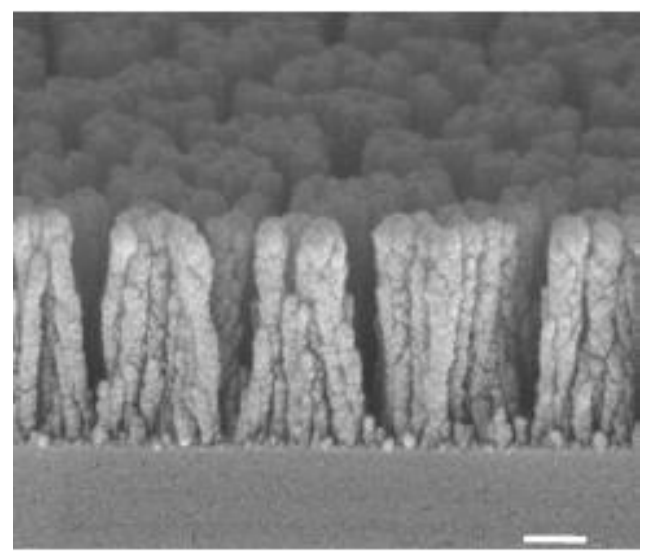

Figure 6. SEM cross-section of vertically aligned silicon dioxide nanorods deposited with GLAD. Reprinted with permission from Y.P. Zhao, D.X. Ye, G.C. Wang and T.M. $\mathrm{Lu}$, "Novel nano-column and nano-flower arrays by glancing angle deposition," Nano Lett., 2(4), 351-354 (2002). Copyright 2002 American Chemical Society.

\subsection{Hydrothermal Synthesis}

Hydrothermal solution synthesis has shown promise as a method for more economical mass production than the deposition methods discussed above.

Hydrothermal synthesis of a material involves dissolving and recrystallizing in a hightemperature, high-pressure aqueous solution [19]. Often hydrothermal synthesis is done with materials that are relatively insoluble at ambient temperature and pressure. The 
process takes place inside of an autoclave pressure vessel with a solution containing a precursor for the material and an aqueous growth mixture.

A good deal of research has gone into understanding hydrothermal synthesis of oxides including titanium dioxide. For example, Li et al. studied the growth of aligned single crystal titania nanorod arrays by hydrothermal solution [20]. In their experiments, nanorod arrays were grown on prepared glass substrates in a hydrothermal autoclave, at $160{ }^{\circ} \mathrm{C}$ for three hours. The resulting titania nanorods were rutile, single crystal with an average width of around $20 \mathrm{~nm}$ and an average length of around $400 \mathrm{~nm}$.

The research has shown that there are several parameters affecting film growth $[8$, 20-23]. Some of the factors that determine how a titania nanorod film grows hydrothermally include the solution mixture, titanium precursor, substrate, baking temperature, baking time, and additives.

\subsubsection{Solution Mixture}

Several different solution mixtures have been shown to facilitate the growth of titania nanorod arrays. Table 1 lists the solutions used by several groups that have investigated the hydrothermal growth of titanium dioxide nanorod arrays. Of note, Li et al. used an aqueous solution that was saturated with sodium chloride [20]. Liu et al. used deionized (DI) water and concentrated hydrochloric acid [8] and reported nanorods of up to $4 \mu \mathrm{m}$ long. Feng et al. used a 10:1 toluene hydrochloric acid mixture [21] and reported nanorods of up to $5 \mu \mathrm{m}$ long. Pavasupree et al. used a distilled water and aqueous ammonia solution at $28 \%$ [22] and reported nanorods of $200 \mathrm{~nm}$. 
Liu et al. studied the effect of the relative amounts of DI water and hydrochloric acid in the solution on the nanorod growth [8]. In Liu et al.'s experiment, the solution was varied from $100 \%$ DI water to $100 \%$ concentrated hydrochloric acid. They found that a one-to-one DI water and concentrated hydrochloric acid mixture was most favorable. When there was little or no hydrochloric acid, the titanium precursor precipitated out and no growth was shown. They also found that there was no growth when the hydrochloric acid concentration was high. They hypothesized that this was because the hydrolysis of the titanium precursor occurred too quickly.

Table 1. The hydrothermal solutions and titanium precursors used by several research groups.

\begin{tabular}{|c|c|c|}
\hline Group & Hydrothermal solution & Titanium precursor \\
\hline Li et al. [20] & $\begin{array}{c}\mathrm{NaCl} \text { saturated aqueous } \\
\text { solution }\end{array}$ & Titanium trichloride \\
\hline Liu et al. [8] & 1:1 $\mathrm{DI} \mathrm{H}_{2} \mathrm{O}$ and conc. $\mathrm{HCl}$ & Titanium butoxide \\
\hline Feng et al. [21] & $\begin{array}{l}\text { 10:1 toluene and conc. } \\
\mathrm{HCl}\end{array}$ & $\begin{array}{l}\text { Tetrabutyl titanate and } \\
\text { titanium tetrachloride }\end{array}$ \\
\hline Pavasupree et al. [22] & $\begin{array}{c}\text { 4:3 distilled } \mathrm{H}_{2} \mathrm{O} \text { and } 28 \% \\
\text { aqueous } \mathrm{NH}_{3}\end{array}$ & Titanium butoxide \\
\hline
\end{tabular}

\subsubsection{Titanium Precursor}

Several different titanium precursors have been used to provide the titanium for the titania nanorods. The titanium precursors used by several groups are also shown in Table 1. 
Liu et al. studied the effect that the amount of titanium precursor had on nanorod growth [8]. In their experiment, nanorods were grown in solutions containing increasing amounts of titanium butoxide, ranging from $0.83 \%$ to above $1.7 \%$. They reported that as the concentration of precursor increased, the density of the nanorods increased (as shown in Figure 7) until the concentration reached $1.7 \%$ and the precursor began to precipitate out.
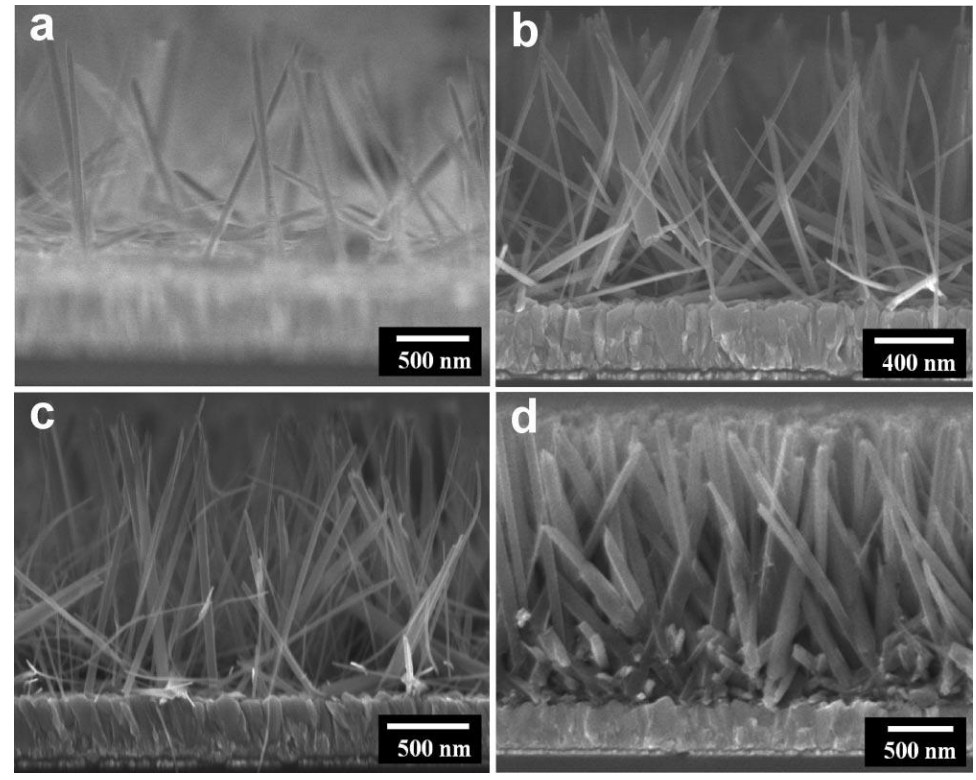

Figure 7. FESEM images of $\mathrm{TiO}_{2}$ nanorods grown in $30 \mathrm{~mL}$ DI water and $30 \mathrm{~mL}$ concentrated hydrochloric acid with (a) $0.5 \mathrm{~mL}$, (b) $0.75 \mathrm{~mL}$, (c) $0.85 \mathrm{~mL}$, and (d) $1 \mathrm{~mL}$ of titanium butoxide. Reprinted with permission from B. Liu and E.S. Aydil, "Growth of oriented single-crystalline rutile $\mathrm{TiO}_{2}$ nanorods on transparent conducting substrates for dye-sensitized solar cells," J. Am. Chem. Soc., 131, 3985-3990 (2009). Copyright 2009 American Chemical Society.

\subsubsection{Substrate}

The selection of a substrate can affect film growth properties, cost, and the ability to integrate the film into applications. Kakiuchi et al. grew titanium dioxide nanorods onto glass substrates using a hydrothermal synthesis in which a titanium trichloride 
solution was baked at various temperatures for various times [23]. They proposed that the growth was a result of heterogeneous nucleation and presented results that on a glass substrate the vertical alignment of titania nanorods was not very uniform (Figure 8).

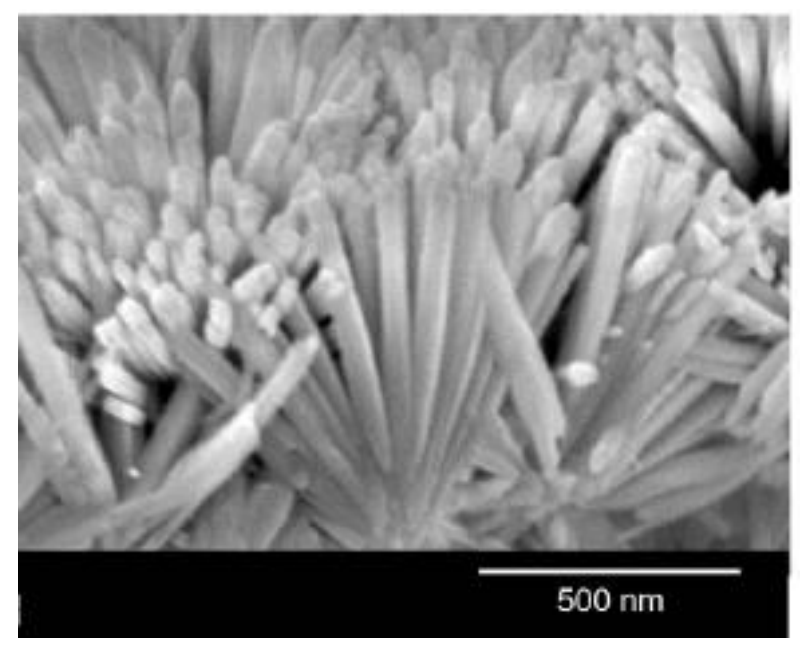

Figure 8. FESEM image of $\mathrm{TiO}_{2}$ nanorods on glass grown at $80{ }^{\circ} \mathrm{C}$ for $168 \mathrm{hrs}$. Reprinted from Journal of Cryatal Growth, vol. 293, K. Kakiuchi, E. Hosono, H. Imai, T. Kimura and S. Fujihar, $\left\{\begin{array}{lll}1 & 1 & 1\end{array}\right\}$-faceting of low-temperature processed rutile $\mathrm{TiO}_{2}$ rods, 543, Copyright 2006, with permission from Elsevier.

Li et al. investigated the effects that coating the glass with a flat titanium dioxide seed layer had on the hydrothermally grown titania nanorods [20]. In their experiment, each glass substrate was coated twice with spun on layers of a tetrabutyl titanate mixture that were dried and then annealed at $700{ }^{\circ} \mathrm{C}$ for 30 minutes. With the addition of the seed layer, and especially the annealed seed layer, the nanorods became much more aligned. Figure 9 shows the effects of adding a seed layer and of heat treating the seed layer. 

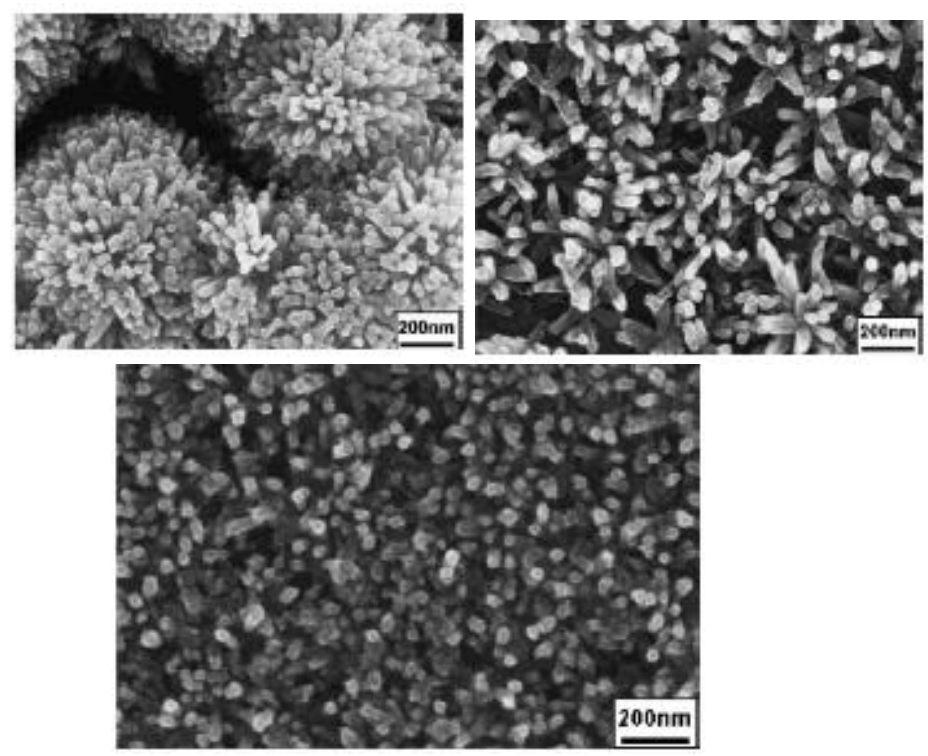

Figure 9. FESEM images of titania nanorods grown on (a) glass, (b) glass coated with a flat $\mathrm{TiO}_{2}$ dried seed layer, and (c) glass coated with a flat $\mathrm{TiO}_{2}$ dried and annealed seed layer. Reprinted from Materials Research Bulletin, vol. 44, Y. Li, M. Guo, M. Zhang and $\mathrm{X}$. Wang, Hydrothermal synthesis and characterization of $\mathrm{TiO}_{2}$ nanorod arrays on glass substrates, 1233-1235, Copyright 2009, with permission from Elsevier.

Feng et al. grew titania nanorod arrays on glass coated with transparent conducting oxide (TCO) [21] and incorporated them into dye-sensitized solar cells. They hypothesized that the TCO substrate could greatly enhance the performance of titania nanorods for PV cell applications because the TCO would be the electrical contact. In their experiments, titania nanorods were grown on glass substrates coated with a TCO of fluorine-doped tin oxide (FTO). They reported that DSSC using 2-3 $\mu \mathrm{m}$ long nanorod arrays have an efficiency of $5.02 \%$.

\subsubsection{Baking Time and Temperature}

Time and temperature are the easiest parameters to vary and must be studied to optimize results. Liu et al. investigated the effects of both hydrothermal baking time and 
temperature [8]. They observed that initially there was no growth, but that after a certain time the nanorods began to grow and continued growing at a decreasing rate until the titania nanorod film began to peel off. They proposed that the peeling off occured when the reaction reached equilibrium and that peeling off can be prevented if the reaction is stopped prior to equilibrium. No growth took place at temperatures lower than $100{ }^{\circ} \mathrm{C}$, and higher temperatures increased the growth rate. For example, it took 24 hours for peel-off to occur at $150{ }^{\circ} \mathrm{C}$, while at $200{ }^{\circ} \mathrm{C}$ it only took six hours.

\subsubsection{Additives}

Surface interactions play an important role in film growth. Additives, such as surfactants, can alter the surface energy of the film and change growth properties.

Yang et al. grew titanium dioxide nanorods with a surfactant-assisted

hydrothermal process [24]. In their experiment, the surfactant $\mathrm{EO}_{5} \mathrm{PO}_{68} \mathrm{EO}_{5}$ was added to the hydrothermal solution. They reported DSSC having an efficiency of $6.03 \%$.

Liu et al. investigated the effects of several hydrothermal solution additives including EDA, EDTA, SDS, CTAB, PVP and $\mathrm{NaCl}$ [8]. They observed that with the exception of $\mathrm{NaCl}$, the salts and surfactants had minimal effect on the titania nanorod morphology (distribution, diameter, and length). When $\mathrm{NaCl}$ was added to the hydrothermal solution, the density and diameter of the nanorods decreased. Liu et al. proposed three alternative explanations for this: (1) the $\mathrm{NaCl}$ increases the ionic strength of the solution, which favors smaller crystals; (2) ions next to the nanorods form a 
diffusion barrier and inhibit surface access, slowing growth; (3) lastly, chlorine ions may adsorb to the nanorod surface and slow growth.

Several other surfactants have been shown to affect or interact with titanium dioxide or other nanoscale material fabrication. These surfactants include oleic acid, tetradecylphosphonic acid (TDPA), polyethylenimine (PEI), high molecular weight polyethylene glycol (PEG), and sodium dodecyl sulfate (NaDDS). Manera et al. used oleic acid in a low-temperature titania nanostructure hydrolytic synthesis method and showed that TDPA also interacted with the titania structures by adhering to titania nanocrystals [25]. Tang et al. studied the adsorption behavior of PEI on nano-sized titania particles during dispersion and electrophoretic deposition [26]. Kajihara et al. fabricated macroporous titania films using high molecular weight PEG through a sol-gel dip-coating method and reported that the shape and distribution of the macropores was controlled by the amount and molecular weight of the PEG [27].

PEGs of differing molecular weight are referred to by the molecular weight, for example PEG with a molecular weight of 400 is PEG 400. If the molecular weight is greater than 20,000, the polymer is called a polyethylene oxide (PEO) rather than PEG. Kajihara et al. found that lower molecular weights of PEG had higher compatibility with water and that increasing the PEG amount increases the solution viscosity. Yu et al. used PEG 6000 in both sol-gel and hydrothermal synthesis [28]. Yu et al. found that the ether oxygens in PEG interact with metal ions and affect the crystallization of titania. Liao et al. used NaDDS as a surfactant to decrease the van der Waals force between carbon nanotubes in an aluminum matrix composite fabrication process [29]. By decreasing the 
van der Waals force, Liao et al. increased the dispersion carbon nanotubes in the aluminum matrix.

\subsection{Characterization}

Several different characterization techniques can be used to characterize the titania nanorod thin films. The properties of interest include distribution, length, diameter, crystal structure, microstructure, and electrical properties.

\subsubsection{Scanning Electron Microscopy}

Nearly all of the research groups noted above used a scanning electron microscope (SEM) or a field emission scanning electron microscope (FESEM) to investigate the length, diameter and density of the titanium dioxide nanorods [8-9, 1424]. Figures 4-9 are all examples of how SEM can be used to characterize nanorod thin films.

\subsubsection{Transmission Electron Microscopy}

Peng et al. used a high-resolution transmission electron microscope (TEM) to investigate the microstructure of a single nanorod [30]. Figure 10 shows further structural detail of a single nanorod. They observed, from the TEM images, that this nanorod appears to consist of smaller rodlike crystals and measured the (110) and (001) planes with respective $d$ spacing of $0.320 \mathrm{~nm}$ and $0.295 \mathrm{~nm}$. 

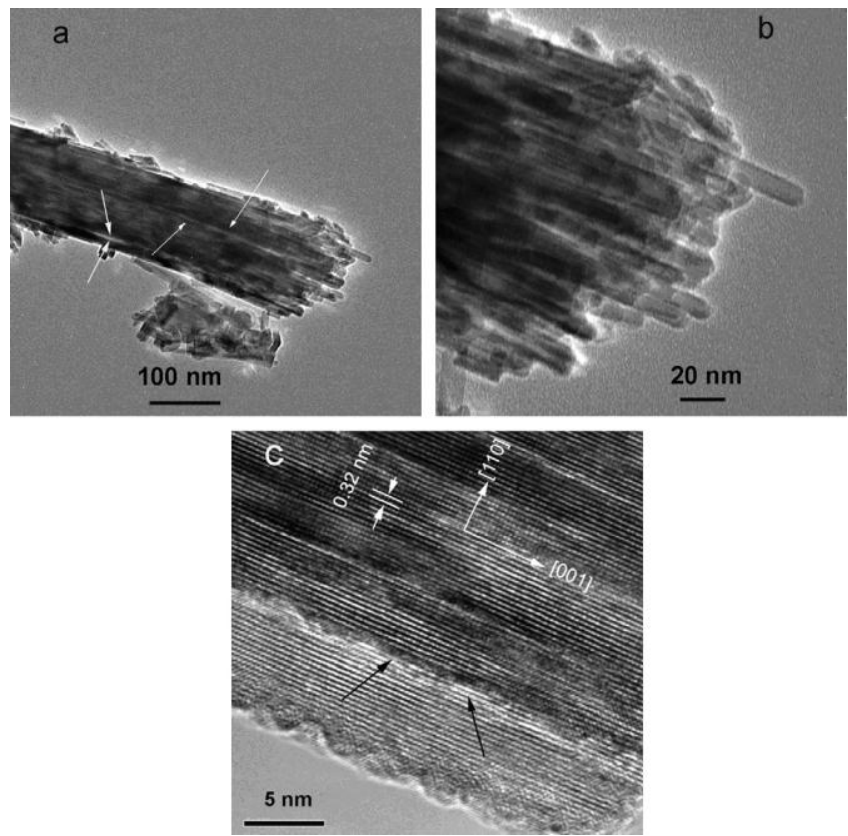

Figure 10. TEM images of a $\mathrm{TiO}_{2}$ nanorod structure. Reprinted from Journal of Solid State Chemistry, vol. 182, P. Peng, X. Liu, C. Sun, J. Ma and W. Zheng, Facile fabrication of rutile monolayer films consisting of well crystalline nanorods by following an IL-assisted hydrothermal route, 1005, Copyright 2009, with permission from Elsevier.

Wu et al. used TEM to investigate the titania nanorods and to characterize the crystal structure based on the electron diffraction pattern [15]. Figure 11 shows the TEM image of a nanorod and the corresponding electron diffraction pattern. Based on the electron diffraction pattern, they reported that the nanorod in Figure 11 has the anatase crystal structure.
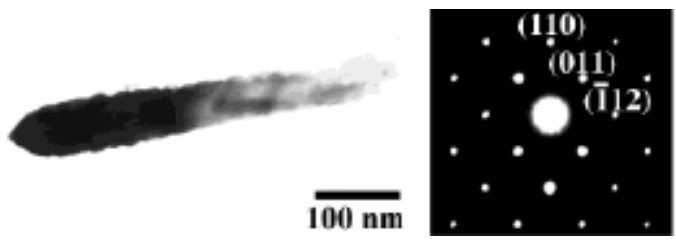

Figure 11. TEM image and corresponding electron diffraction pattern of an anatase titania nanorod. Reprinted with permission from J. Wu and C. Yu, "Aligned $\mathrm{TiO}_{2}$ nanorods and nanowalls," J. Phys. Chem. B, 108(11), 3377-3379 (2004). Copyright 2004 American Chemical Society. 


\subsubsection{X-ray Diffraction}

$\mathrm{Xu}$ et al. used x-ray diffraction (XRD) to determine the crystal structure of different hydrothermally grown titania nanomaterials [31]. In their experiment, the $\mathrm{pH}$ of the hydrothermal solution was varied. Based on the XRD data from the grown nanorods, they concluded that for their solution the anatase crystal structure was formed when the $\mathrm{pH}$ was 7 and 2. The rutile crystal structure formed when the $\mathrm{pH}$ was 0 ; the lower $\mathrm{pH}$ prevented a dehydration reaction and allowed the rutile structure to form. 


\section{CHAPTER THREE}

\section{OBJECTIVES}

The primary objective of this research was to develop a controlled growth method for surfactant-assisted hydrothermal synthesis of single-crystal titania-nanorod thin films. Controlled growth allows for tailoring of film properties, including aspect ratio and nanorod distribution, by varying hydrothermal synthesis parameters. Additionally, the films created by surfactant-assisted hydrothermal synthesis were characterized, and the additive with the most profound effect on morphology was investigated in-depth.

Hydrothermal solution synthesis assisted by either oleic acid, tetradecylphosphonic acid, lithium chloride, potassium chloride, calcium chloride, sodium dodecyl sulfate, polyethylenimine, or one of several molecular weights of polyethylene glycol (PEG), was investigated. Scanning Electron Microscope (SEM) was used to characterize the resulting titania nanorod thin films to determine their height, width, and nanorod array density. The surfactant that produced the nanorods with the highest aspect ratio and highest surface area, PEG, was then studied in more detail. 


\section{CHAPTER FOUR}

\section{EXPERIMENTAL METHODS}

\subsection{Introduction}

The objective of this project was to control the growth of titanium dioxide thin films. All research was conducted at the IBM Almaden research facility in San Jose, California, where all of the needed materials and equipment were available. Several process parameters, including hydrothermal solution mixture, concentration of titanium precursor, substrate preparation, baking time, baking temperature, and the addition of certain additives, had previously been investigated [8, 19-24]. This study examined hydrothermal fabrication of titania nanorods assisted by several different surfactants: oleic acid, tetradecylphosphonic acid (TDPA), polyethylenimine (PEI), several molecular weights of polyethylene glycol (PEG), sodium dodecyl sulfate (NaDDS), lithium chloride ( $\mathrm{LiCl})$, potassium chloride $(\mathrm{KCl})$, and calcium chloride $\left(\mathrm{CaCl}_{2}\right)$.

These surfactants were added to the hydrothermal solution and titania nanorod films were grown. These films were then characterized by SEM to determine their morphology and microstructure. After preliminary results, this study further investigated the effects of PEG.

\subsection{Substrate Preparation}

\subsubsection{Cleaning}

The substrates needed to be cleaned before they could be used. Glass substrates coated on one side with FTO were swabbed with a mild soap solution and then rinsed 
with deionized water. Once dry, the substrates were loaded with the FTO side facing up into a UV-ozone cleaner to remove organics. Then the UV-ozone cleaner was run for 20 minutes. Following this, the substrates were loaded into a carrier, placed into a crystallizing dish with liquid detergent and deionized water, and placed into the sonicator (with sonicating tip placed in the water). After running the sonicator for 30 minutes, the substrates were rinsed and dried.

\subsubsection{Flat Titania}

Each cleaned substrate was loaded individually into a spin coater and received two drops of a titanium precursor (30 weight percent one-to-one tyzor to acetylacetane in propylene glycol propyl ether (PGPE)). The substrates were spun at $2000 \mathrm{rpms}$ for 45 seconds and then two opposite edges of each substrate were wiped with ethyl alcohol. The substrates were then flash heated at $450{ }^{\circ} \mathrm{C}$ for five minutes. After heating, the substrates were cooled and then cleaned in a UV-ozone cleaner for one minute. This spin process through the flash heating step (not including cleaning), was repeated. Afterwards, the substrates were placed into a furnace and heated to $450{ }^{\circ} \mathrm{C}$ at $5{ }^{\circ} \mathrm{C}$ per minute and held at $450{ }^{\circ} \mathrm{C}$ for two hours.

\subsubsection{Evaporating $\mathrm{SiO}_{2}$}

Substrates were rinsed with deionized water and put in a deionized spray bar for 5 minutes, then soaked in a circulating deionized water bath for 20 minutes. After the bath, the substrates were put into an isopropyl alcohol de-greaser for 5 minutes. Then they 
were dried in a nitrogen bath for approximately one minute (until dry). Substrates were loaded FTO side down into a mask that covers a strip parallel to the opposite wiped regions down the middle of the substrate. The mask was then loaded into a vented evaporator. A silicon monoxide source was loaded into the evaporator, and the evaporator was closed and the pump-down process was started. When the pressure had reached at least $5 \times 10^{-6}$ Torr or below (at around 45 minutes), the current was turned on and ramped up until the deposition rate reached between $1.6 \AA / \mathrm{s}$ and $2.2 \AA / \mathrm{s}$. The oxygen tank was then opened until the pressure in the evaporator reached $3 \times 10^{-4}$ Torr and the current was adjusted to stabilize the deposition rate back to the previous range (between 1.6 and $2.2 \AA / s$ ). The gate was then opened and silicon dioxide was deposited onto the substrates to a thickness of $2500 \AA$. During the evaporation, the deposition rate was kept between 1.6 $\mathrm{A} / \mathrm{s}$ and $2.2 \AA / \mathrm{s}$, and the film thickness was calculated based on the deposition rate. After deposition was complete, the evaporator was vented and the mask removed. Each substrate was removed, wiped gently with a cloth, and replaced in the mask. The evaporation process was repeated and another $2500 \AA$ was deposited on each substrate (to $5000 \AA$ total).

\subsection{Solution Preparation}

To make the non-additive solution for the hydrothermal process, high performance liquid chromatography (HPLC) water and concentrated hydrochloric acid $(\mathrm{HCl})$ were mixed one-to-one in a $100 \mathrm{ml}$ jar and set to stir until they reached room temperature. Titanium butoxide $\left(\mathrm{Ti}(\mathrm{OBu})_{4}\right)$ was then added at one volume percent of the 
water- $\mathrm{HCl}$ solution. After the $\mathrm{Ti}(\mathrm{OBu})_{4}$ was added, the solution was stirred for five minutes or until clear.

To make the additive solution for the hydrothermal process, the desired amount of additive was added to a one-to-one solution of HPLC water, and concentrated $\mathrm{HCl}$. This solution was either (1) shaken for an hour with the wrist shaker machine, or (2) heated and stirred on a hot plate at $80^{\circ} \mathrm{C}$, until dissolved.

\subsection{Autoclave Bomb Assembly}

A substrate and fifteen milliliters of either an additive or non-additive hydrothermal solution were placed inside of a Teflon-lined steel autoclave. The parts of an autoclave bomb are shown in Figure 12. The substrate and solution were placed in the Teflon autoclave liner and capped with a Teflon lid. The liner was then inserted into the stainless steel pressure vessel. The corrosion disc and rupture disc were placed on top of the liner, followed by the lower pressure plate, spring, and upper pressure plate. The screw cap was put on and tightened by hand, then further tightened with a hook spanner. The assembly process was then repeated for each bomb in the batch. Each bomb within a batch could contain a different hydrothermal solution. 


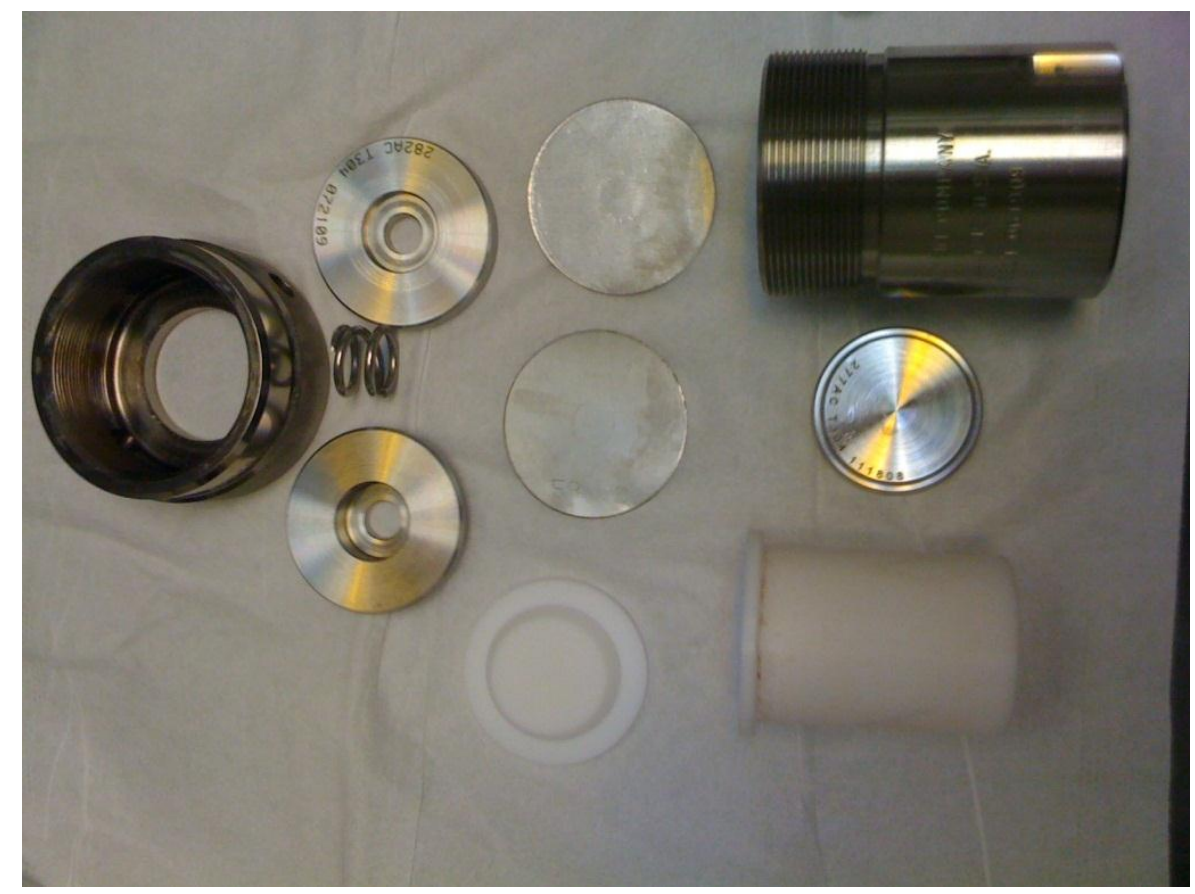

Figure 12. Parts of the steel autoclave bomb used in the hydrothermal synthesis.

\subsection{Heating}

The autoclave bombs in each batch were heated either in a furnace or a wellcirculated silicone oil bath. The number of bombs per batch could range from one to six in the furnace, or up to five in the oil bath. If the furnace method was used, the autoclave bombs were placed in a pre-heated furnace that was held at $130{ }^{\circ} \mathrm{C}$ for the desired amount of time. If the silicone oil bath heating method was used, the bombs were placed in a preheated bath at $130{ }^{\circ} \mathrm{C}$; once the temperature of the bath returned to $130{ }^{\circ} \mathrm{C}$, the bombs were baked for the desired amount of time. After baking, the bombs were cooled in circulating deionized water until cool. The autoclave bombs were then disassembled and the substrates removed. Finally the substrates were rinsed in deionized water and dried. 


\subsection{Actual Titania Growth Processes}

Several batches of titania nanorods were hydrothermally grown to test some process parameters and the effects that several additives had on nanorod growth. The initial process parameters that were used for these experiments were chosen based on published research [8, 19-23]. Table 2 summarizes these initial hydrothermal parameters.

Table 2. Initial process parameters for hydrothermal synthesis of titania nanorods.

\begin{tabular}{|c|c|}
\hline Process Parameter & Process Parameter \\
\hline Solution composition & $1: 1 \mathrm{DI} \mathrm{H}_{2} \mathrm{O}$ and conc. $\mathrm{HCl}$ \\
\hline Ti precursor and concentration & $1 \%$ Titanium butoxide \\
\hline Substrate preparation & $\mathrm{TiO}_{2}$ seed layer annealed at $450^{\circ} \mathrm{C}$ \\
\hline Baking time & $17 \mathrm{hrs}$ \\
\hline Oil temperature & $130^{\circ} \mathrm{C}$ \\
\hline
\end{tabular}

Figure 13 shows a flow chart of the standard nanorod thin film fabrication process steps used in these experiments.

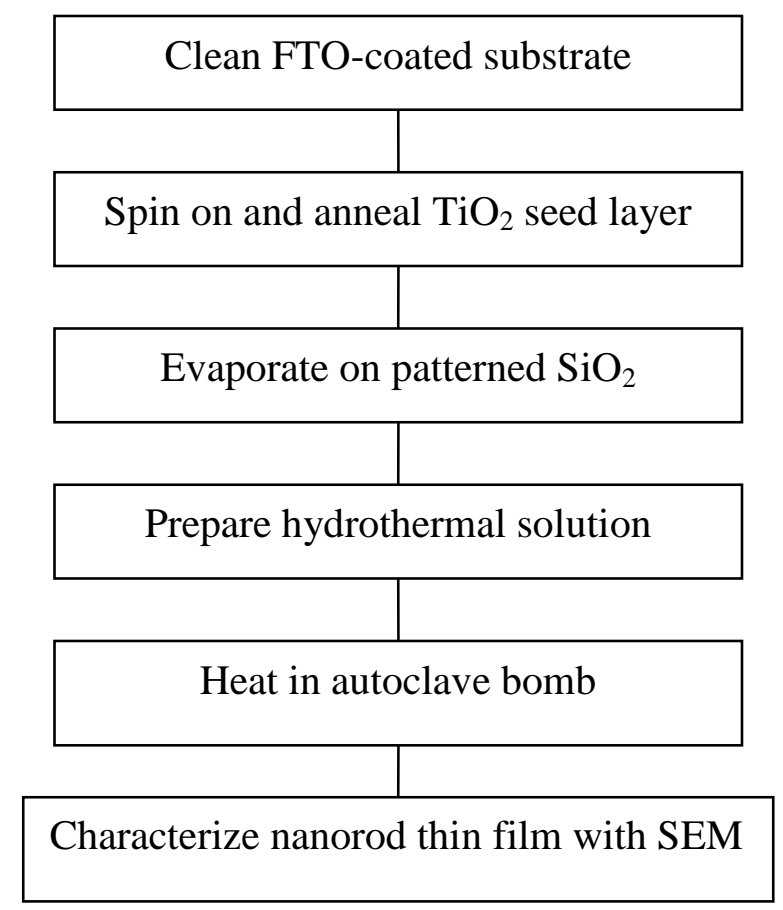

Figure 13. Flow chart of the titania nanorod thin film fabrication process. 
This research tested: the effect of hand tightening versus hook spanner tightening, furnace versus silicone oil bath baking, and several additives including multiple concentrations and molecular weights of PEG. The batches, experiments, and numbers of bombs are broken down in Table 3 .

Table 3. Summary of the experiments, batches, and number of bombs per batch.

\begin{tabular}{|c|c|c|}
\hline Batch & Experiment & Number of Bombs \\
\hline B-1 & Tightening Method & 6 \\
\hline B-2 & Tightening Method & 5 \\
\hline B-3 & Tightening and Heating Method & 6 \\
\hline B-4 & Tightening and Heating Method & 6 \\
\hline B-5 & Heating Method & 4 \\
\hline B-6 & Heating Method & 4 \\
\hline B-7 & Additives & 5 \\
\hline B-8 & Additives & 4 \\
\hline B-9 & Additives & 2 \\
\hline B-10 & Additives & 4 \\
\hline B-11 & PEG & 2 \\
\hline B-12 & PEG & 5 \\
\hline B-13 & PEG & 4 \\
\hline B-14 & PEG & 4 \\
\hline B-15 & PEG & 4 \\
\hline B-16 & PEG & 4 \\
\hline B-17 & PEG & 4 \\
\hline
\end{tabular}

\subsubsection{Using the Hook Spanner}

Initially, the hook spanner tool was not used to tighten the autoclave bombs. Four batches of nanorods (B-1 through B-4) were grown without additives in the furnace ; all four of these batches were baked for 17 hours. B-1 and B-2 were heated in autoclave bombs that were tightened only by hand, and B-3 and B-4 were heated in autoclave bombs tightened using the hook spanner tool. 


\subsubsection{Silicone Oil Bath Versus Furnace}

Two batches of nanorods (B-5 and B-6) were grown without additives in the silicone oil bath to compare to B-3 and B-4 (which were grown in the furnace). All four batches were baked for 17 hours at $130{ }^{\circ} \mathrm{C}$ by their respective heating methods.

\subsubsection{Additives}

Several batches were grown with various additives, each batch consisting of multiple bombs. Most additives were chosen based on their known interaction with titania. The salts $\left(\mathrm{LiCl}, \mathrm{KCl}\right.$, and $\left.\mathrm{CaCl}_{2}\right)$ were chosen based on the known effects of $\mathrm{NaCl}$ discussed in the literature review [8] to see if other salts had a similar effect. Batch B-7 had one bomb of each: (1) $1.37 \mathrm{wt} \%$ Oleic acid, (2) $1.31 \mathrm{wt} \%$ NaDDS, (3) $1.26 \mathrm{wt} \%$ TDPA, (4) 3.93 wt\% PEI, and (5) without additive. Batch B-8 contained one bomb of each: (1) $6.05 \mathrm{wt} \% \mathrm{LiCL}$, (2) $2.71 \mathrm{wt} \% \mathrm{KCl}$, (3) $6.84 \mathrm{wt} \% \mathrm{CaCL}_{2}$, and (4) without additive. Finally, batch B-9 had one bomb with 20.4 wt\% PEG400, and one bomb without additive. All batches were baked for 17 hours.

\subsubsection{PEG Bake Time}

Nanorod growth was enhanced by addition of PEG 400, so a shorter bake time was needed to obtain a titania nanorod thin film in which the nanorods had not fused together and peeled off from the substrate. In batch B-10, all four bombs had $13.6 \mathrm{wt} \%$ PEG 400. The bombs in B-10 were removed from the oil bath after 4, 5.5, 7, and 8 hours. 


\subsubsection{PEG Bake Temperature}

Because of the enhanced growth observed with the addition of PEG 400, lower bake temperatures were also tried. In batch B-11, two bombs at 20.4 wt $\%$ PEG 400 were baked at $90^{\circ} \mathrm{C}$ for 17 hours.

\subsubsection{PEG Concentration}

Batch B-12 contained five bombs with varying concentrations of PEG 400: (1) $3.39 \mathrm{wt} \%$; (2) $6.78 \mathrm{wt} \%$; (3) $10.16 \mathrm{wt} \%$; (4) $13.53 \mathrm{wt} \%$; and (5) $20.26 \mathrm{wt} \%$. Batch B-13 was comprised of four bombs containing the following concentrations of PEG 400: (1) $13.53 \mathrm{wt} \%$; (2) $20.26 \mathrm{wt} \%$; (3) $26.96 \mathrm{wt} \%$; and (4) $33.64 \mathrm{wt} \%$. Batch B-14 contained four bombs with PEG 2000 added at the following concentrations: (1) $6.34 \mathrm{wt} \%$; (2) $12.02 \mathrm{wt} \%$; (3) $16.88 \mathrm{wt} \%$; and (4) $21.46 \mathrm{wt} \%$. Batch B-15 contained four bombs with PEO 1,000,000 added at the following concentrations: (1) $3.22 \mathrm{wt} \%$; (2) $7.00 \mathrm{wt} \%$; (3) $11.17 \mathrm{wt} \%$; and (4) $21.42 \mathrm{wt} \%$.

\subsubsection{PEG Molecular Weight}

Batch B-16 contained four bombs with different molecular weights of the PEG (or PEO) additive: (1) PEG 400 at $11.84 \mathrm{wt} \%$; (2) PEG 1500 at $12.02 \mathrm{wt} \%$; (3) PEG 8000 at $12.01 \mathrm{wt} \%$; and (4) PEO 100,000 at $12.04 \mathrm{wt} \%$. 


\subsubsection{Different PEG Bottles}

Batch B-17 contained four bombs, two with PEG 400 from a bottle labeled Sigma-Aldrich batch MKBD5053, and two with PEG 400 from a bottle labeled SigmaAldrich batch 05818JJ. All four bombs contained the respective PEG 400 chemical at $13.5 \mathrm{wt} \%$.

\subsection{Film Characterization}

The films grown were characterized by SEM. Multiple images at different magnifications (images of all samples were taken at $25 \mathrm{k}$ and $60 \mathrm{k}$ magnification, images of some samples were also taken at other magnifications) and different regions of the films were gathered from each sample from every batch. All samples were imaged from the top down, and if significant growth occurred, the samples were cut so cross-sectional images could be taken. From these images the height, thickness, and array density of the nanorod films were determined using the image analysis program Image $\mathbf{J}$. 


\section{CHAPTER FIVE}

\section{RESULTS AND DISCUSION}

\subsection{Controlling Pressure and Temperature}

\subsubsection{Tightening Autoclave Bombs with the Hook Spanner}

Tightening the bombs with the hook spanner increased the uniformity of the nanorod arrays grown within a batch and from batch to batch. Table 4 summarizes the results of batches B-1 through B-4.

Table 4. Summary of the results of the tightening method experiment batches.

\begin{tabular}{|l|l|l|l|}
\hline Batch & $\begin{array}{l}\text { Number of } \\
\text { Bombs }\end{array}$ & $\begin{array}{l}\text { Tightening } \\
\text { Method }\end{array}$ & Results \\
\hline B-1 & 6 & Only by hand & Inconsistent nanorod length and distribution \\
\hline B-2 & 5 & Only by hand & Inconsistent nanorod length and distribution \\
\hline B-3 & 4 & $\begin{array}{l}\text { Hand and hook } \\
\text { spanner }\end{array}$ & $\begin{array}{l}\text { Consistent nanorod length and distribution } \\
\text { between batches, furnace position affects } \\
\text { length and distribution }\end{array}$ \\
\hline B-4 & 4 & $\begin{array}{l}\text { Hand and hook } \\
\text { spanner }\end{array}$ & $\begin{array}{l}\text { Consistent nanorod length and distribution } \\
\text { between batches, furnace position affects } \\
\text { length and distribution }\end{array}$ \\
\hline
\end{tabular}

Figures 14 and 15 show SEM images and oven placement of batches of titania nanorods grown without any additives in bombs only tightened by hand and not with the hook spanner (batches B-1 and B-2). 

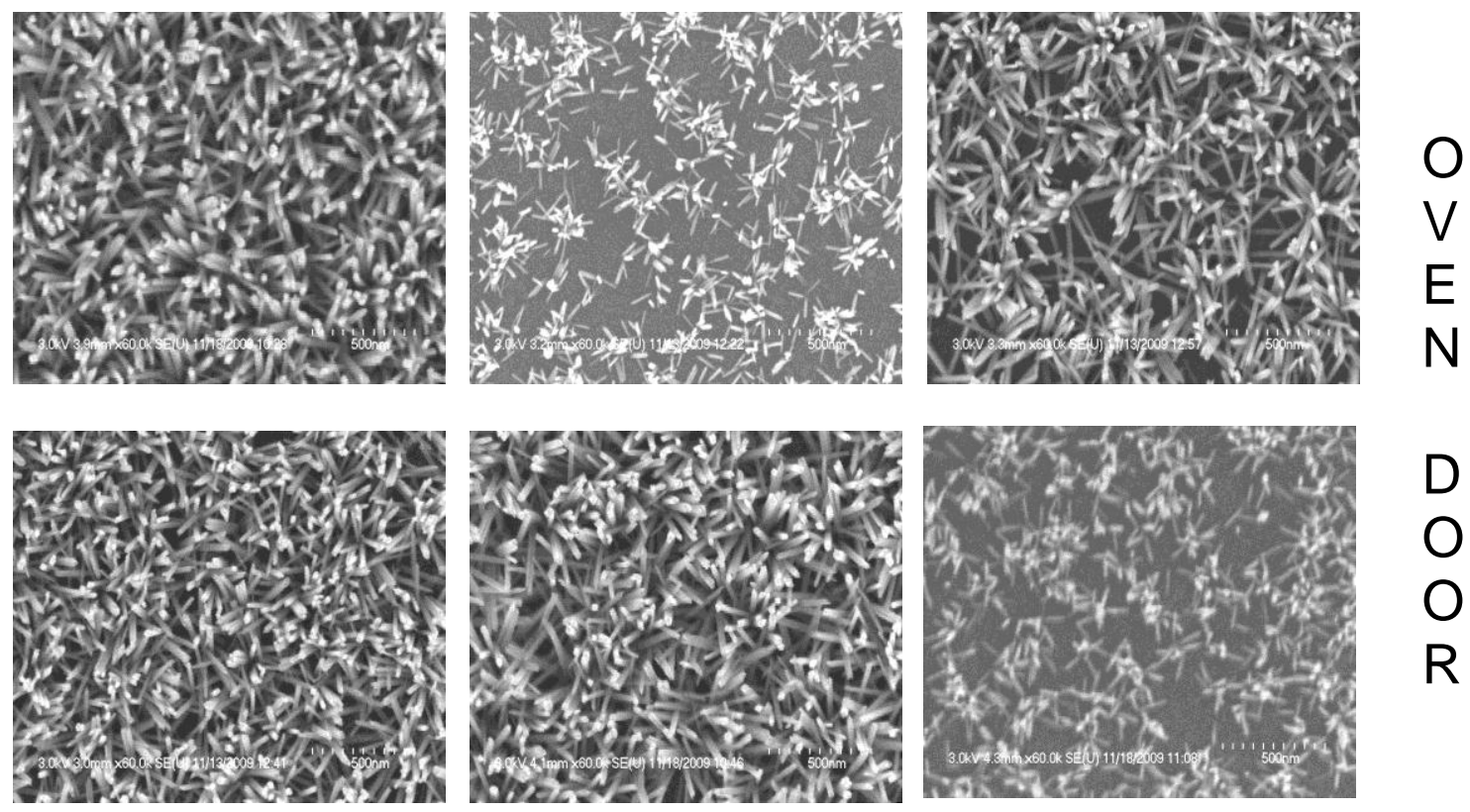

D
O
O
$R$

Figure 14. 60K magnification SEM images of titania nanorods, from batch B-1, hydrothermally grown in autoclave bombs not tightened with the hook spanner.
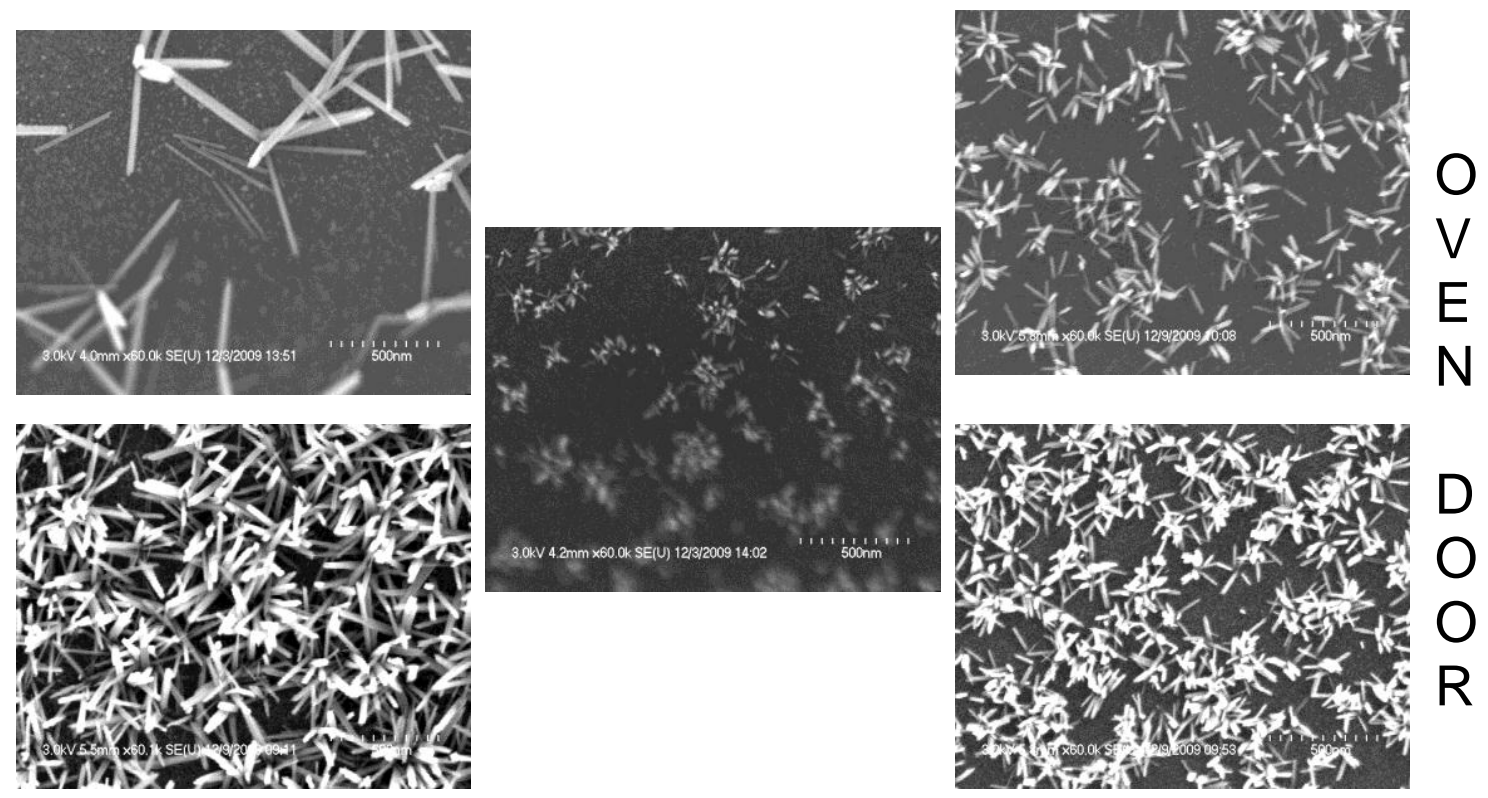

Figure 15. 60K magnification SEM images of titania nanorods, from batch B-2, hydrothermally grown in autoclave bombs not tightened with the hook spanner. 
The titania nanorods in Figures 14 and 15 did not have a consistent length or density.

Their properties varied randomly from the batch to batch and by distance from the oven door. Figures 16 and 17 show SEM images and oven placement of batches B-3 and B-4, which were titania nanorods grown without any additives in bombs tightened by hand and additionally with the hook spanner.
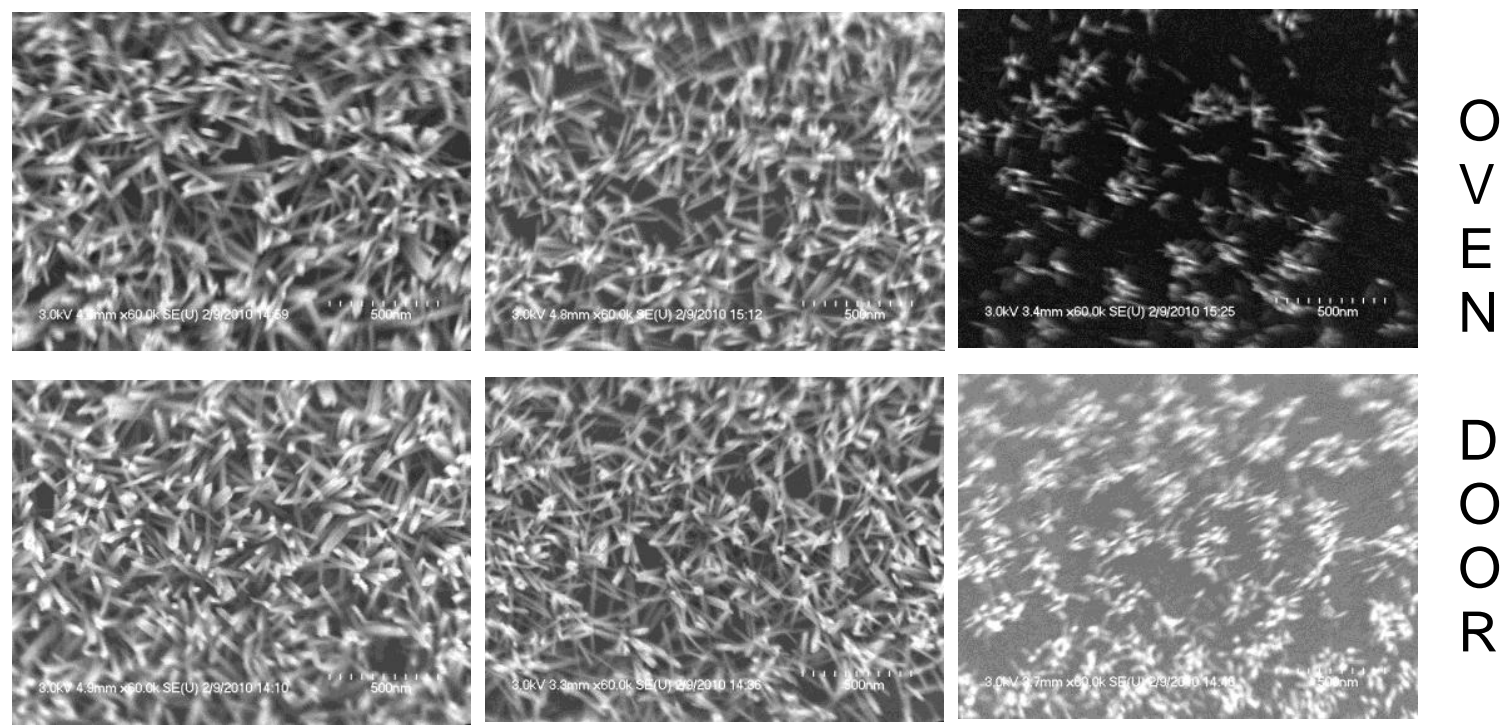

Figure 16. 60K magnification SEM images of titania nanorods in batch B-3 hydrothermally grown in autoclave bombs tightened with the hook spanner. 

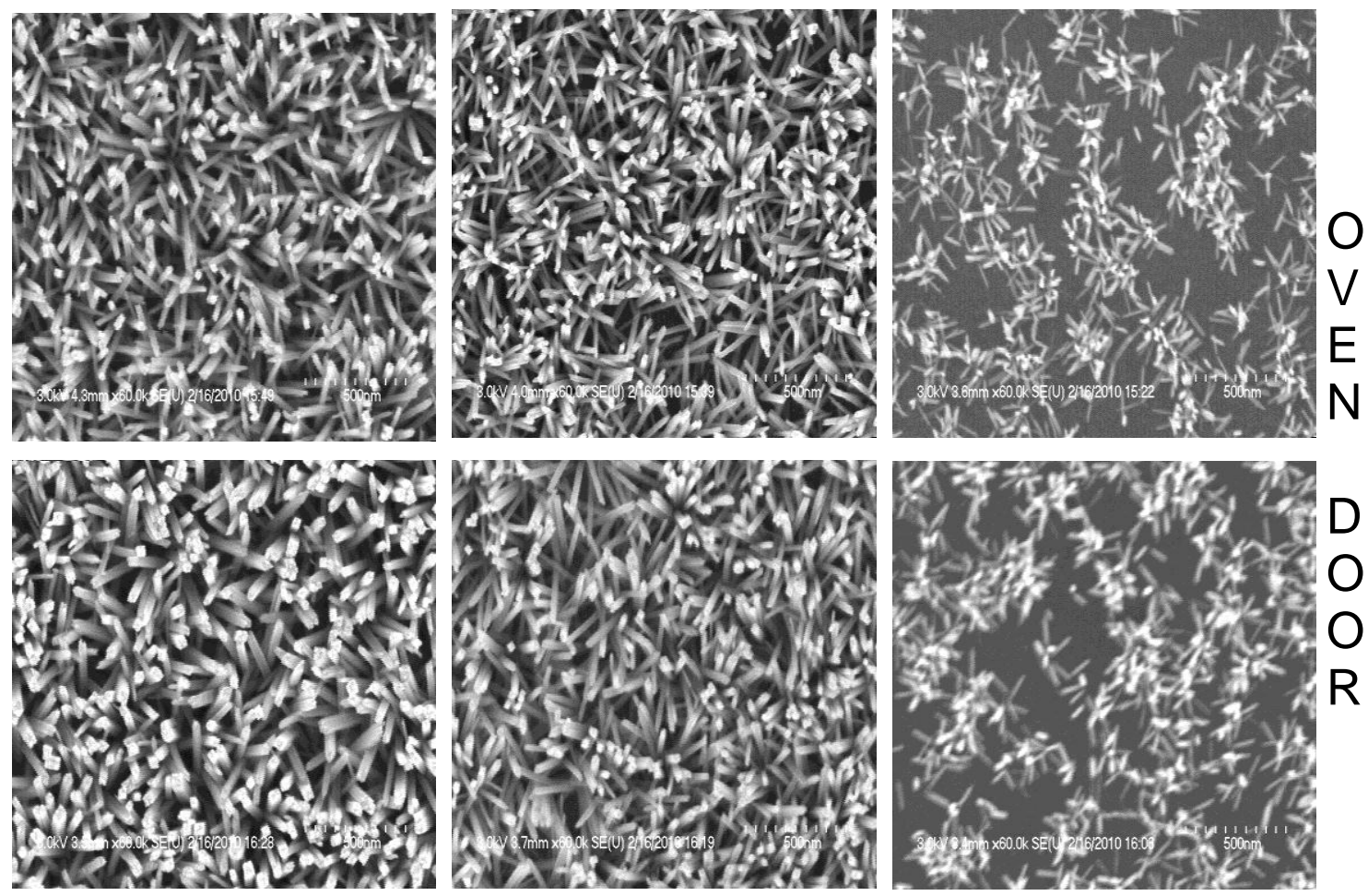

Figure 17. 60K magnification SEM images of titania nanorods in batch B-4 hydrothermally grown in autoclave bombs tightened with the hook spanner.

The titania nanorods in Figures 16 and 17 were more consistent in length and density.

The same trend occured in both batch B-3 (shown in Figure 16) and batch B-4 (shown in Figure 17). The nanorod length and density increased the further the bombs were from the oven door.

The increased uniformity of nanorod length and density between batches when the hook spanner was used to tighten the autoclave bombs confirms that the hook spanner was required to fully seal the bombs. Tightening only by hand led to an inconsistent seal and thus did not allow for consistent pressure between bombs or predictable internal bomb pressure. Lower pressure prevented the internal conditions from facilitating the desired crystallization rate. 


\subsubsection{Heating in a Silicone Oil Bath}

The trend shown in Figures 16 and 17, where the nanorod length and density increased the further the bombs were from the furnace door, indicated that bomb position in the furnace had an effect on the conditions the bomb experienced. The most likely varying condition inside of the furnace that would lead to the observed length and density increase is temperature [8]. A temperature gradient inside of the furnace likely caused this trend.

Using a well-circulated silicone oil bath instead of the furnace increased the reproducibility and consistency of all of the bombs in each batch and between batches. Figures 18 and 19 show SEM images of two batches (B-5 and B-6) of titania nanorods grown without additives in autoclave bombs heated in the silicone oil bath.
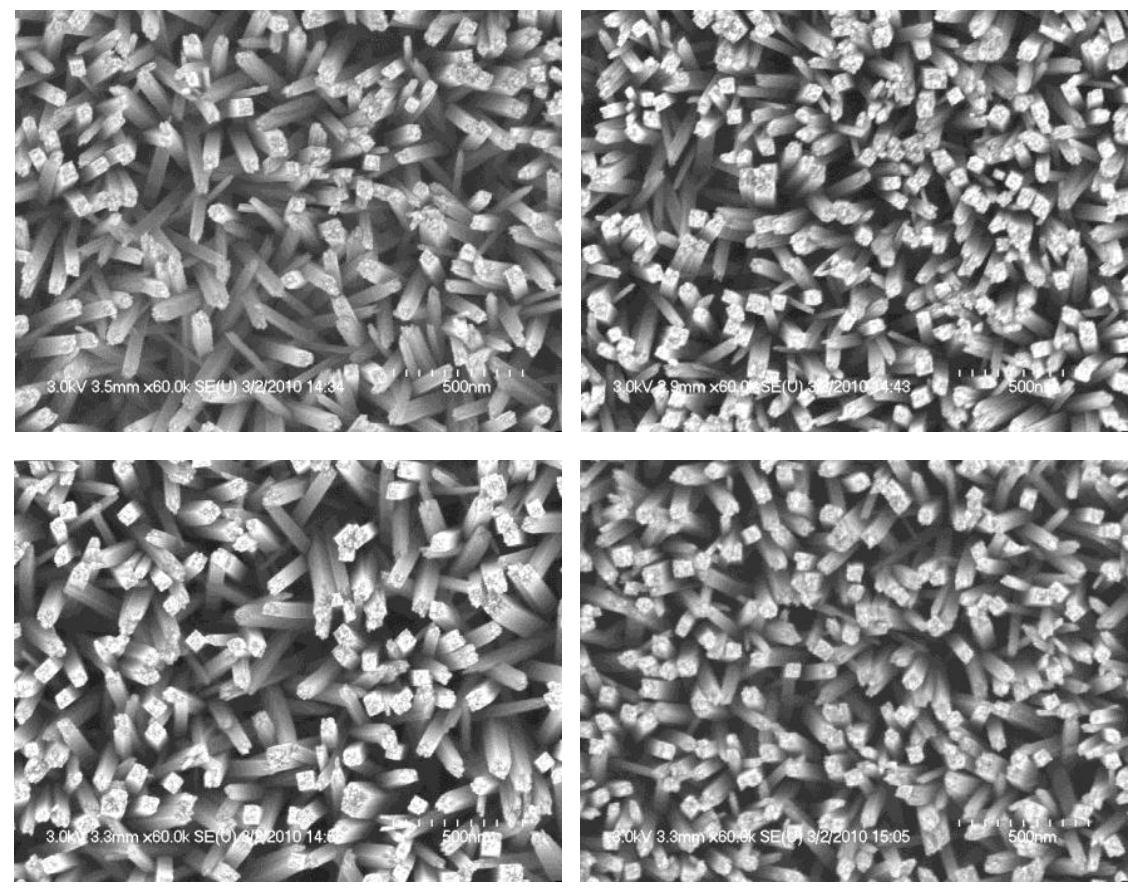

Figure 18. 60K magnification SEM images of titania nanorod batch B-5, hydrothermally grown in autoclave bombs heated in silicone oil bath. 

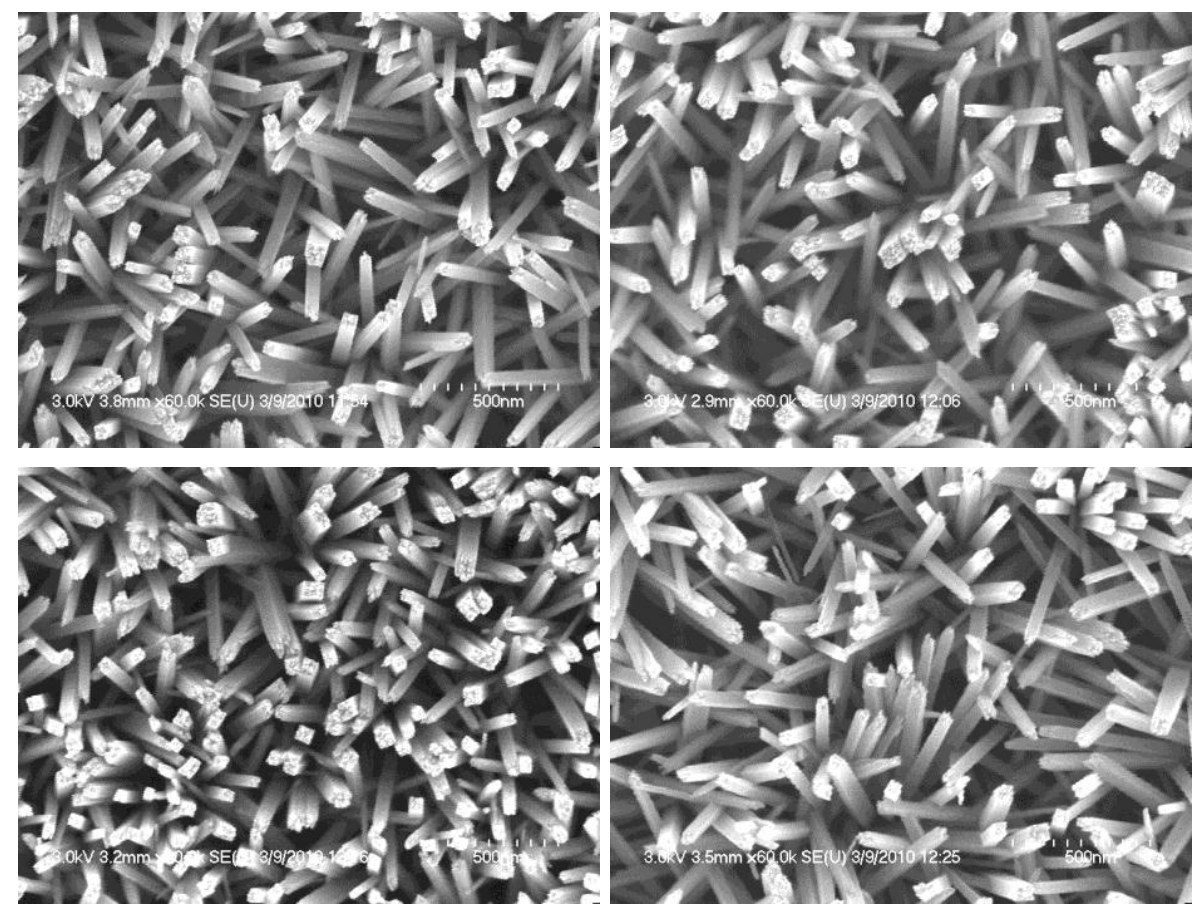

Figure 19. 60K magnification SEM images of titania nanorod batch B-6, hydrothermally grown in autoclave bombs heated in silicone oil bath.

The density of the nanorod arrays grown when the bombs were heated in the silicone oil bath, shown in Figures 18 and 19, allowed for greater consistency between the bombs in a batch and from batch to batch compared to those in Figures 16 and 17. The nanorod array density was much more reproducible when the bombs were heated in the oil bath than in the furnace. Figure 20 shows cross-sectional view SEM images from batches B-5 and B-6. Both batches produced nanorods that range in length from around $1.1 \mu \mathrm{m}$ to $1.35 \mu \mathrm{m}$; the average nanorod length in Figure 18 was about $100 \mathrm{~nm}$ longer. 

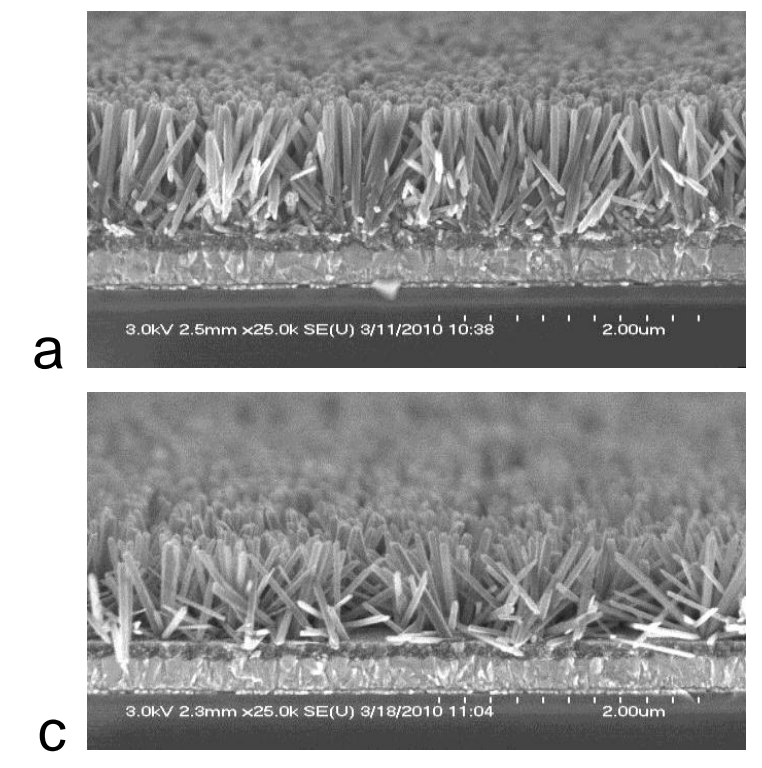
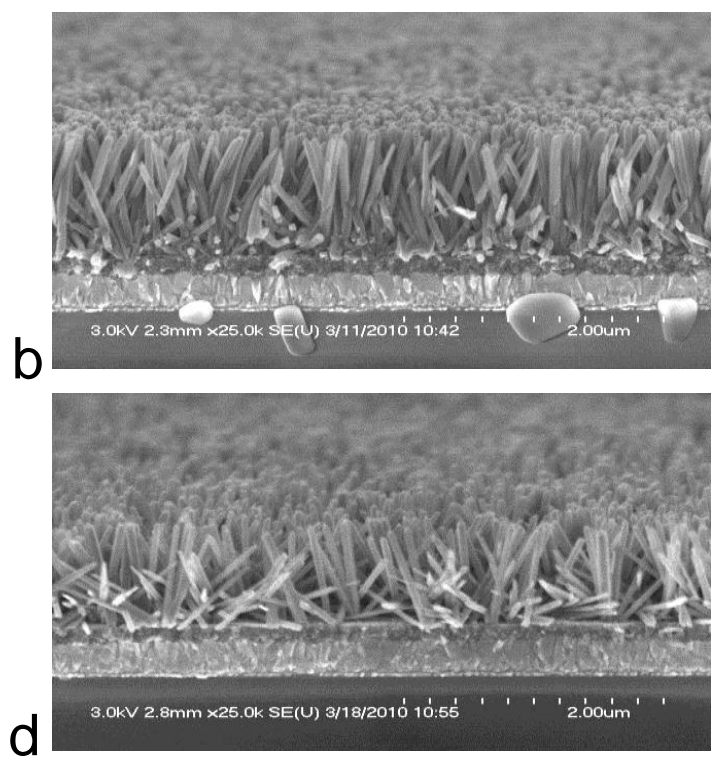

Figure 20. 25k magnification cross-sectional view SEM images of titania nanorods grown hydrothermally in autoclave bombs heated in a silicone oil bath. [Images a and $b$ are of batch B-5. Images c and d are of batch B-6.]

\subsection{Reproducibility Without Additives}

A comparison of the titania nanorods grown without surfactant assistance shows that there was some variability in the nanorod characteristics between the different batches. Table 5 shows each batch, and the range of thickness, length, and aspect ratio for several of the titania nanorod arrays grown without surfactant assistance. Appendix A contains SEM images of the nanorods grown without surfactant assistance that are summarized in Table 5. This variability between the shape and size of the nanorods despite consistent procedure suggests that there is some level of variability to be expected from batch to batch. 
Table 5. Comparison of titania nanorods that were grown hydrothermally, without surfactant assistance.

\begin{tabular}{|l|l|l|l|}
\hline Batch & Thickness $(\mathrm{nm})$ & Length $(\mathrm{nm})$ & Aspect Ratio \\
\hline B-7 & $35-60$ & 1200 & $20-35$ \\
\hline B-8 & $50-75$ & $950-1200$ & $12-24$ \\
\hline B-9 & $50-70$ & 1200 & $17-24$ \\
\hline
\end{tabular}

\subsection{Additives}

The different surfactants examined had various effects on the growth of the titania nanorods. The effects varied between: none, preventing growth, slowing growth, speeding growth, and altering the size and shape of the nanorods. Table 6 summarizes the effect each surfactant had on the titania nanorod synthesis. Appendix B contains the SEM images of the nanorods grown with the surfactants in listed Table 6.

Table 6. The effects of different surfactants on the hydrothermal growth of titania nanorods.

\begin{tabular}{|c|c|c|c|}
\hline Surfactant & Batch & $\begin{array}{c}\text { Concentration } \\
(\mathrm{wt} \%)\end{array}$ & $\begin{array}{c}\text { Effect on Titania Nanorod } \\
\text { Growth }\end{array}$ \\
\hline Oleic acid & B-7 & 1.37 & None \\
\hline NaDDS & B-7 & 1.31 & Slowed growth rate \\
\hline TDPA & B-7 & 1.26 & Prevented growth \\
\hline PEI & B-7 & 3.93 & Increased growth rate \\
\hline LiCl & B-8 & 6.05 & $\begin{array}{c}\text { Slowed growth rate, decreased aspect } \\
\text { ratio }\end{array}$ \\
\hline $\mathrm{KCl}$ & B-8 & 2.71 & Slowed growth rate \\
\hline $\mathrm{CaCl}_{2}$ & B-8 & 6.84 & Slowed growth rate \\
\hline PEG 400 & B-9 & 20.4 & Greatly increased growth rate \\
\hline
\end{tabular}




\subsection{Effects of Polyethylene Glycol}

The growth rate of titania nanorods was greatly increased when PEG 400 was added to the reaction solution. Figure 21 shows SEM images of the titania nanorods grown with $20.5 \mathrm{wt} \%$ PEG 400 in batch B-9. The nanorods fused together and the titania layer was around $5.5 \mu \mathrm{m}$ thick.
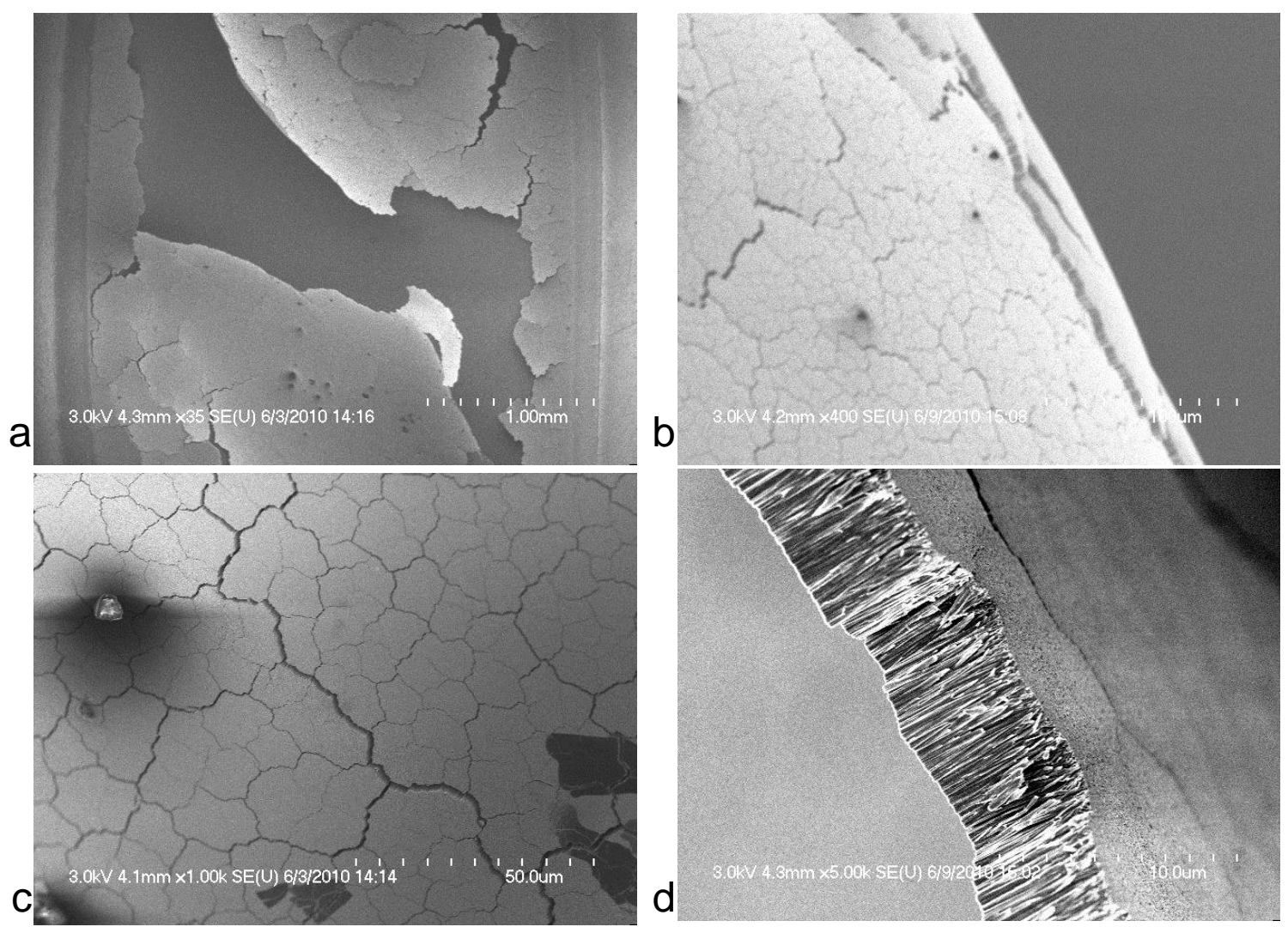

Figure 21. SEM images of PEG 400 assisted hydrothermally grown titania nanorods. (a) 35 times, (b) 400 times, (c) 1k times, and (d) 5k times magnification.

The 17 hour bake time was too long since peel-off had begun. The accelerated growth rate could have been caused by the interaction of the ether oxygens in the PEG with the 
titanium butoxide precursor [28]. This acceleration of the growth rate makes PEG a possible additive for titania nanorod fabrication at shorter times and lower temperatures. Better understanding of how and why PEG affects the titania growth rate was gained by investigating the effects of different concentrations and molecular weights of PEG.

\subsubsection{PEG 400 Time Experiment}

The length and thickness of the titania nanorods increased, as expected, as the hydrothermal bake time increased. Figure 22 shows SEM images of the batch B-10 titania nanorods grown, with 13.6 wt\% PEG 400 present in the hydrothermal solution, for different periods of time. Table 7 shows the dimensions of the grown nanorods. Appendix C contains the other SEM images used to measure the dimensions in Table 7. The aspect ratio remains roughly the same, between 10 and 20, for all four lengths of time. The constant aspect ratio result differed from the results of the varied time experiment conducted by Liu et al., which was conducted without an additive [8]. Liu et al. reported that the nanorod diameter remained constant once it reached $90 \mathrm{~nm}$. Thus, in Liu et al.'s research, the aspect ratio was changing as the nanorods grew longer, but did not grow in diameter. Here, both the length and diameter continued to grow, maintaining a constant aspect ratio. 

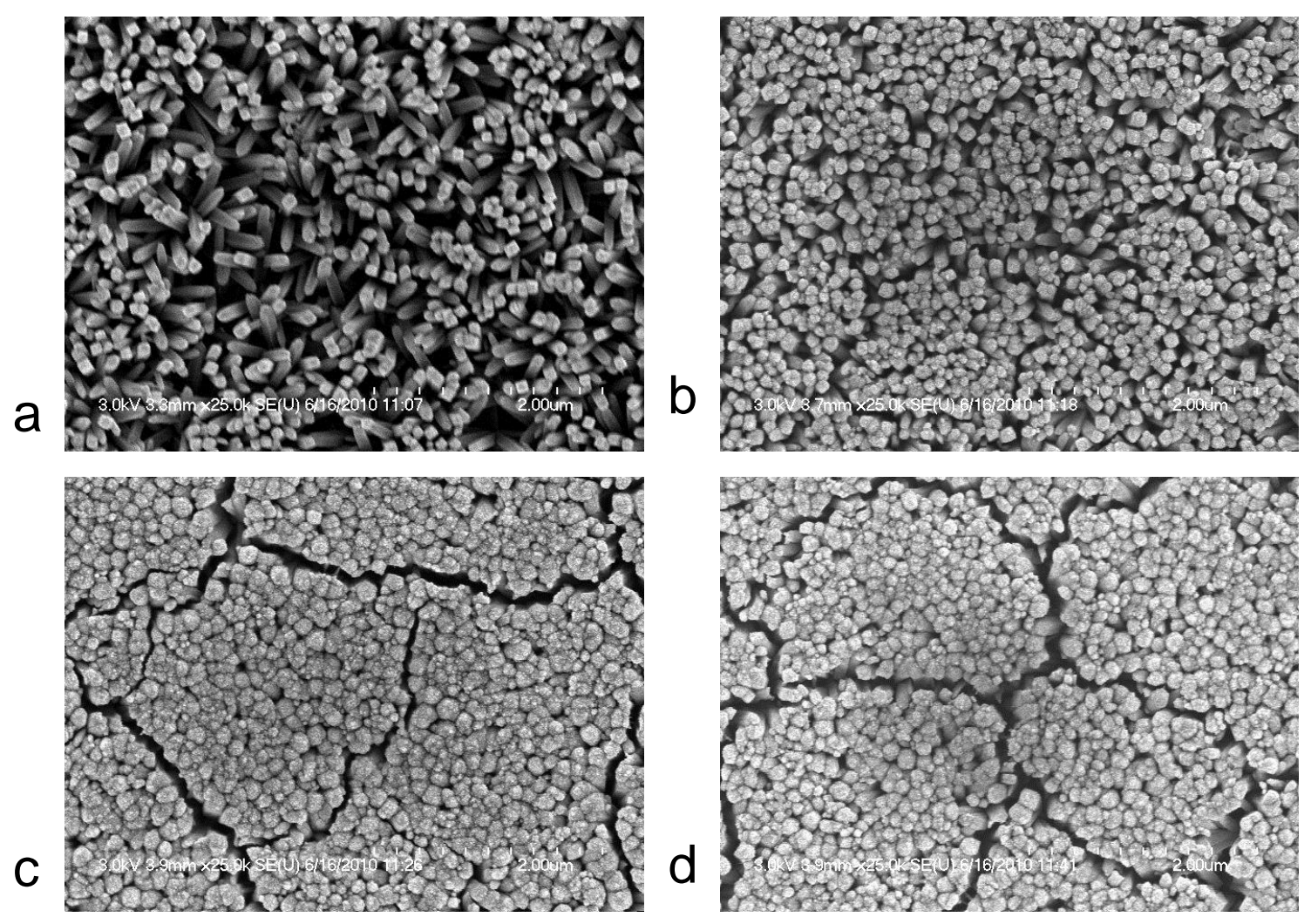

Figure 22. 25k magnification SEM images of PEG 400 assisted hydrothermally grown titania nanorods, from batch B-10, grown for (a) 4, (b) 5.5, (c) 7, and (d) 8 hours.

Table 7. Dimensions of titania nanorods grown for different times by PEG 400 assisted hydrothermal process in batch B-10.

\begin{tabular}{|c|c|c|c|}
\hline Time (hours) & $\begin{array}{c}\text { Thickness } \\
(\mathrm{nm})\end{array}$ & $\begin{array}{c}\text { Height } \\
(\mathrm{nm})\end{array}$ & AR \\
\hline 4 & $60-85$ & $800-900$ & $10-15$ \\
\hline 5.5 & $75-125$ & 1200 & $10-15$ \\
\hline 7 & $100-200$ & 2100 & $10-21$ \\
\hline 8 & $100-200$ & 2000 & $10-20$ \\
\hline
\end{tabular}

\subsubsection{Lower Temperature Titania Nanorod Growth}

The PEG 400 assisted hydrothermal process at $90{ }^{\circ} \mathrm{C}$ did not produce significant nanorod growth. This is most likely because the internal conditions inside of the 
autoclave bomb were not sufficient to dissolve and recrystallize enough of the titanium precursor. The nanorods that were grown were short and sparse, even after 17 hours. Figure 23 shows SEM images of these substrates, which had minimal titania growth.
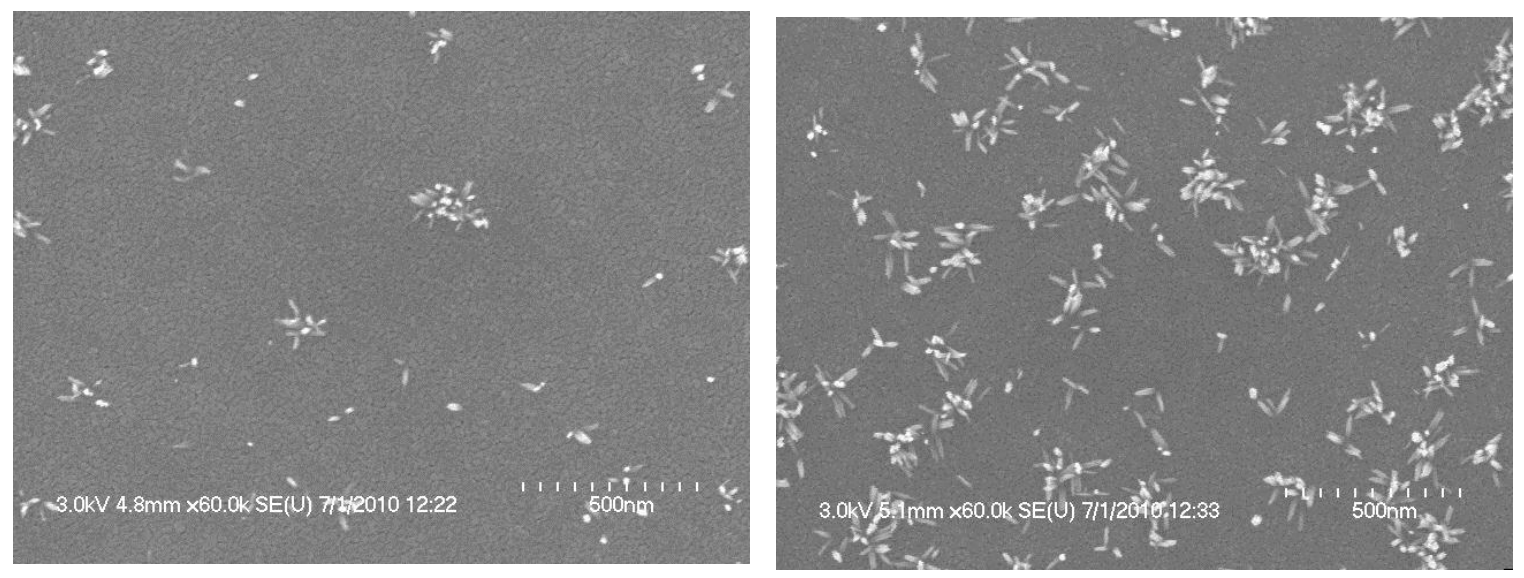

Figure 23. 60k magnification SEM images of PEG 400 assisted hydrothermally grown titania nanorods grown at $90^{\circ} \mathrm{C}$.

\subsubsection{Effect of Additive Concentration on Nanorod Growth}

The amount of PEG in the hydrothermal solution affected the growth rate of the titania nanorods. Figures 24 and 25 show SEM images of titania nanorods grown in two batches with different concentrations of PEG 400. In both Figures, the size of the nanorods increased as the PEG 400 concentration increased. When the concentration was high enough, for example $33.64 \mathrm{wt} \%$ (Figure 26d), the nanorods formed a near-solid layer in less than half the time than at $13.6 \mathrm{wt} \%$ (Figure 23), where the nanorod layer was less dense after 8 hours. 

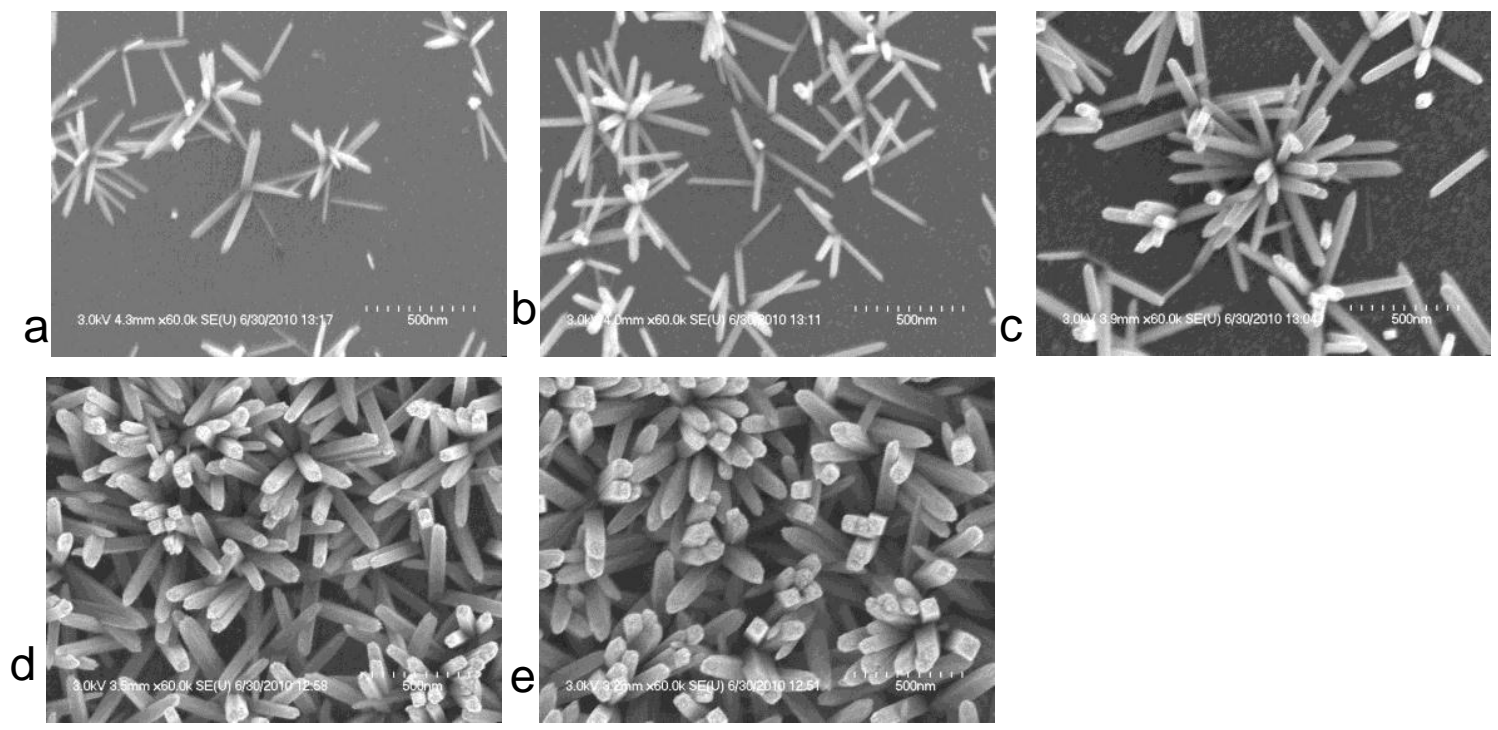

Figure 24. 60k magnification SEM images of titania nanorods grown with different concentrations of PEG 400; (a) 3.39, (b) 6.78, (c) 10.16, (d) 13.53, and (e) $20.26 \mathrm{wt} \%$.
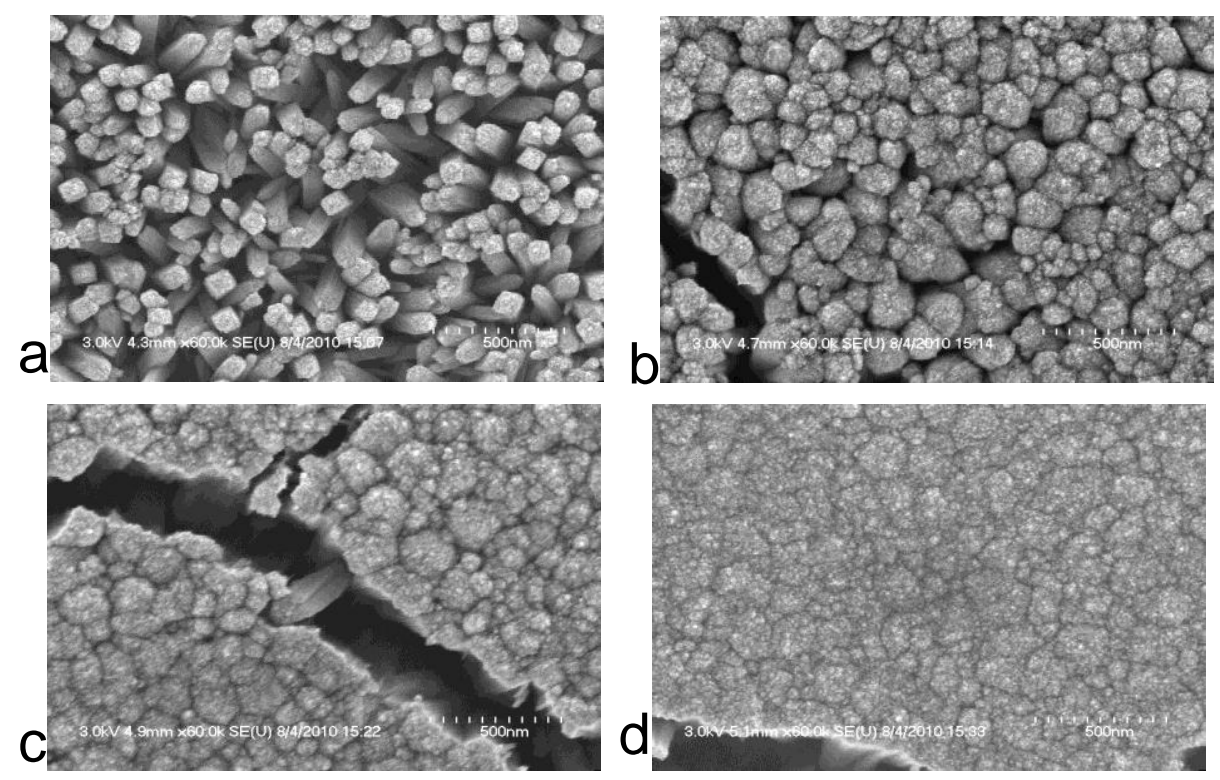

Figure 25. 60k magnification SEM images of titania nanorods grown with different concentrations of PEG 400; (a) 13.53, (b) 20.26, (c) 26.96, and (d) $33.64 \mathrm{wt} \%$.

This effect of PEG concentration on nanorod growth also occurred at higher molecular weights of PEG. Figures 26 and 27 show SEM images of titania nanorods 
grown with different concentrations of PEO 1,000,000 and PEG 2000, respectively. As with PEG 400, the size (diameter and length) of the nanorods increased as the concentration of the additive increased.
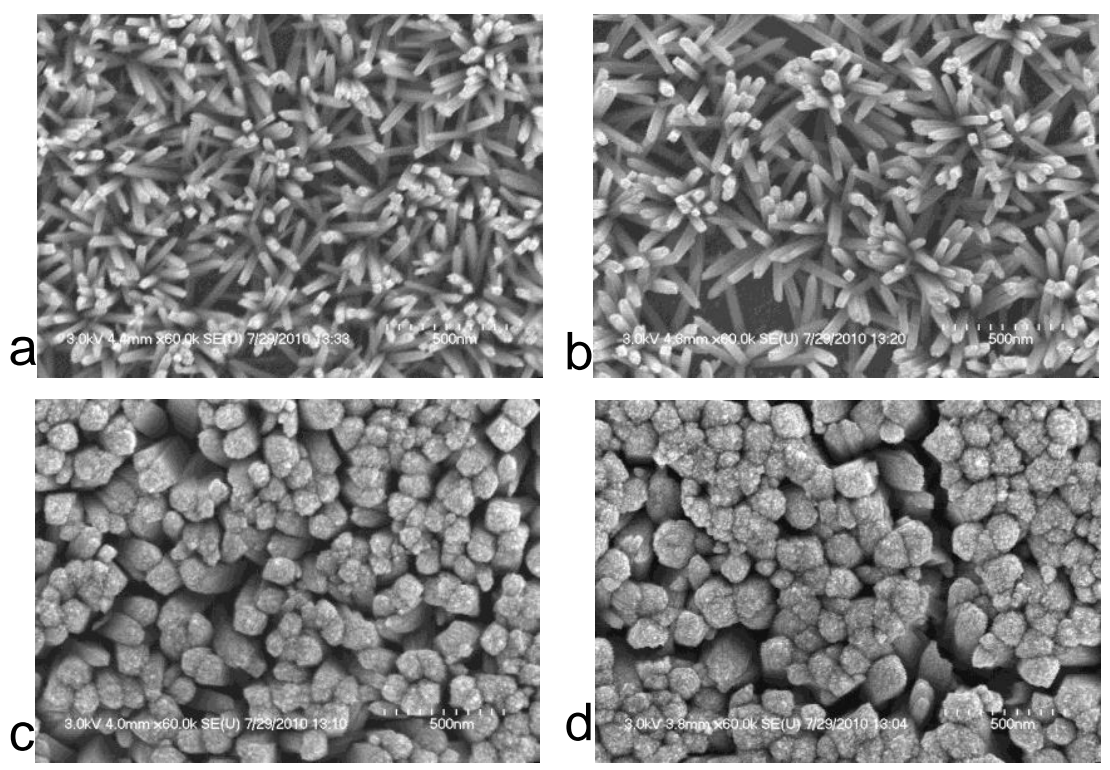

Figure 26. 60k magnification SEM images of titania nanorods grown with different concentrations of PEO 1,000,000; (a) 3.32, (b) 7.00, (c) 10.17, and (d) $21.42 \mathrm{wt} \%$.
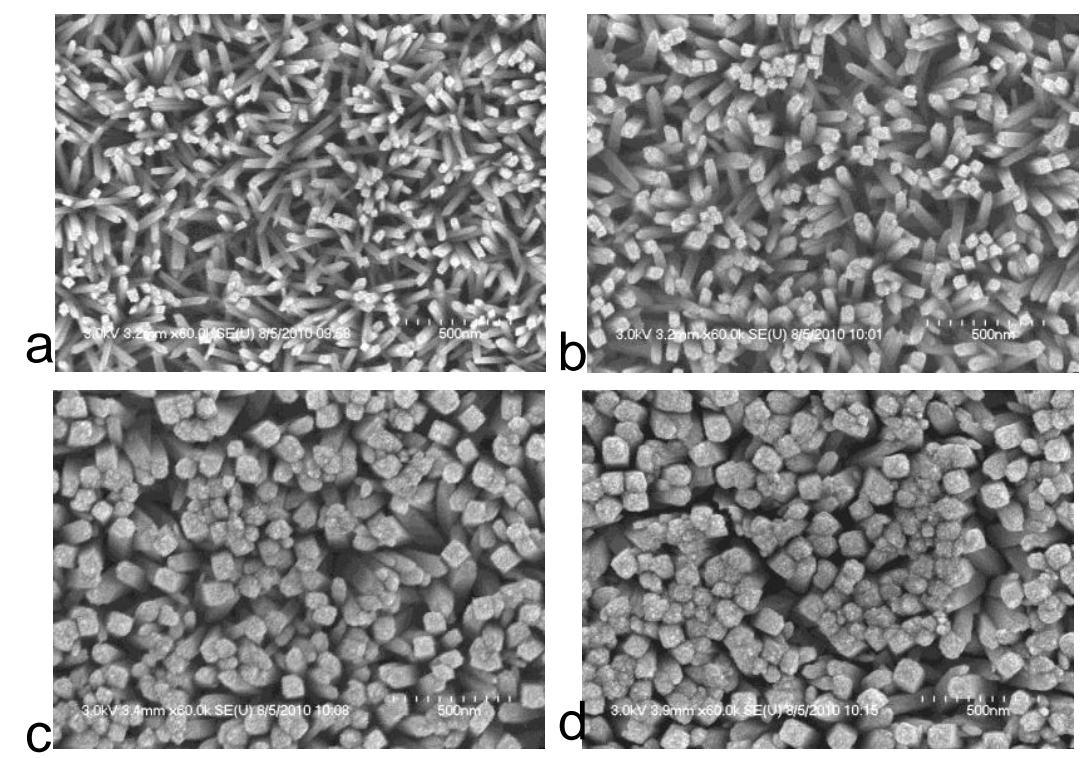

Figure 27. 60k magnification SEM images of titania nanorods grown with different concentrations of PEG 2000; (a) 6.34, (b) 12.02, (c) 16.88, and (d) $21.46 \mathrm{wt} \%$. 


\subsubsection{Different Molecular Weights of Polyethylene Glycol}

Different molecular weights of PEG also affected the growth of the titania nanorods. SEM images of nanorods grown with around $12 \mathrm{wt} \%$ of different molecular weights of PEG and PEO are shown in Figure 28. PEG 400 and PEO 100,000 accelerated the growth of the titania nanorods while PEG 1500 and 8000 prevented the growth of titania. PEG 2000 and PEO 1,000,000, shown in Figures 27 and 26 respectively, also accelerated hydrothermal titania nanorod growth.
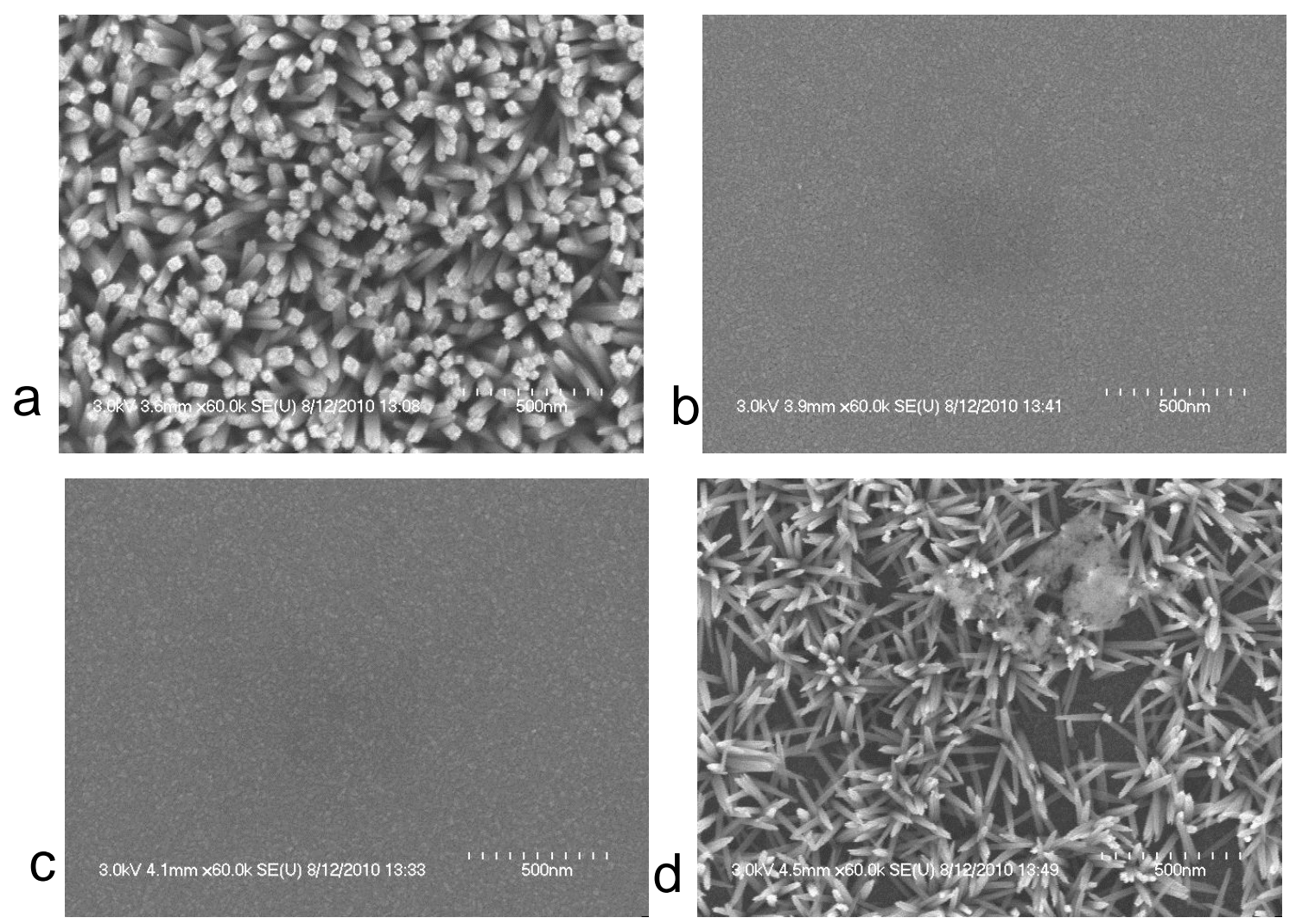

Figure 28. 60k magnification SEM images of titania nanorods grown with different molecular weights of polyethylene glycol; (a) $11.84 \mathrm{wt} \%$ PEG 400, (b) $12.02 \mathrm{wt} \%$ PEG 1500 , (c) $12.01 \mathrm{wt} \%$ PEG 8000, and (d) $12.04 \mathrm{wt} \%$ PEO 100,000. 


\subsubsection{Different Chemical Bottles}

The particular bottle of the PEG 400 also affected the growth of the titania nanorods. The SEM images in Figure 29 show nanorods grown in four hours with 13.5 wt\% PEG 400 from two different bottles, both from Sigma-Aldrich. The PEG 400 from the different bottles had very different effects. The PEG from the bottle labeled 05818JJ accelerated nanorod growth, while the PEG from the bottle labeled MKBD5053 slowed nanorod growth. The different bottles were opened at different times and had been stored for different lengths of time, which may have in part caused the differences. Also, the different bottles could have undergone different processing, including coming from different processing facilities or being manufactured with different catalysts or stabilizers; this could also account for the differences observed.
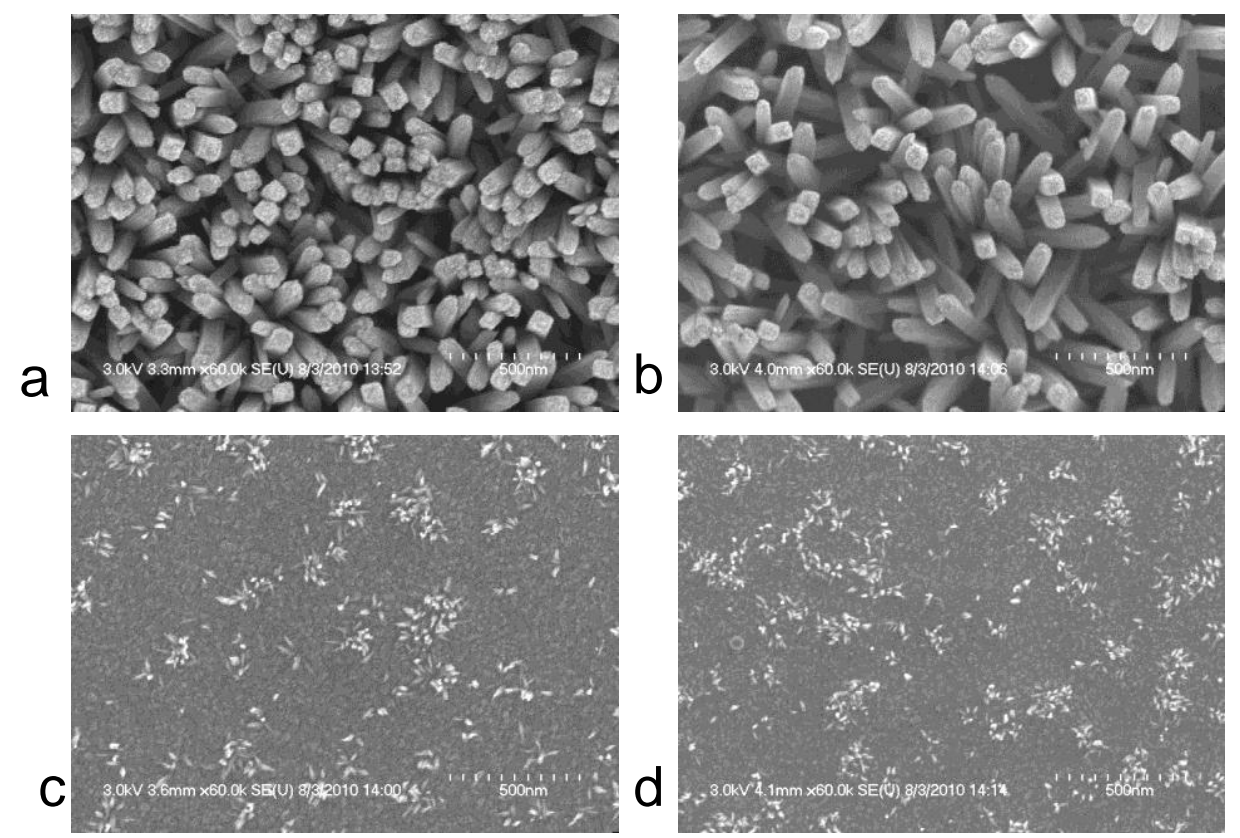

Figure 29. 60k magnification SEM images of titania nanorods grown with PEG 400 from different bottles. Images a and b show nanorods grown with PEG 400 from the bottle labeled batch 05818JJ. Images c and d show nanorods grown with PEG 400 from the bottle labeled batch MKBD5058. 


\section{CHAPTER SIX}

\section{CONCLUSIONS}

Metal oxides, such as titanium dioxide, have shown potential as semiconductors in solar cells. This study first examined a method for consistently growing titania nanorods, and found that temperature and pressure are important for obtaining reproducible hydrothermally grown titania nanorods.

This study then examined additives to determine their effect on the nanorods' growth properties. Most additives examined appeared to inhibit or have little effect on growth: oleic acid, $\mathrm{NaDDS}$, TDPA, PEI, $\mathrm{LiCl}, \mathrm{KCl}$, and $\mathrm{CaCl}_{2}$. PEG, which showed promise to enhance growth, was examined in more detail, at multiple different molecular weights and concentrations. Use of PEG 400, 2000, PEO 100,000 and PEO 1,000,000 as additives enhanced growth.

A couple of challenges also arose with the addition of PEG: different chemical bottles of PEG 400 inexplicably produced different results. PEG 1500 and PEG 8000 inhibited growth, while the other molecular weights of PEG compounds had the opposite effect, enhancing growth. It is unclear whether different bottles of these molecular weight compounds would have produced different results. It is possible that different bottles contain polymers that underwent different processing. The different processing may lead to varied results even when using the same molecular weight of polyethylene glycol. This phenomenon may also explain why increasing the molecular weight of the PEG additive had non-linear and erratic effects on nanorod growth. 


\section{CHAPTER SEVEN}

\section{FUTURE WORK}

First, DSSC should be fabricated using the PEG-assisted hydrothermally grown titania nanorods to test their efficiency and workability in this application. The enhanced growth of titania nanorods with the PEG compounds is promising for the future feasibility of nanorod use in solar cells. However, more research needs to be done. Further investigation into the reasons for the variation in results between different bottles of the same additive compound is also needed. Additionally, more study into the reason for the aspect ratio for PEG 400 remaining constant instead of the nanorod diameter remaining constant is also required. Finally, TEM and XRD analysis of the nanorods resulting from growth in the PEG additive should be performed to confirm the nanorods' crystal structure. 


\section{REFERENCES}

1. Energy Information Administration (2009). International Energy Outlook 2009 [Online]. Available at www.eia.doe.gov/oiaf/ieo/index.html (accessed 24 March 2010). Posted pdf file.

2. B. Li, L. Wang, B. Kang, P. Wang and Y. Qiu, "Review of recent progress in solid-state dye-sensitized solar cells," Sol. Energ. Mat. Sol. C., 90, 549-573 (2006).

3. M. Grätzel, "Photoelectrochemical cells,” Nature, 414, 338-344 (2001).

4. A. Goetzberger, J. Luther and G. Willeke, "Solar cells: past, present, future," Sol. Energ. Mat. Sol. C., 74, 1-11 (2002).

5. M.A. Green, "Thin-film solar cells: review of materials, technologies and commercial status," J. Mater. Sci.: Mater. El., 18, S15-S19 (2007).

6. G.K. Mor, O.K. Varghese, M. Paulose, K. Shankar and C.A. Grimes, "A review on highly ordered, vertically oriented $\mathrm{TiO}_{2}$ nanotube arrays: Fabrication, material properties, and solar energy applications," Sol. Energ. Mat. Sol. C., 90, 2011-2075 (2006).

7. X. Yang and J. Loos, "Toward high-performance polymer solar cells: The importance of morphology control," Macromolecules, 40(5), 1353-1362 (2007).

8. B. Liu and E.S. Aydil, "Growth of oriented single-crystalline rutile $\mathrm{TiO}_{2}$ nanorods on transparent conducting substrates for dye-sensitized solar cells," J. Am. Chem. Soc., 131, 3985-3990 (2009).

9. B. O'Regan and M. Grätzel, "A low-cost, high-efficiency solar cell based on dyesensitized colloidal $\mathrm{TiO}_{2}$ films," Nature, 353, 737-740 (1991).

10. E. Bequerel, "Recherches sur les effets de la radiation chimique de la lumière solaire, au moyen des courants électriques," C. R. Acad. Sci., 9, 145-149 (1839).

11. J.L. Gray, "The physics of the solar cell," in Handbook of Photovoltaic Science and Engineering, edited by A. Luque and S. Hegedus (John Wiley \& Sons Ltd, West Sussex, England, 2003) pp. 60-112.

12. M.A. Green, "Photovoltaic principles," Physica E, 14, 11-17 (2002). 
13. D.M. Chapin, C.S. Fuller and G.L. Pearson, "A new silicon p-n junction photocell for converting solar radiation into electrical power," J. Appl. Phys., 25, 676 (1954).

14. O. Park, J.Y. Cheng, M.W. Hart, T. Topuria, P.M. Rice, L.E. Krupp, R.D. Miller, H. Ito and H. Kim, "High-aspect-ratio cylindrical nanopore arrays and their use for templating titania nanoposts," Adv. Mater., 20, 738-742 (2008).

15. J. Wu and $\mathrm{C} . \mathrm{Yu}$, “Aligned $\mathrm{TiO}_{2}$ nanorods and nanowalls," J. Phys. Chem. B, 108(11), 3377-3379 (2004).

16. J. Xi, J.K. Kim, E.F. Schubert, D. Ye, T. Lu and S. Lin, "Very low-refractiveindex optical thin films consisting of an array of $\mathrm{SiO}_{2}$ nanorods," Opt. Lett., 31(5), 601-603 (2006).

17. J. Xi, M.F. Schubert, J.K. Kim, E.F. Schubert, M. Chen, S. Lin, W. Liu and J.A. Smart, "Optical thin-film materials with low refractive index for broadband elimination of Fresnel reflection," Nat. Photonics, 1, 176-179 (2007).

18. Y.P. Zhao, D.X. Ye, G.C. Wang and T.M. Lu, "Novel nano-column and nanoflower arrays by glancing angle deposition," Nano Lett., 2(4), 351-354 (2002).

19. K. Byrappa, M. Yoshimura, Handbook of hydrothermal technology: a technology for crystal growth and materials processing, (Noyes Publishing 2001).

20. Y. Li, M. Guo, M. Zhang and X. Wang, "Hydrothermal synthesis and characterization of $\mathrm{TiO}_{2}$ nanorod arrays on glass substrates," Mater. Res. Bull., 44, 1232-1237 (2009).

21. X. Feng, K. Shankar, O.K. Varghese, M. Paulose, T.J. Latempa and C.A. Grimes, "Vertically aligned single crystal $\mathrm{TiO}_{2}$ nanowire arrays grown directly on transparent conducting oxide coated glass: Synthesis details and applications," Nano Lett., 8(11), 3781-3786 (2008).

22. S. Pavasupree, S. Ngamsinlapasathian, Y. Suzuki and S. Yoshikawa, "Hydrothermal synthesis of nanorods/nanoparticles $\mathrm{TiO}_{2}$ for photocatalytic activity and dye-sensitized solar cell applications," Mater. Res. Soc. Symp. Proc. Vol. 951, 2007.

23. K. Kakiuchi, E. Hosono, H. Imai, T. Kimura and S. Fujihar, " $\left\{\begin{array}{lll}1 & 1 & 1\end{array}\right\}$-faceting of low-temperature processed rutile $\mathrm{TiO}_{2}$ rods," J. Cryst. Growth, 293, 541-545 (2006). 
24. W. Yang, F. Wan, Y. Wang and C. Jiang, "Achievement of $6.03 \%$ conversion efficiency of dye-sensitized solar cells with single-crystalline rutile $\mathrm{TiO}_{2}$ nanorod photoanode," Appl. Phys. Lett., 95, 133121 (2009).

25. M.G. Manera, P.D. Cozzoli, M.L. Curri, G. Leo, R. Rella, A. Agostiano and L. Vasanelli, "TiO $\mathrm{O}_{2}$ nanocrystal films for sensing applications based on surface plasmon resonance," Synthetic Met., 148, 25-29 (2005).

26. F. Tang, T. Uchikoshi, K. Ozawa and Y. Sakka, "Effect of polyethylenimine on the dispersion and electrophoretic deposition of nano-sized titania aqueous suspensions," J. Eur. Ceram. Soc., 26, 1555-1560 (2006).

27. K. Kajihara, K. Nakanishi, K. Tanaka, K. Hirao and N. Soga, "Preparation of macroporous titania films by a sol-gel dip-coating method from the system containing poly(ethylene glycol)," J. Am. Ceram. Soc., 81(10), 2670-76 (1998).

28. K. Yu, J. Zhao, Y. Guo, X. Ding, H. Bala, Y. Liu and Z. Wang, "Sol-gel synthesis and hydrothermal processing of anatase nanocrystals from titanium n-butoxide," Mater. Lett., 59, 2515 - 2518 (2005).

29. J. Liao, M. Tan and I. Sridhar, "Spark plasma sintered multi-wall carbon nanotube reinforced aluminum matrix composites," Mater. Design, 31, S96-S100 (2009).

30. P. Peng, X. Liu, C. Sun, J. Ma and W. Zheng, "Facile fabrication of rutile monolayer films consisting of well crystalline nanorods by following an ILassisted hydrothermal route," J. of Solid State Chem., 182, 1003-1008 (2009).

31. Y. Xu, X. Fang and Z. Zhang, "Formation of single-crystalline $\mathrm{TiO}_{2}$ nanomaterials with controlled phase composition and morphology and the application in dye-sensitized solar cell," Appl. Surf. Sci., 255, 8743-8749 (2009). 


\section{APPENDIX A \\ SEM IMAGES OF THE NANORODS GROWN WITHOUT ADDITIVES}

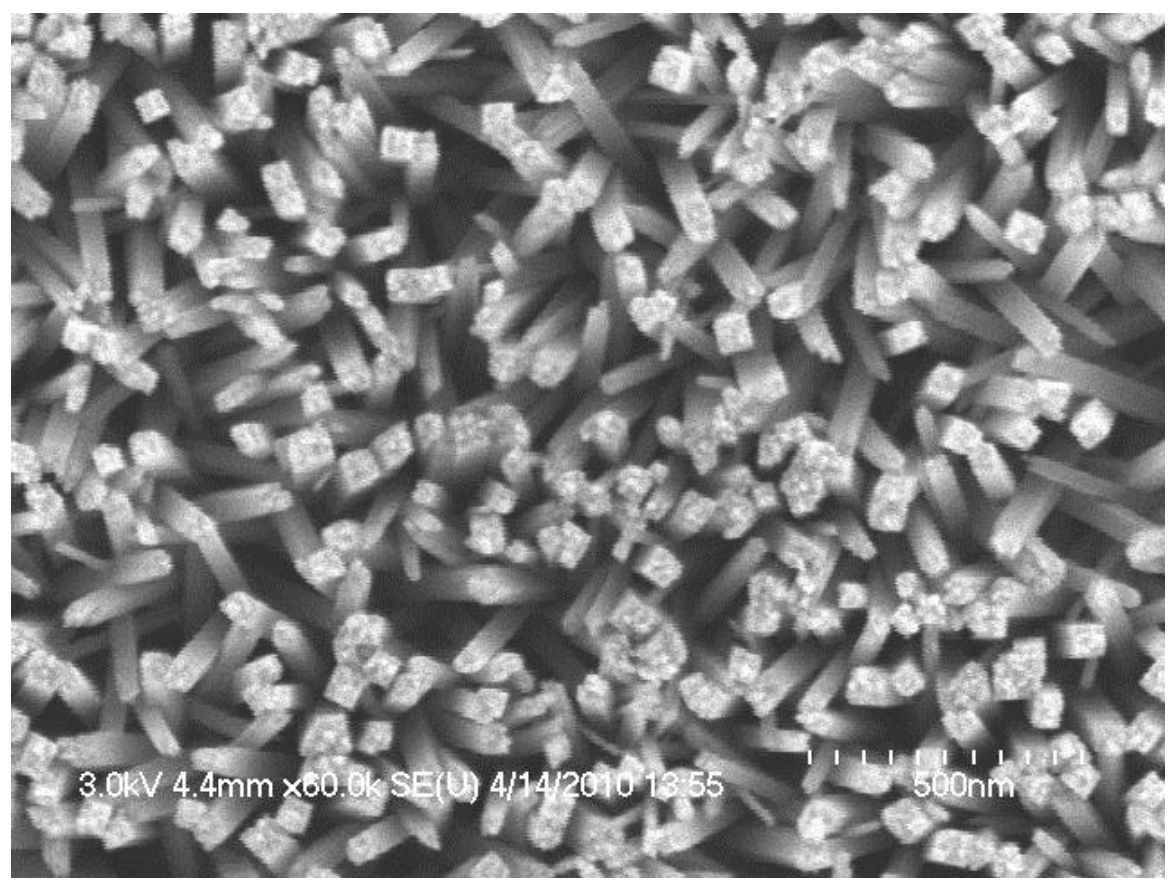

Figure 30. Top view, 60k magnification, SEM image of the titania nanorods grown without additives in batch B-7.

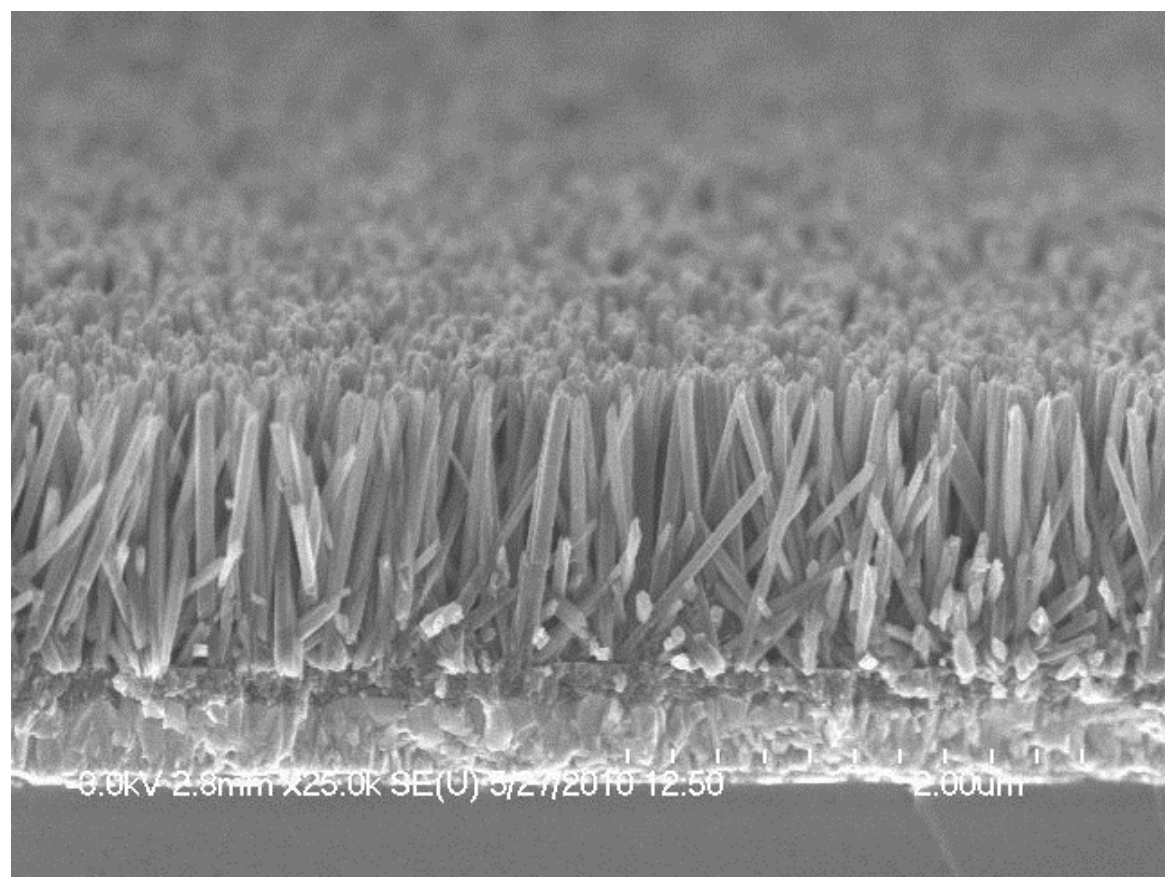

Figure 31. Cross-sectional view, 25k magnification, SEM image of the titania nanorods grown without additives in batch B-7. 


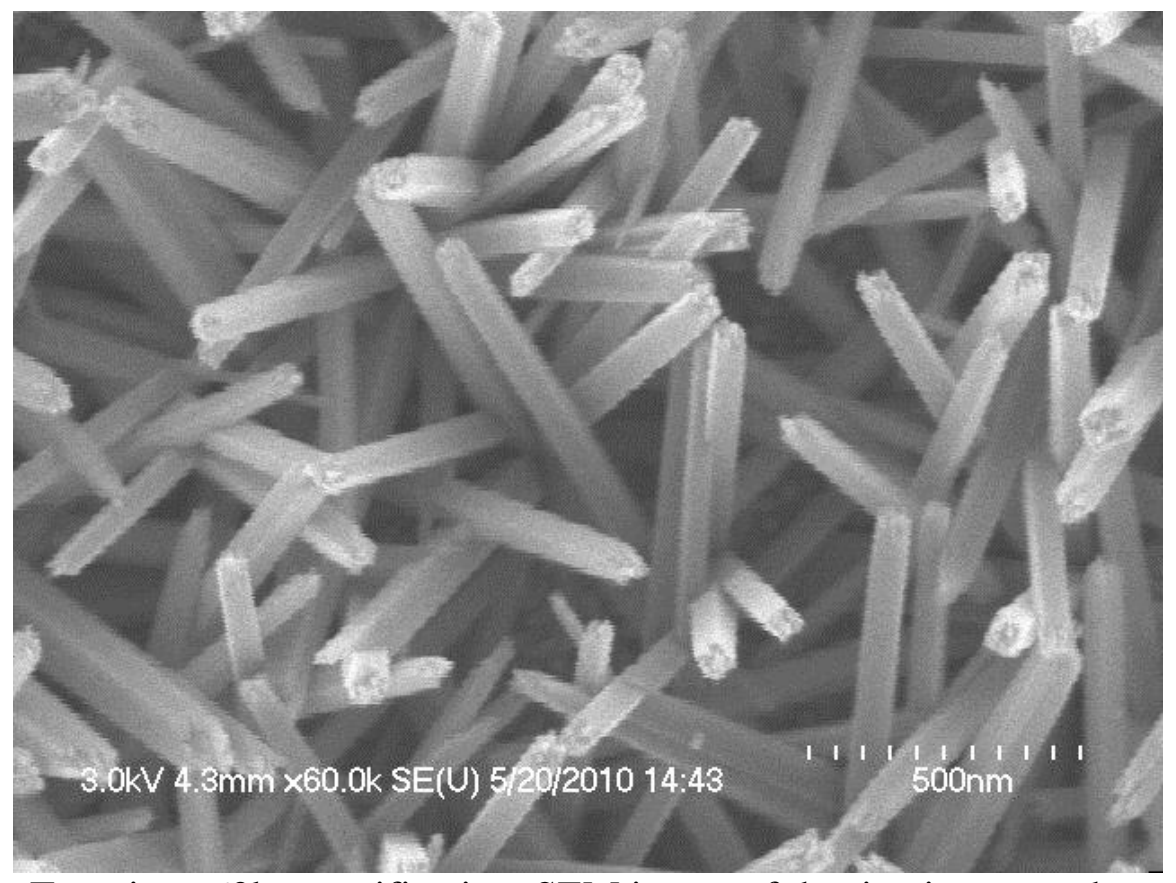

Figure 32. Top view, 60k magnification, SEM image of the titania nanorods grown without additives in batch B-8.

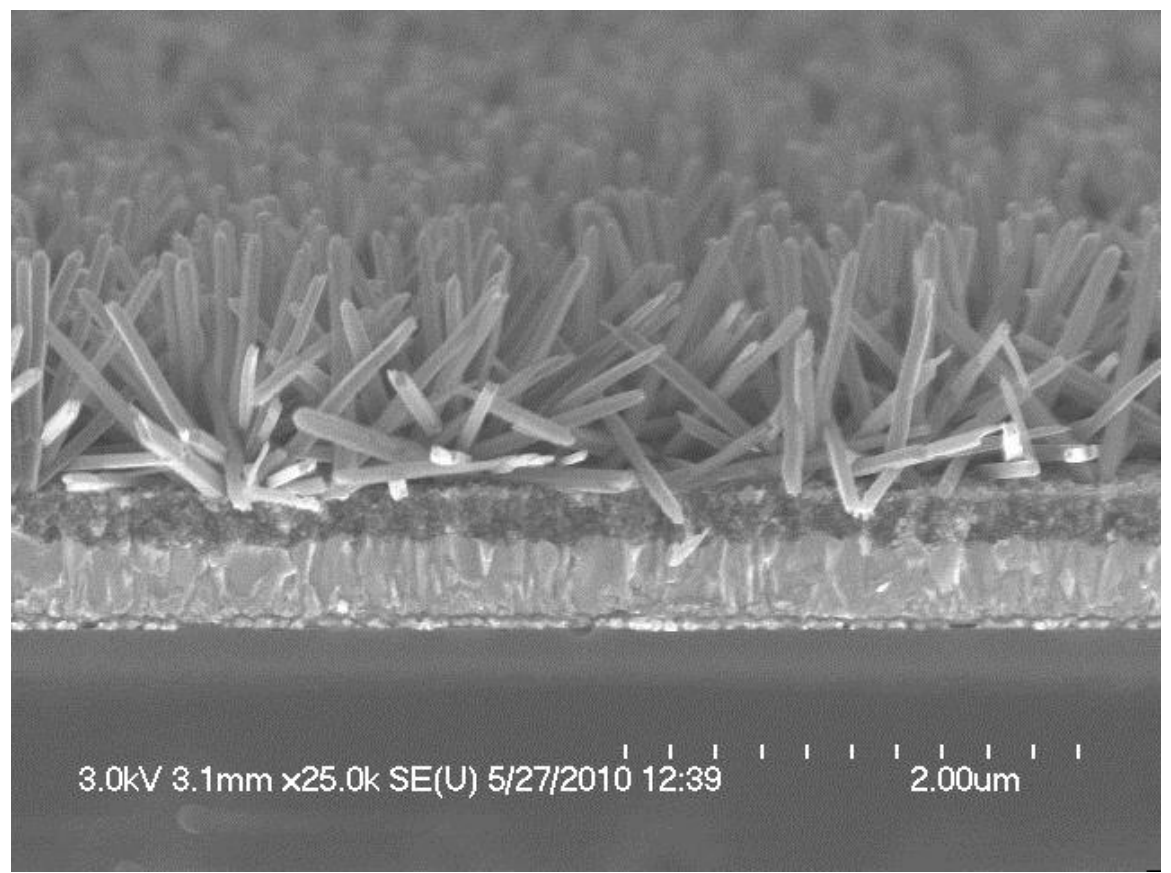

Figure 33. Cross-sectional view, 25k magnification, SEM image of the titania nanorods grown without additives in batch B-8. 


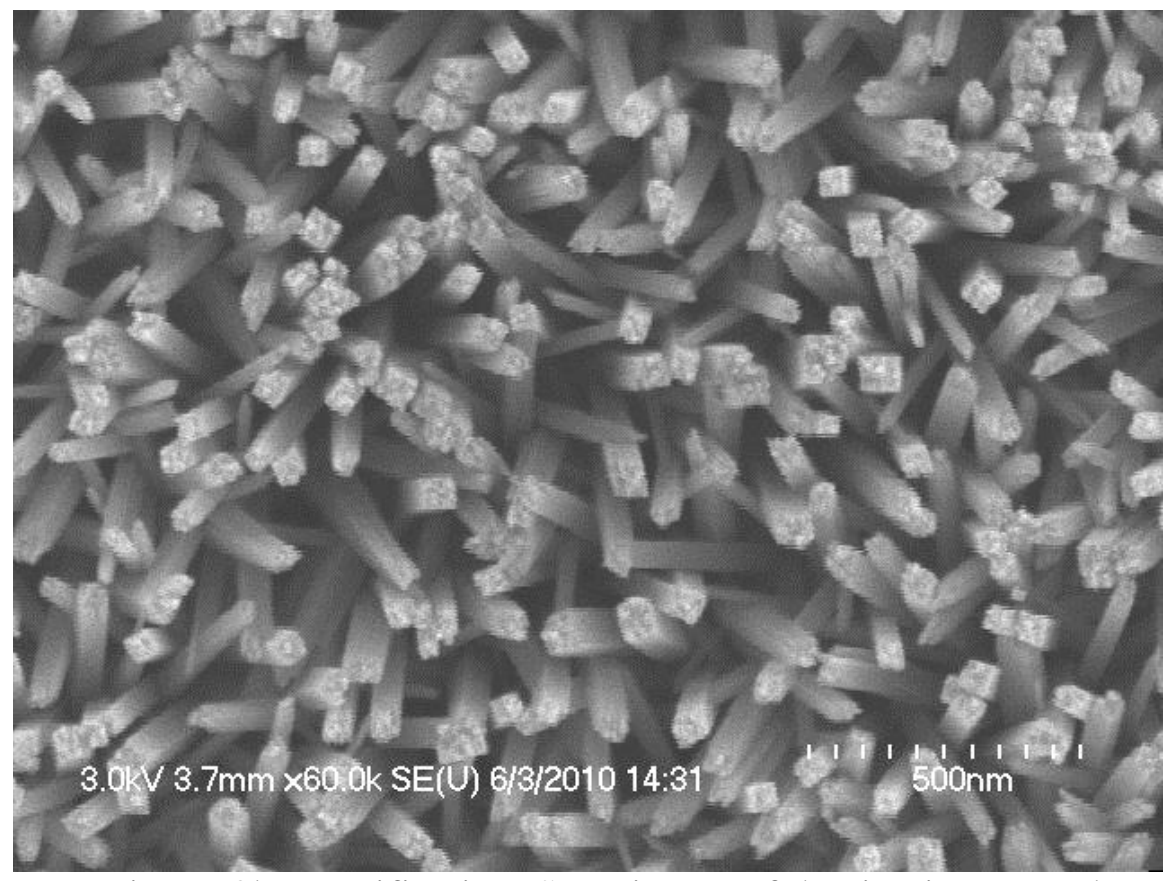

Figure 34. Top view, 60k magnification, SEM image of the titania nanorods grown without additives in batch B-9.

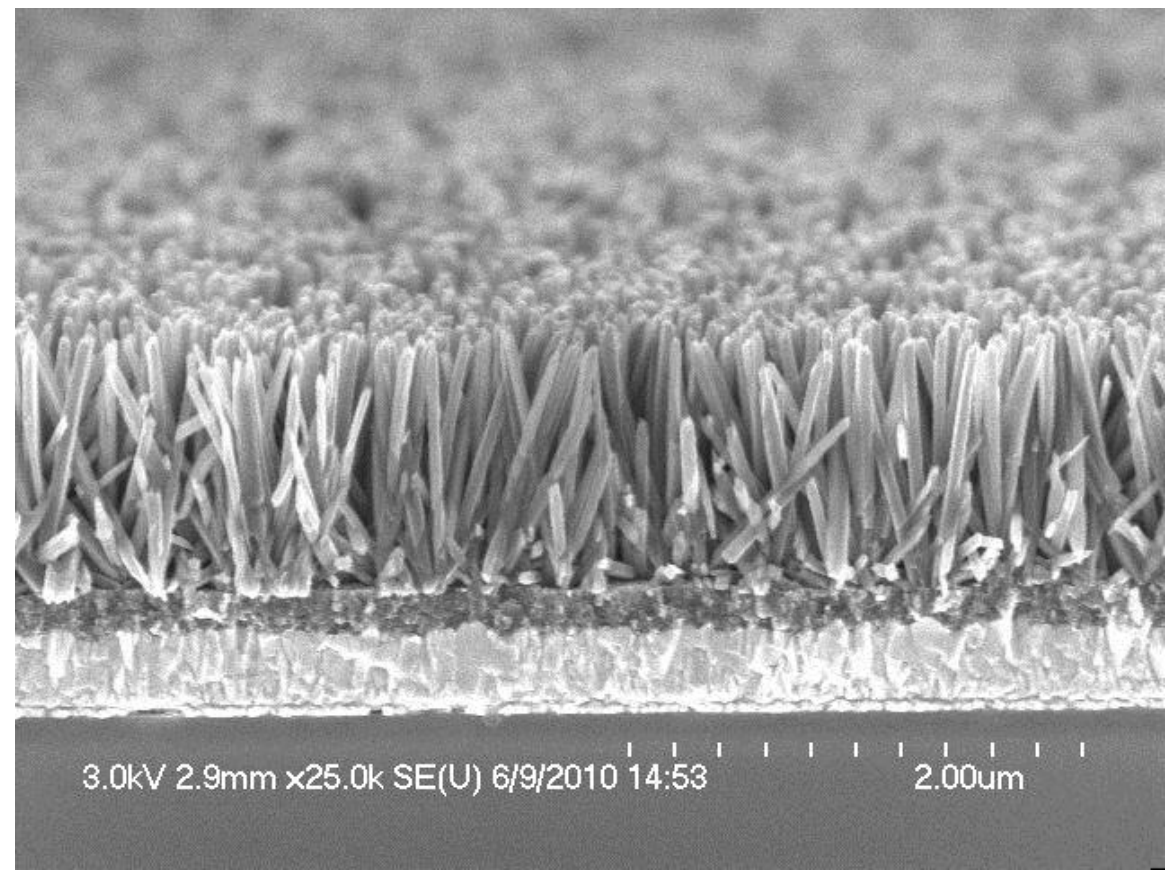

Figure 35. Cross-sectional view, 25k magnification, SEM image of the titania nanorods grown without additives in batch B-9. 


\section{APPENDIX B \\ SEM IMAGES OF THE NANORODS GROWN WITH ADDITIVES IN BATCHES \\ B-7, B-8, AND B-9}

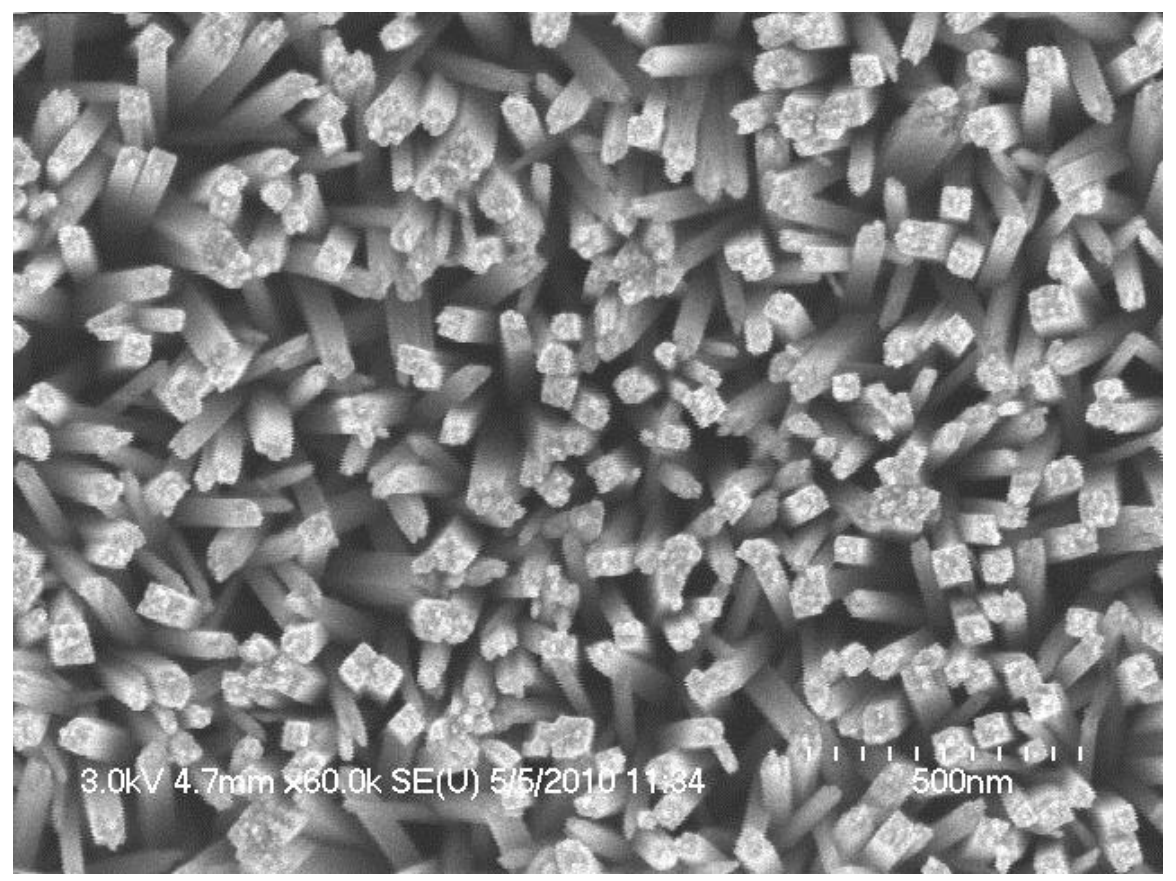

Figure 36. Top view, 60k magnification, SEM image of the titania nanorods grown with oleic acid in batch B-7.

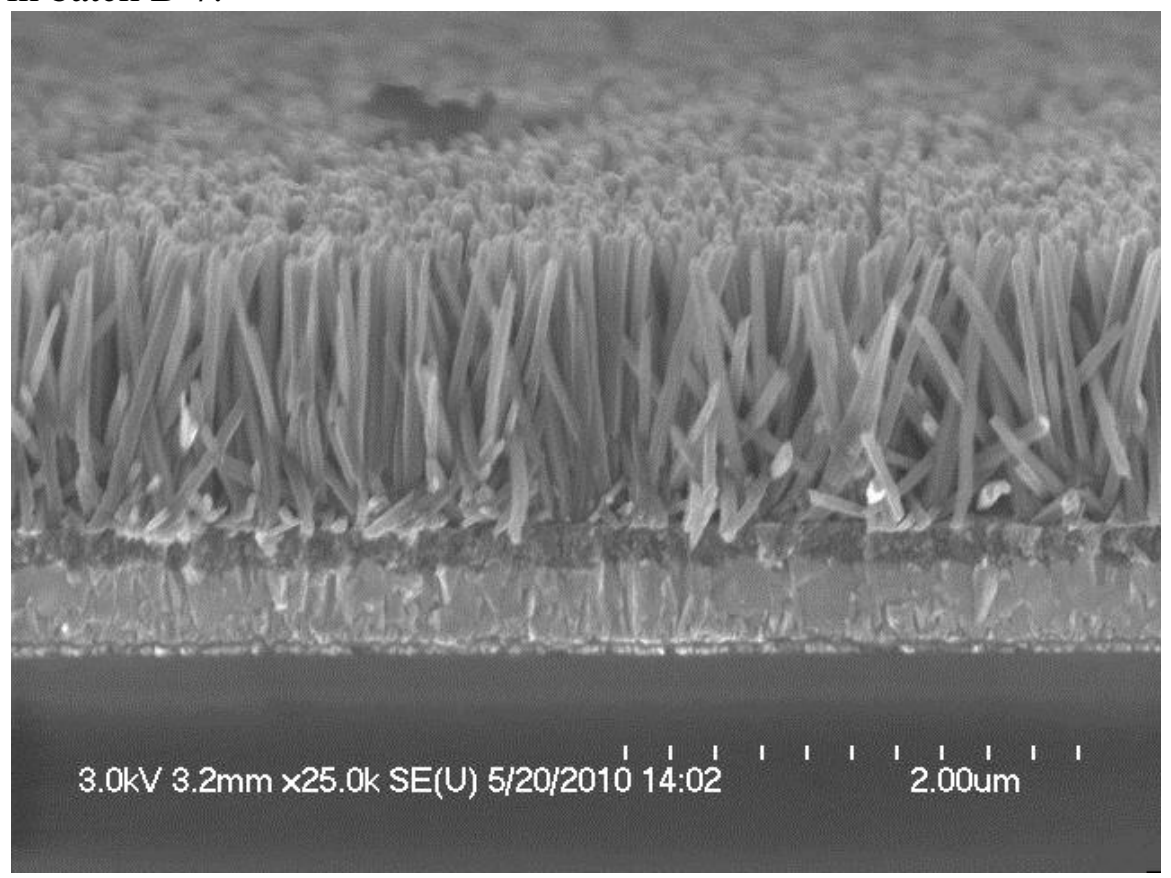

Figure 37. Cross-sectional view, 25k magnification, SEM image of the titania nanorods grown with oleic acid in batch B-7. 


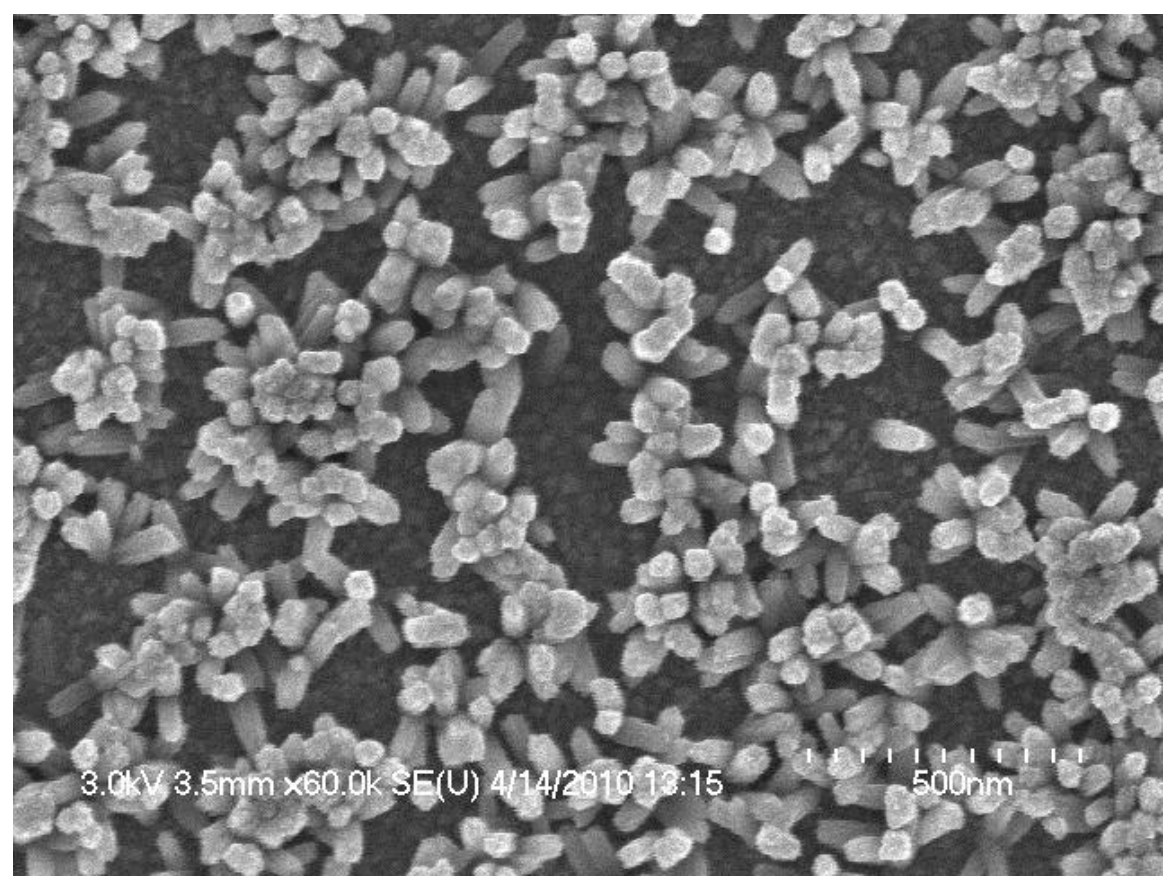

Figure 38. Top view, 60k magnification, SEM image of the titania nanorods grown with NaDDS in batch B-7.

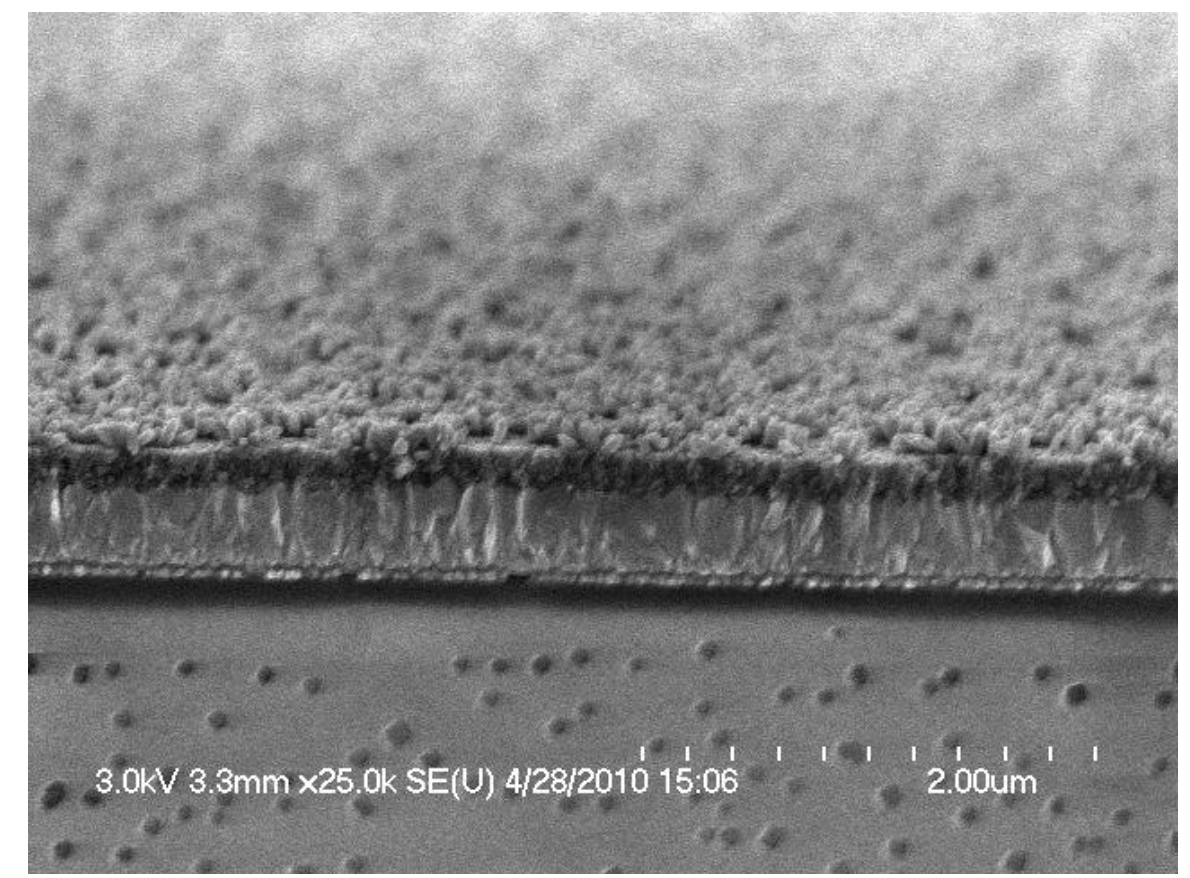

Figure 39. Cross-sectional view, 25k magnification, SEM image of the titania nanorods grown with NaDDS in batch B-7. 


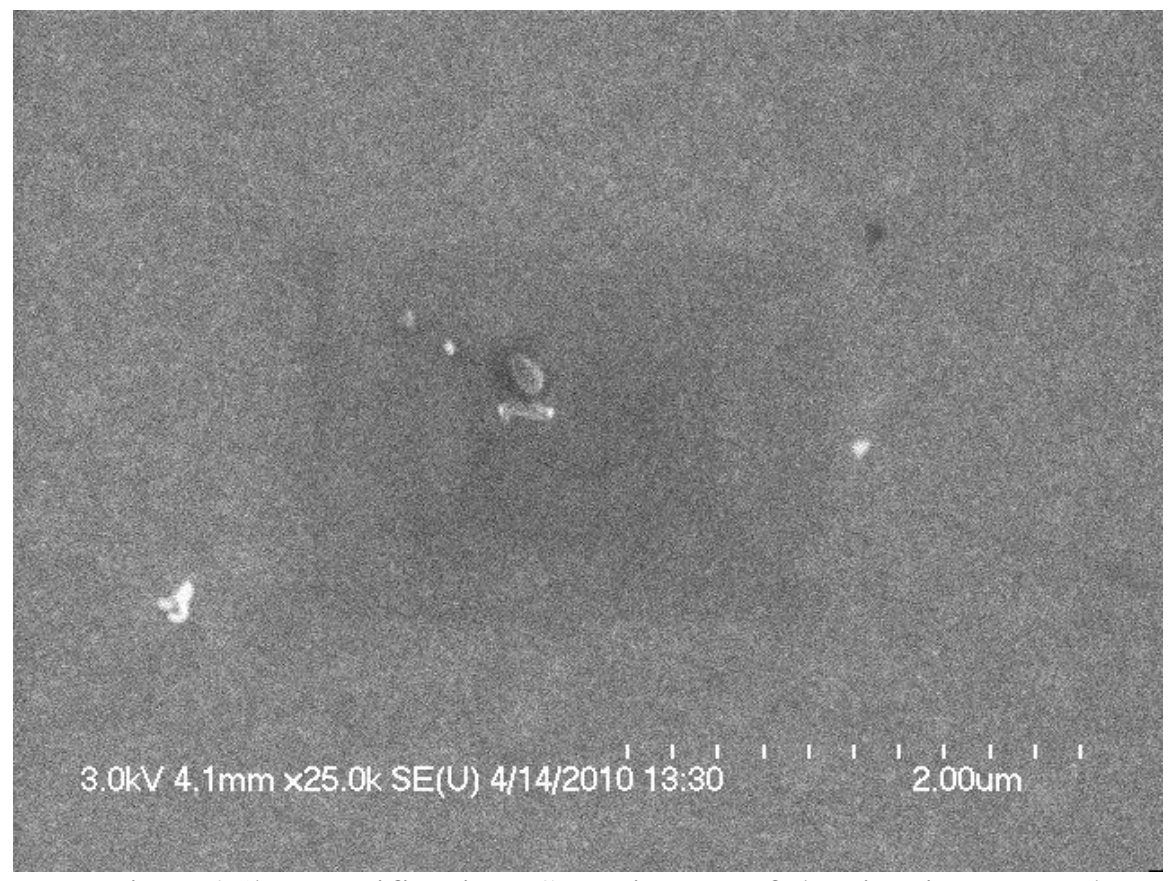

Figure 40. Top view, 25k magnification, SEM image of the titania nanorods grown with TDPA in batch B-7.

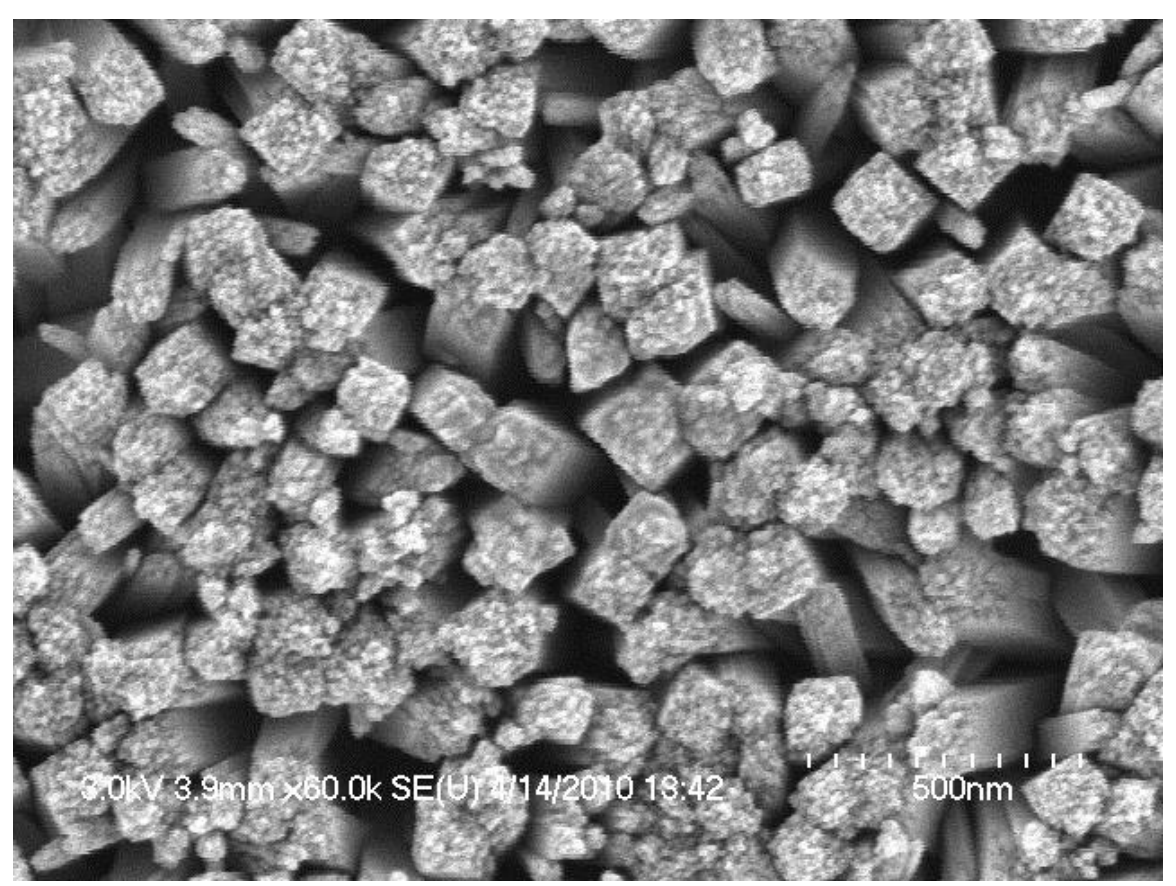

Figure 41. Top view, 60k magnification, SEM image of the titania nanorods grown with PEI in batch B-7. 


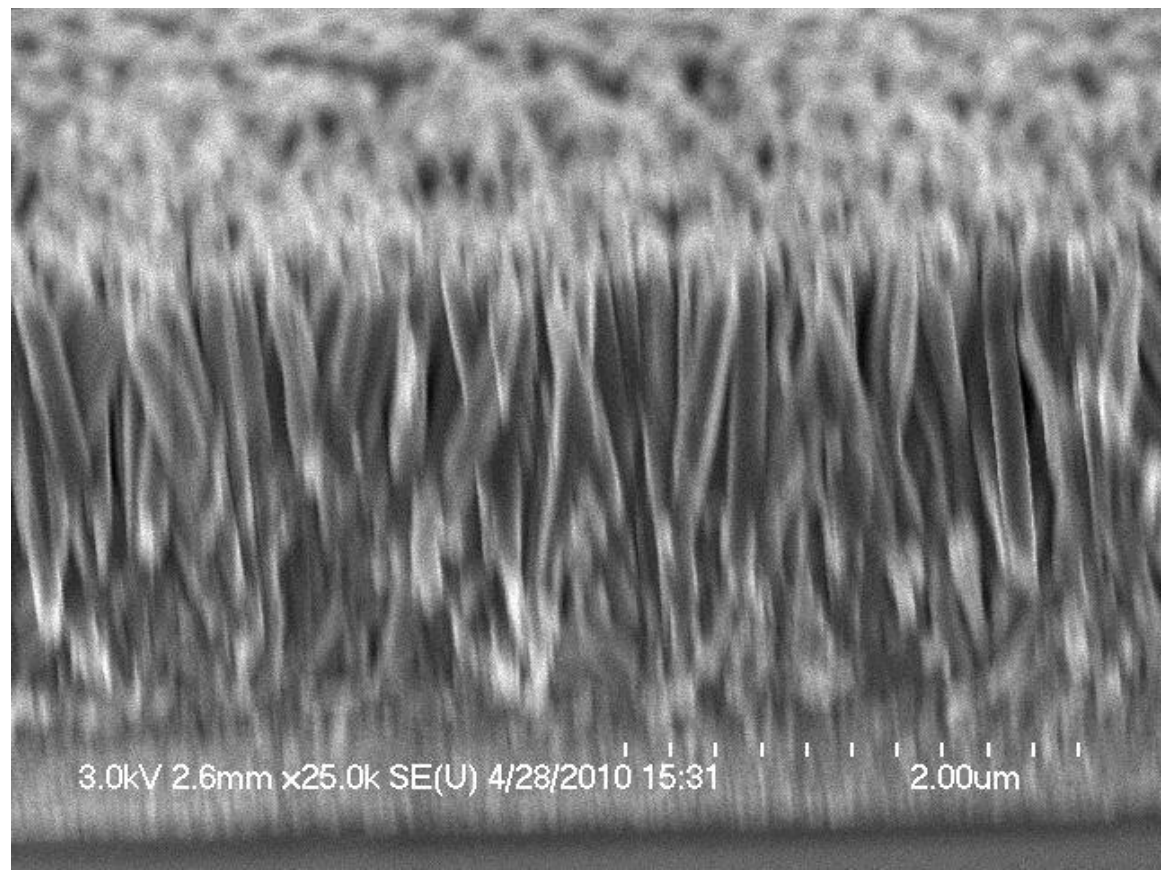

Figure 42. Cross-sectional view, 25k magnification, SEM image of the titania nanorods grown with PEI in batch B-7.

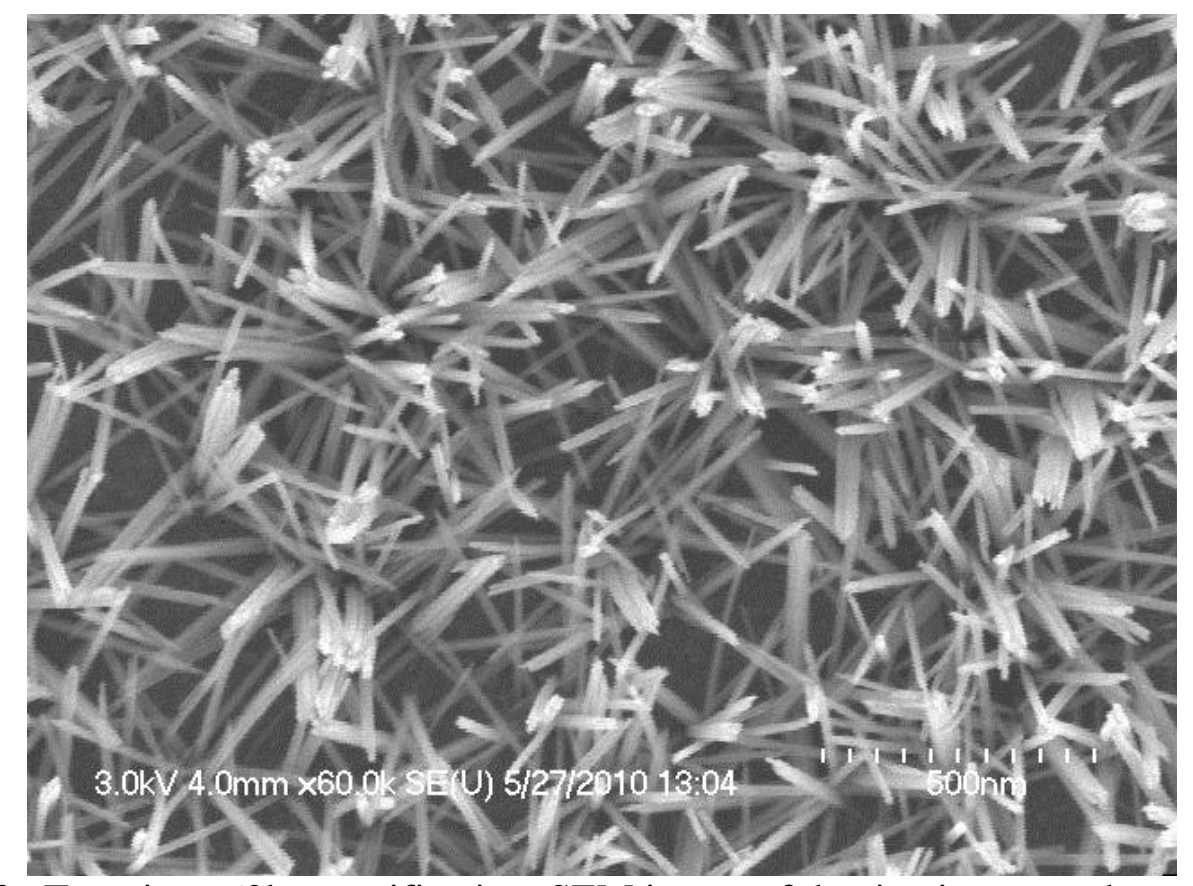

Figure 43. Top view, 60k magnification, SEM image of the titania nanorods grown with $\mathrm{LiCl}$ in batch B-8. 


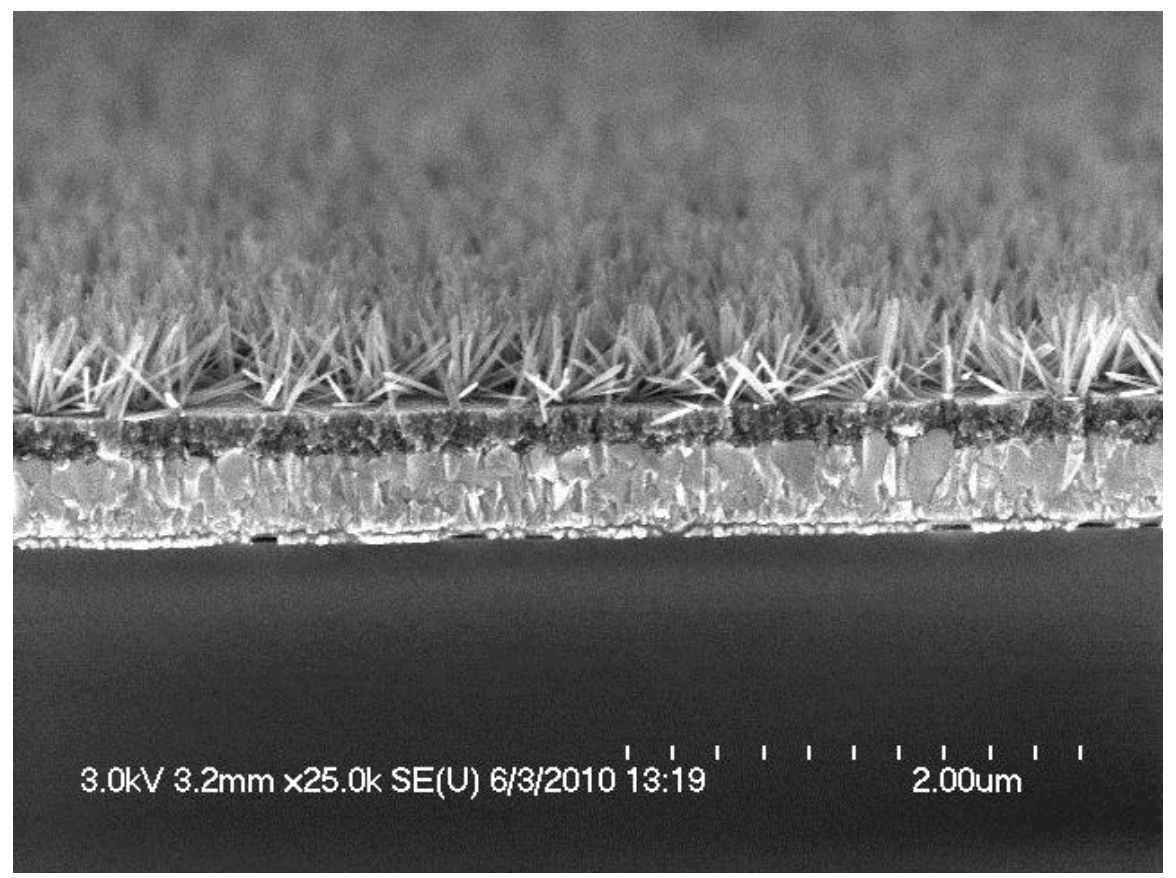

Figure 44. Cross-sectional view, 25k magnification, SEM image of the titania nanorods grown with $\mathrm{LiCl}$ in batch $\mathrm{B}-8$.

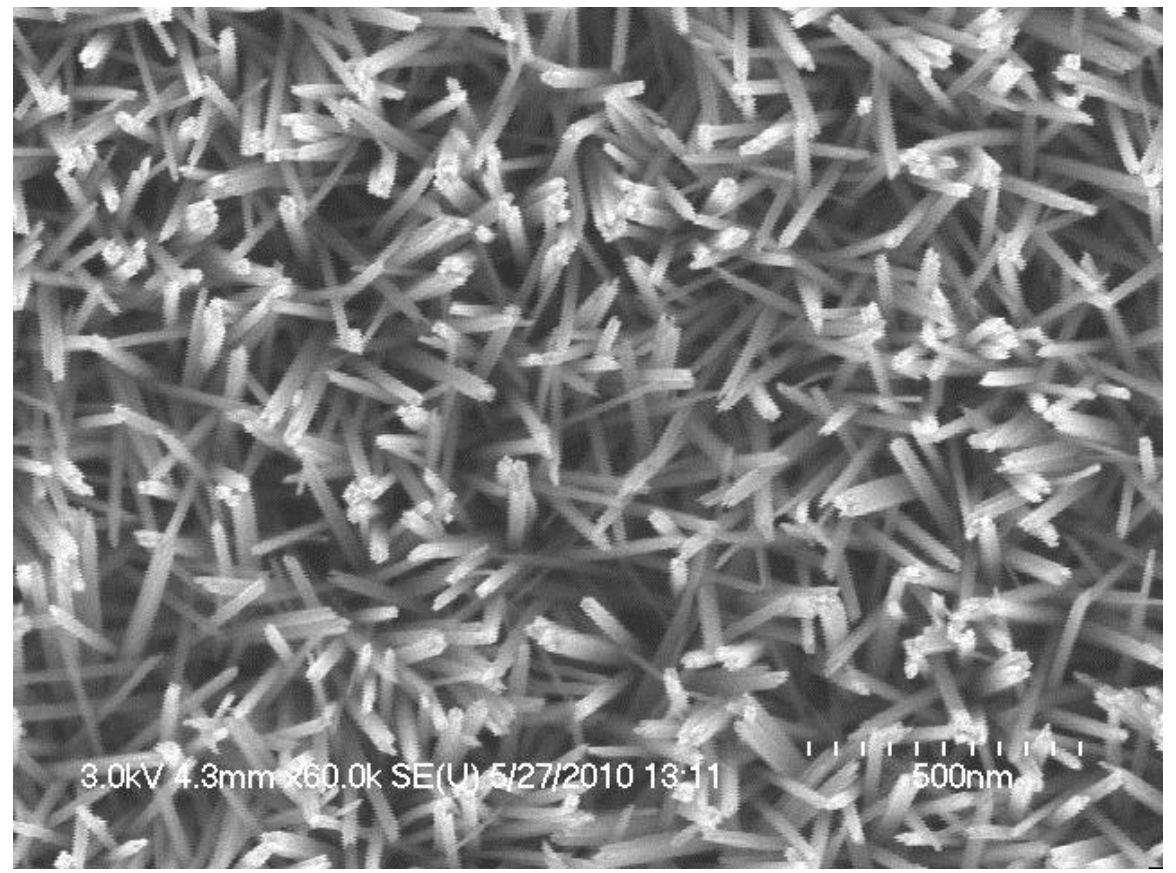

Figure 45. Top view, 60k magnification, SEM image of the titania nanorods grown with $\mathrm{KCl}$ in batch $\mathrm{B}-8$. 


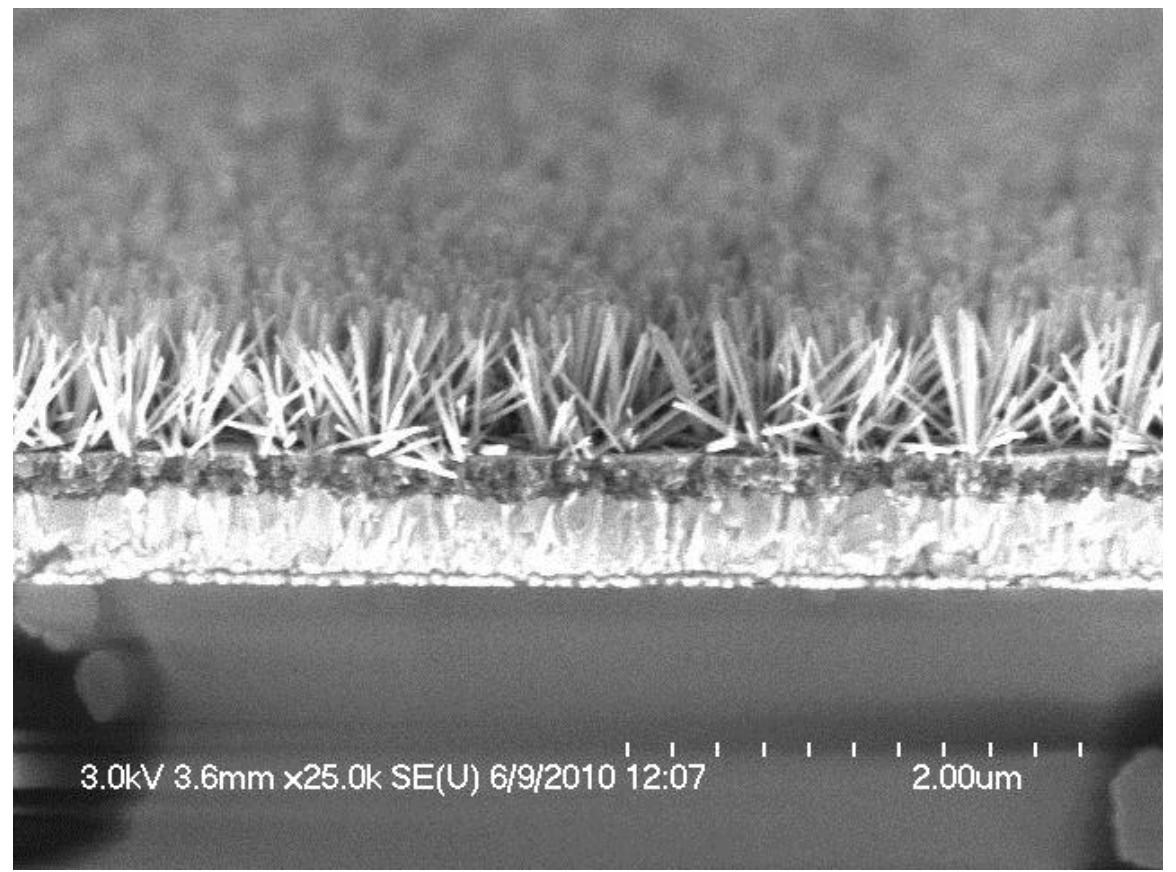

Figure 46. Cross-sectional view, 25k magnification, SEM image of the titania nanorods grown with $\mathrm{KCl}$ in batch $\mathrm{B}-8$.

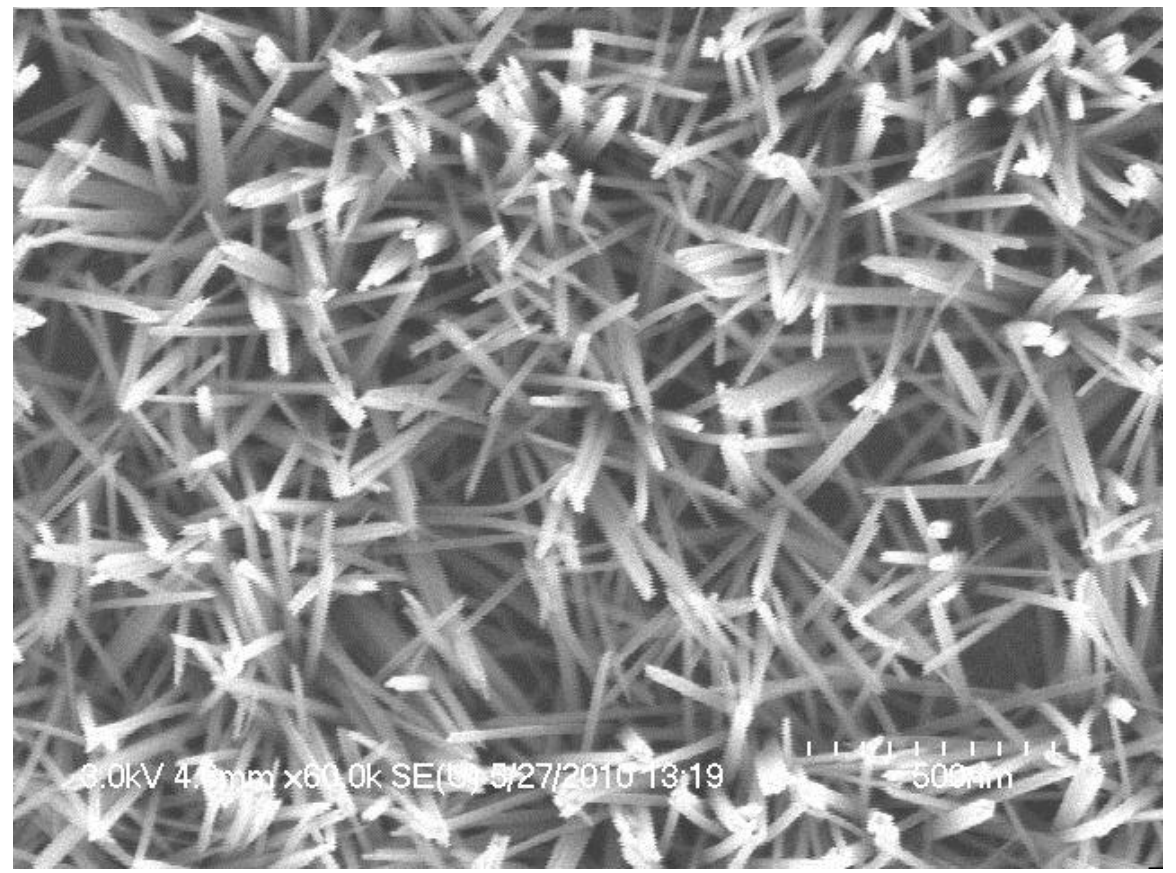

Figure 47. Top view, 60k magnification, SEM image of the titania nanorods grown with $\mathrm{CaCl}_{2}$ in batch B-8. 


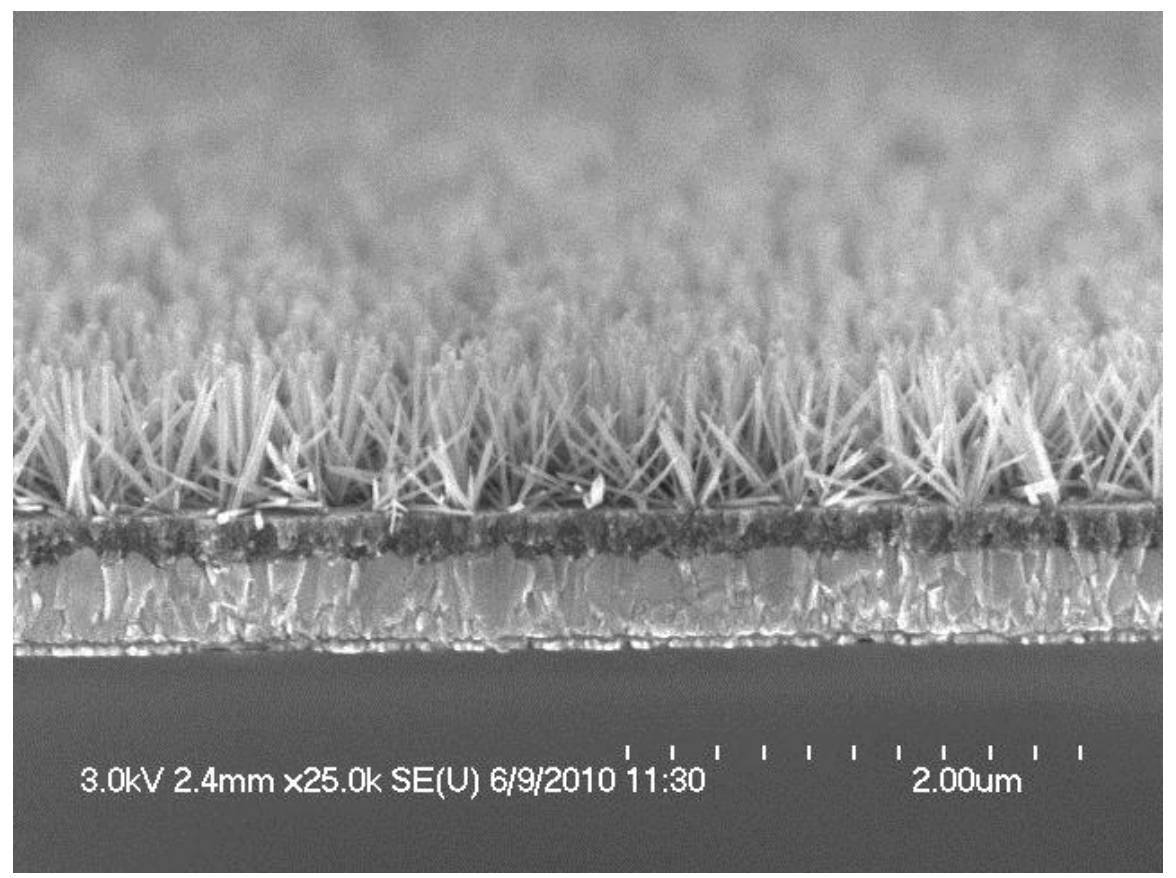

Figure 48. Cross-sectional view, 25k magnification, SEM image of the titania nanorods grown with $\mathrm{CaCl}_{2}$ in batch $\mathrm{B}-8$.

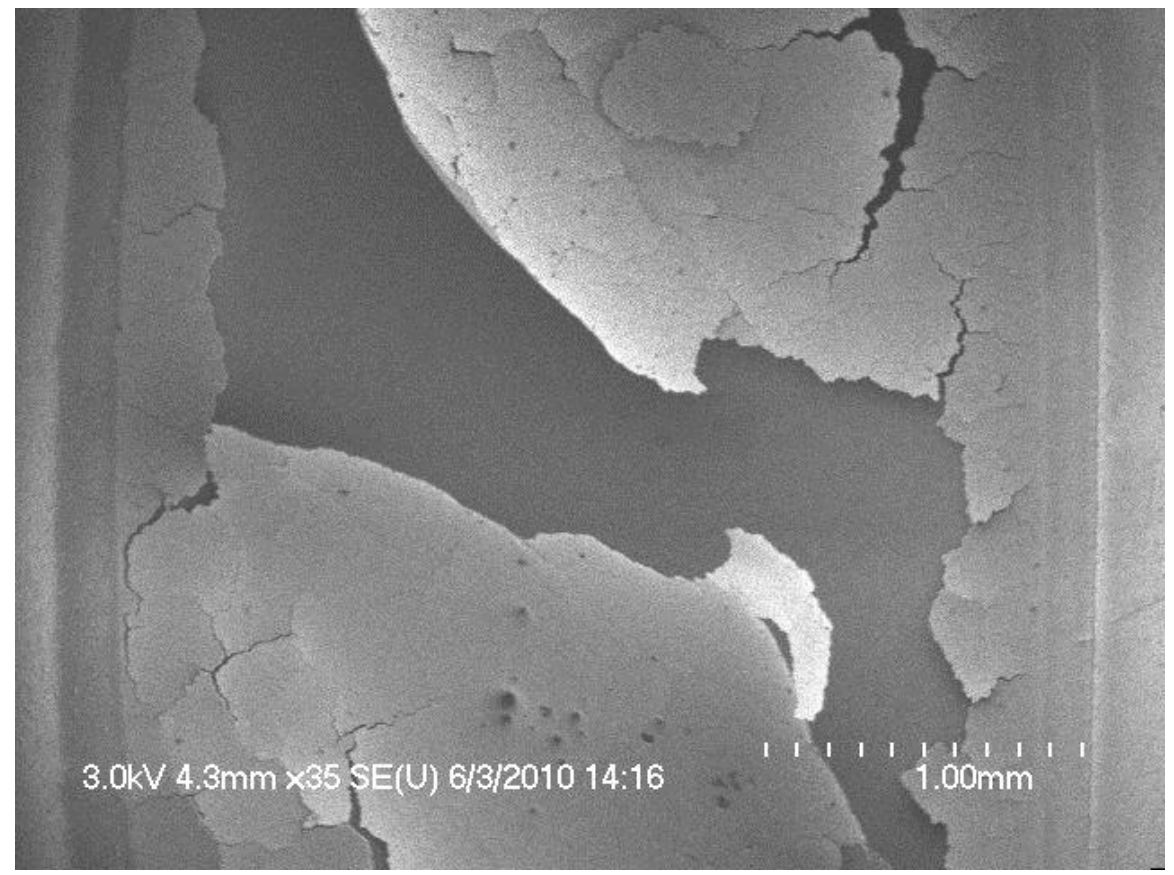

Figure 49. Top view, 35 magnification, SEM image of the titania nanorods grown with PEG 400 in batch B-9. 


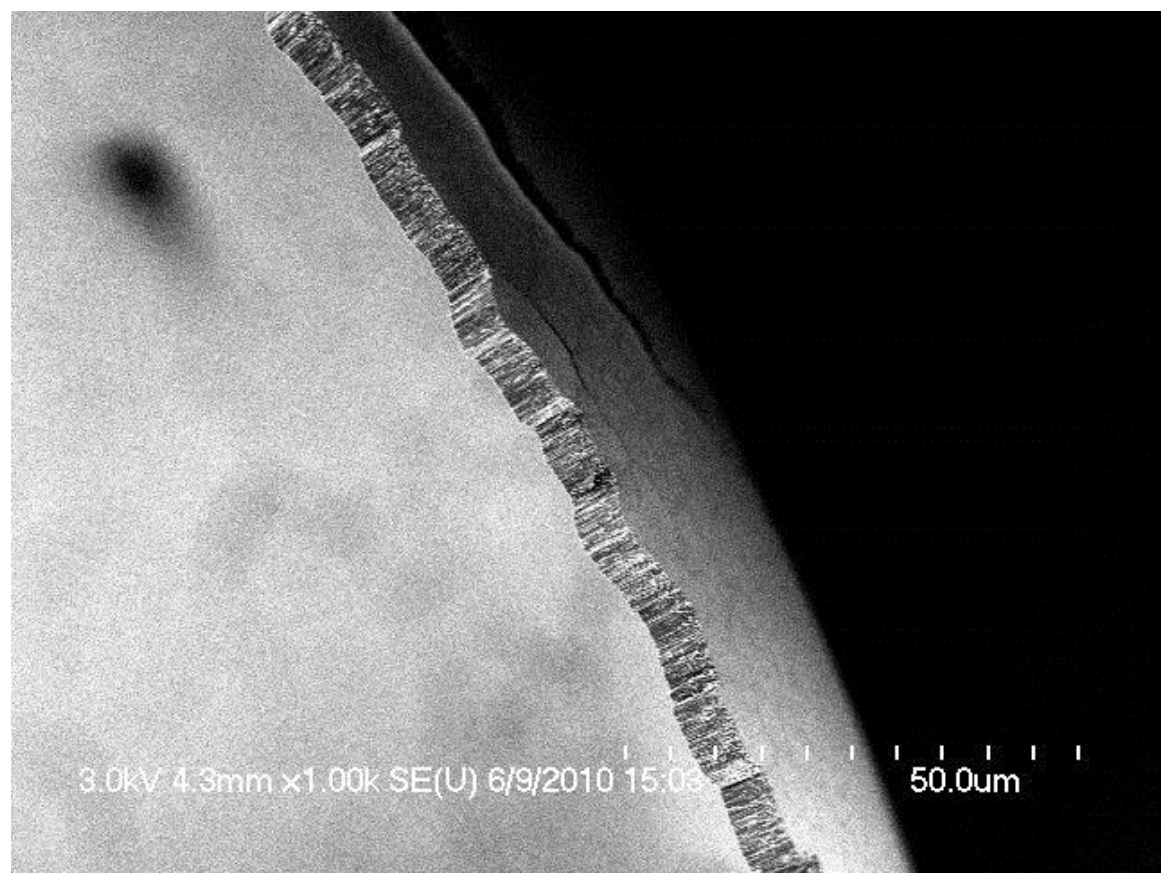

Figure 50. Top view, 1k magnification, SEM image of the titania nanorods grown with PEG 400 in batch B-9.

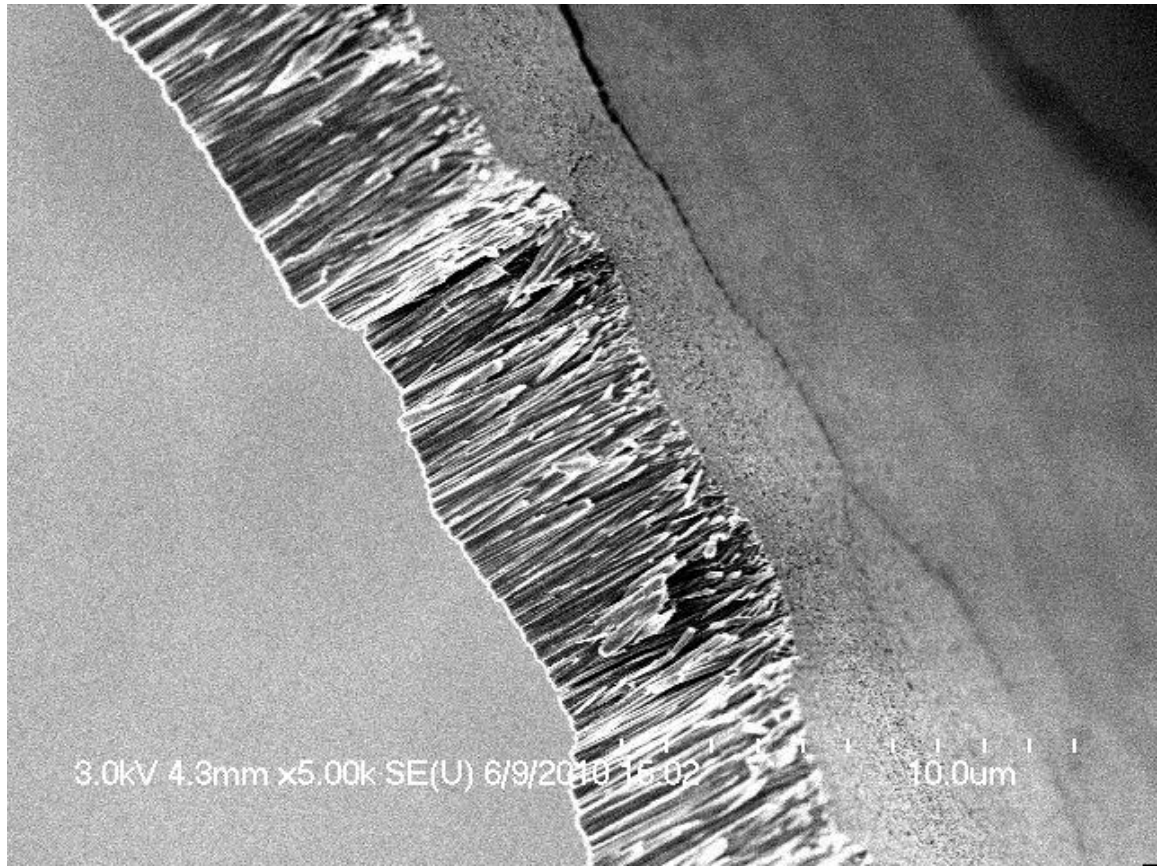

Figure 51. Top view, 5k magnification, SEM image of the titania nanorods grown with PEG 400 in batch B-9. 


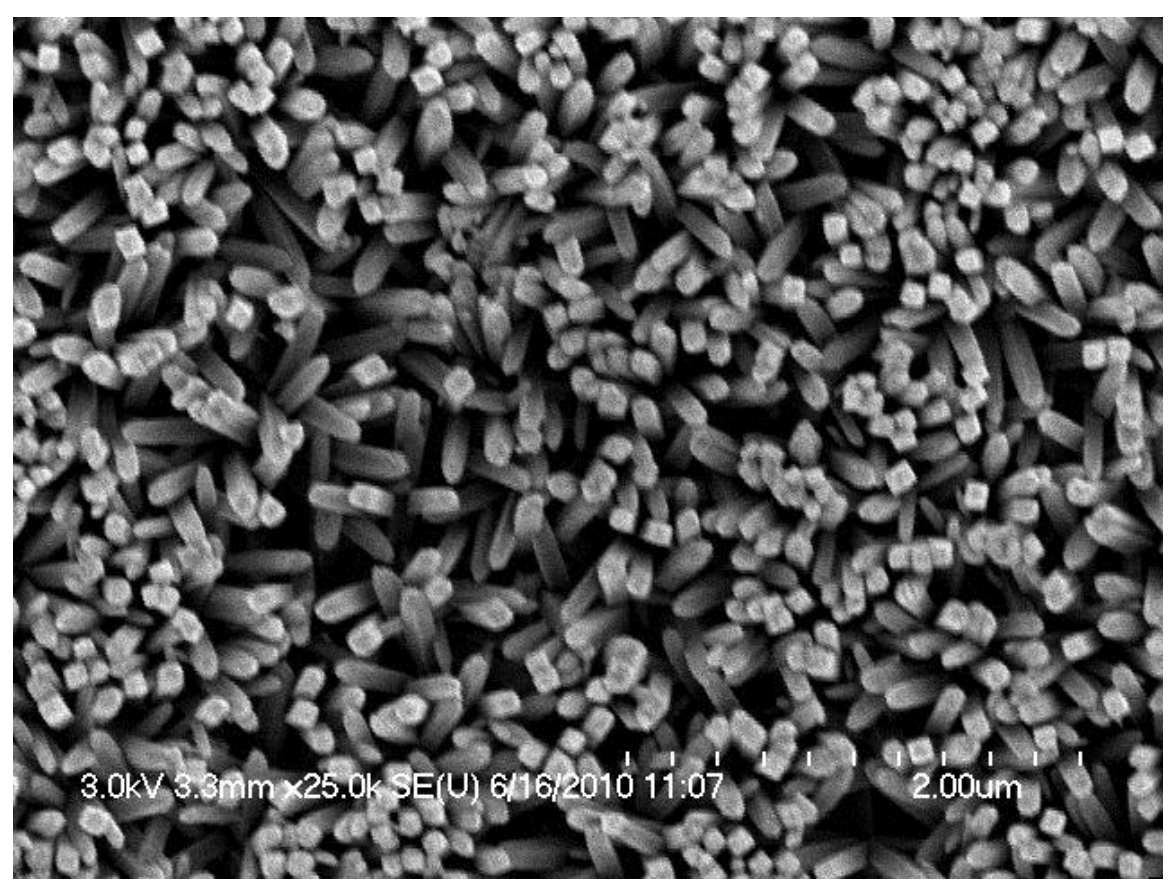

Figure 52. Top view, 25k magnification, SEM image of the titania nanorods grown with PEG 400 for 4 hours in batch B-10.

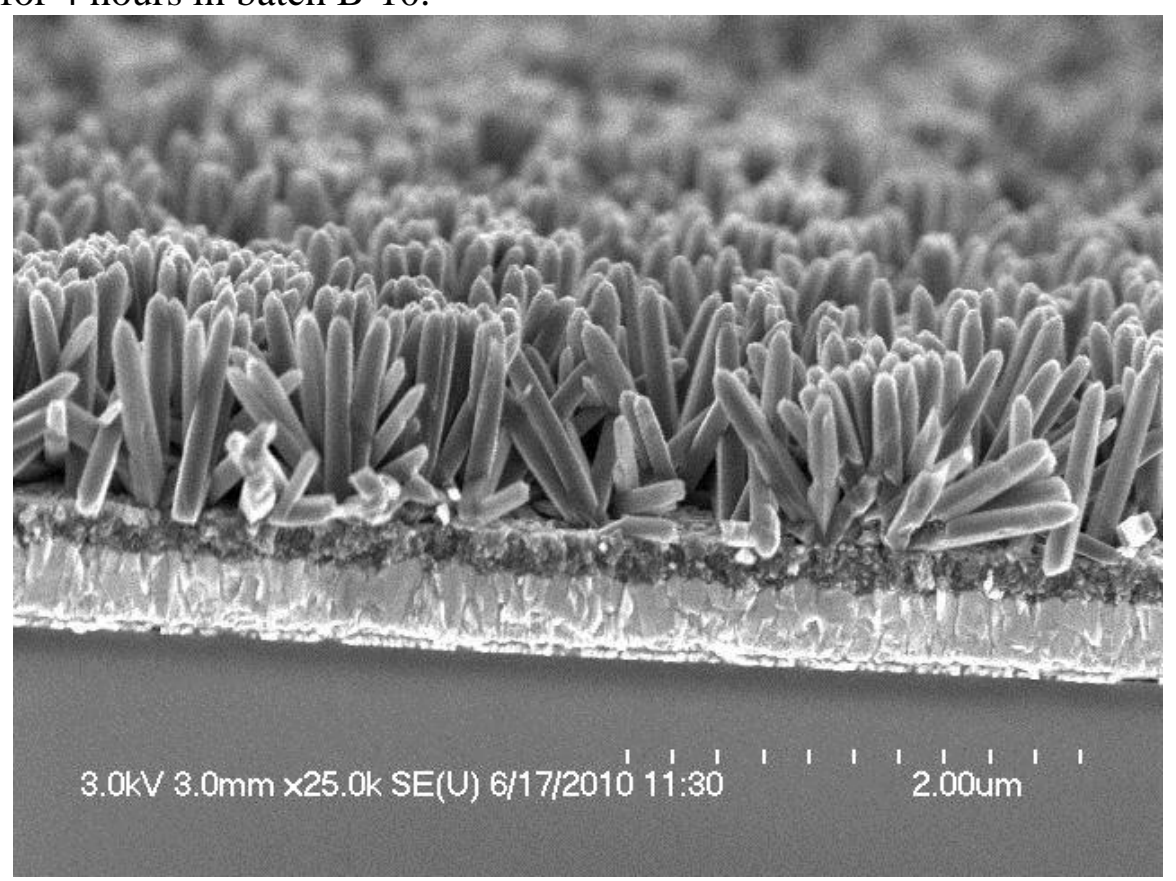

Figure 53. Cross-sectional view, 25k magnification, SEM image of the titania nanorods grown PEG 400 for 4 hours in batch B-10. 


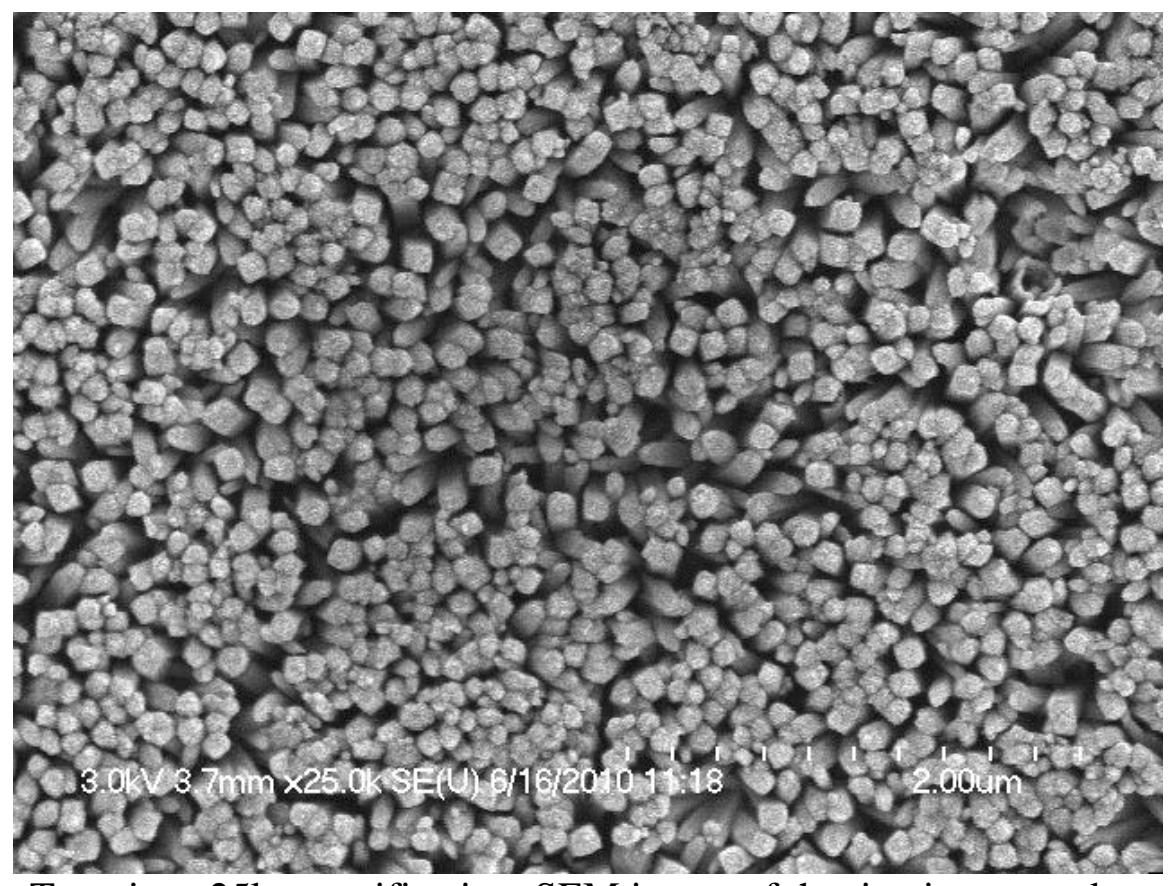

Figure 54. Top view, 25k magnification, SEM image of the titania nanorods grown with PEG 400 for 5.5 hours in batch B-10.

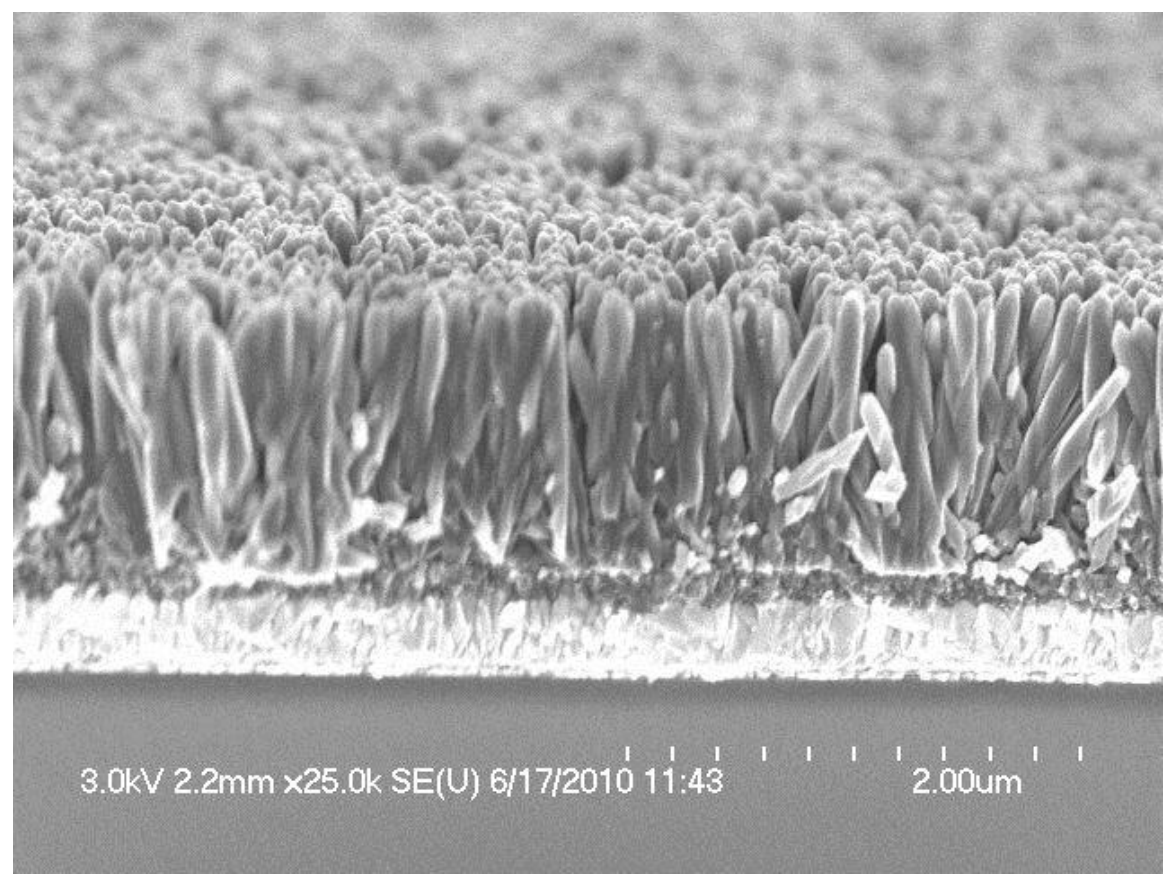

Figure 55. Cross-sectional view, 25k magnification, SEM image of the titania nanorods grown PEG 400 for 5.5 hours in batch B-10. 


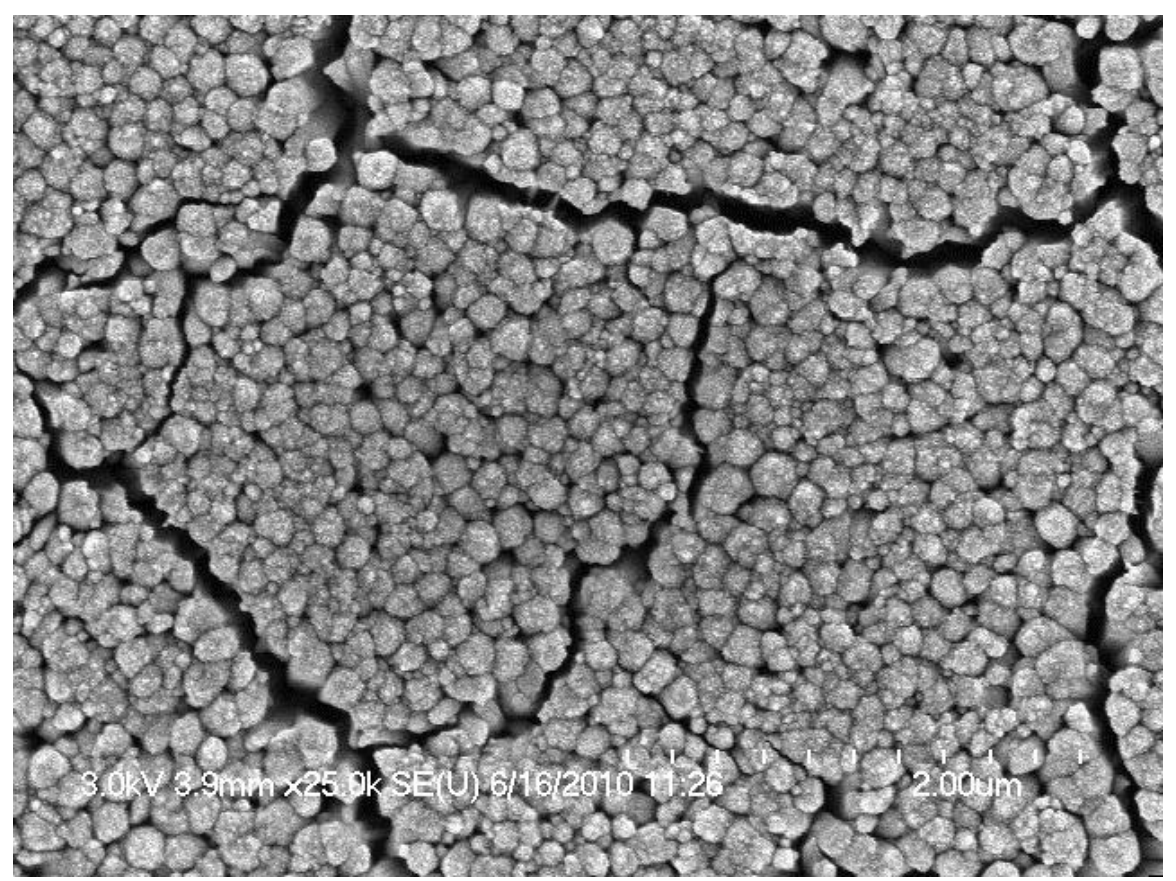

Figure 56. Top view, 25k magnification, SEM image of the titania nanorods grown with PEG 400 for 7 hours in batch B-10.

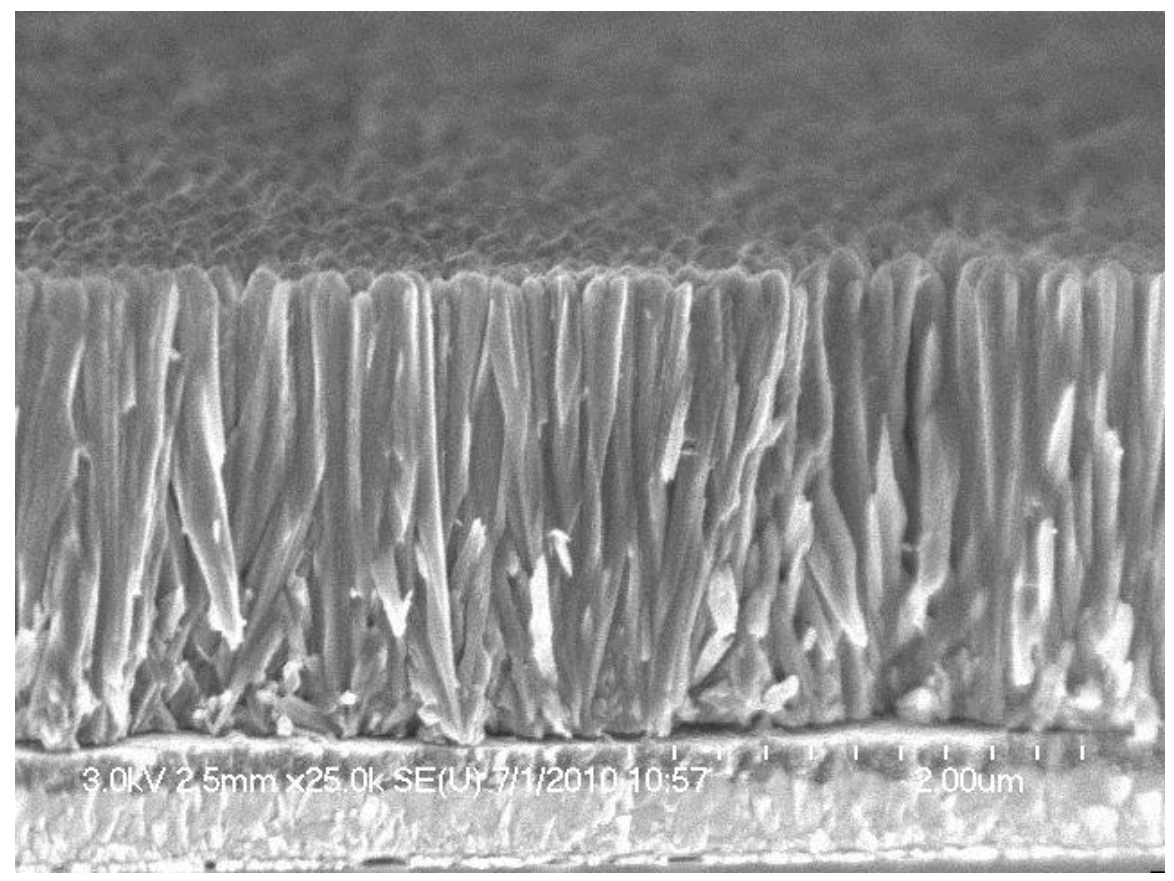

Figure 57. Cross-sectional view, 25k magnification, SEM image of the titania nanorods grown PEG 400 for 7 hours in batch B-10. 


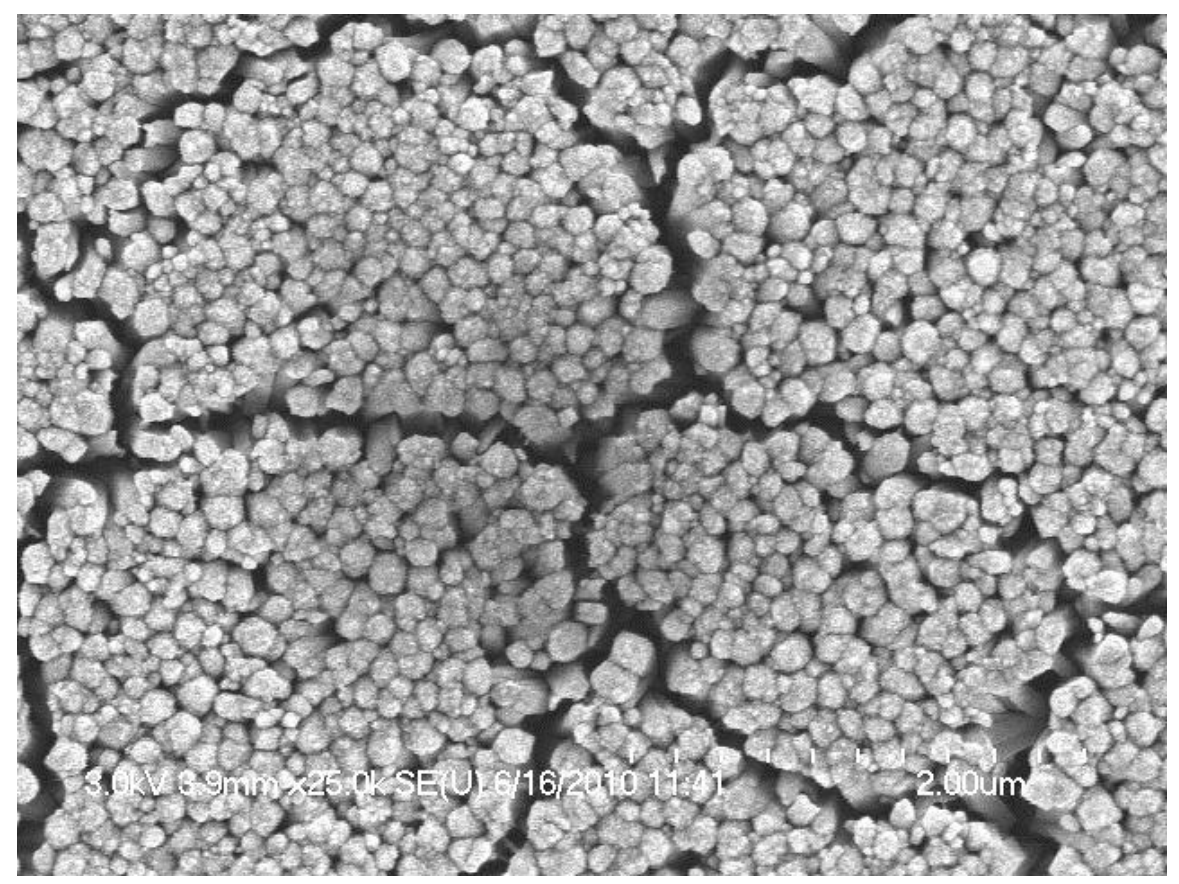

Figure 58. Top view, 25k magnification, SEM image of the titania nanorods grown with PEG 400 for 8 hours in batch B-10.

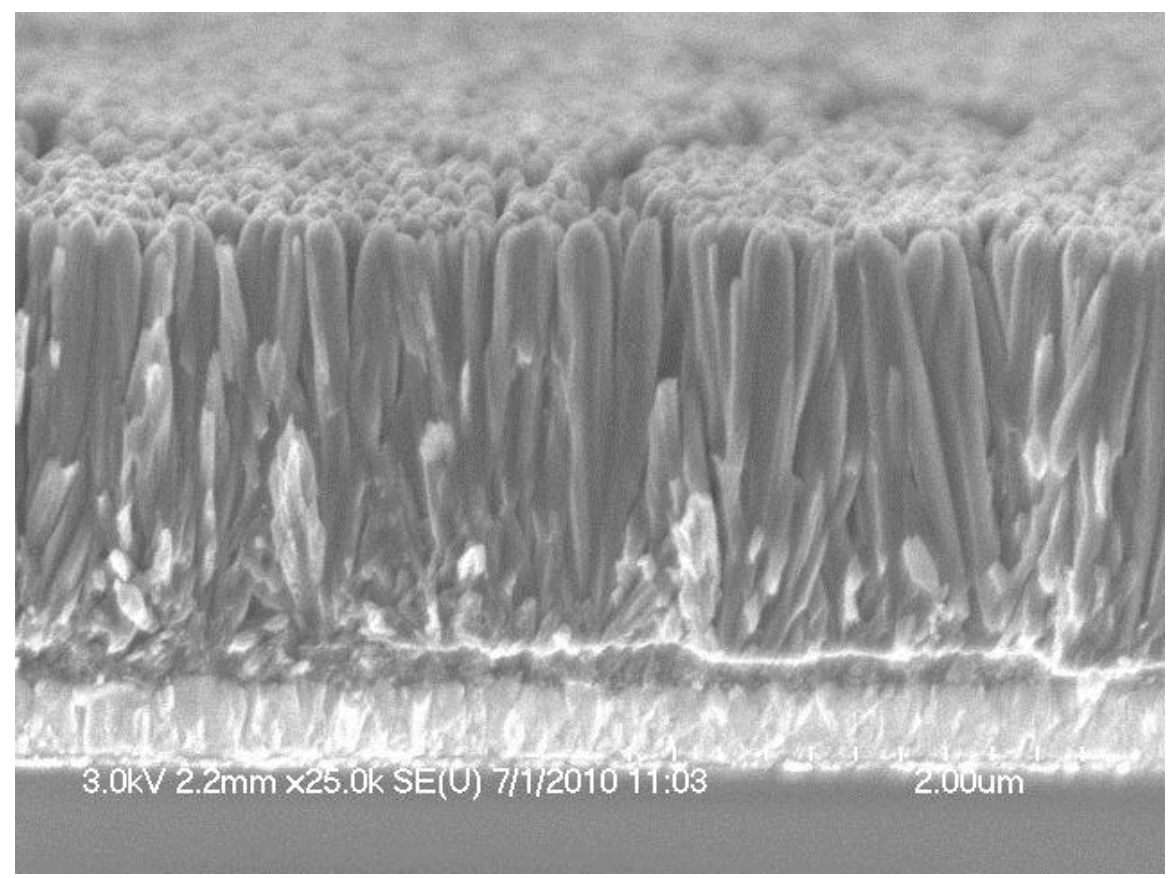

Figure 59. Cross-sectional view, 25k magnification, SEM image of the titania nanorods grown PEG 400 for 8 hours in batch B-10. 